1895. Mille huit cent quatre-vingt-quinze

Revue de l'association française de recherche sur

I'histoire du cinéma

$61 \mid 2010$

Aux sources du burlesque cinématographique : les comiques français des premiers temps

\title{
Un cas d'école. Renouveler l'histoire du cinéma comique français des premiers temps
}

Laurent Guido et Laurent Le Forestier

\section{(2) OpenEdition \\ Journals}

Édition électronique

URL : https://journals.openedition.org/1895/3828

DOI : $10.4000 / 1895.3828$

ISBN : 978-2-8218-0980-2

ISSN : 1960-6176

Éditeur

Association française de recherche sur l'histoire du cinéma (AFRHC)

Édition imprimée

Date de publication : 1 septembre 2010

Pagination : 9-76

ISBN : 978-2-913758-62-9

ISSN : 0769-0959

\section{Référence électronique}

Laurent Guido et Laurent Le Forestier, « Un cas d'école. Renouveler l'histoire du cinéma comique français des premiers temps », 1895. Mille huit cent quatre-vingt-quinze [En ligne], 61 | 2010, mis en ligne le 01 septembre 2013, consulté le 16 avril 2022. URL : http://journals.openedition.org/1895/3828 ; DOI : https://doi.org/10.4000/1895.3828 


\title{
Un cas d'école. Renouveler l'histoire du cinéma comique français des premiers temps
}

\author{
par Laurent Guido et Laurent Le Forestier
}

En 1950, au sein d'un numéro de Ciné-club entièrement consacré au cinéma comique - son passé comme son présent -, Jean Thévenot débute son article par ces quelques phrases, pourvues aujourd'hui encore d'une indéniable pertinence lorsqu'il s'agit de revenir au cinéma comique français des premiers temps :

On en parle beaucoup.

Mais, en fait, y a-t-il une école, et une école française, et une nouvelle école française, du film comique?

Pour ma part, je n'en suis pas bien sûr. Je croirais plutôt qu'il y a un comique qui est cinématographique et un comique qui ne l'est pas. Et le seul fait nouveau, c'est qu'après des années de vaudeville filmé le cinéma français est revenu au comique spécifiquement cinématographique, et singulièrement à celui de ses débuts. Mais il ne faut pas s'abuser, et ce serait en définitive simplement jouer sur les mots que de parler d'école parce qu'un retour à l'enfance et aux premières classes a été constaté.

Et si école il y a, la française est-elle si différente de celles qui ont vu le jour dans d'autres pays à la faveur de conjonctures identiques ?1

Par ces mots, Thévenot interroge quelques aspects essentiels de notre objet, qui ne peuvent que traverser de part en part les diverses études recueillies dans ce numéro de 1895 , comme I'hypothétique unité de ces films comiques français des premiers temps, ainsi que leur capa-

1 Jean Thévenot, « Une nouvelle école française du film comique ? La grande affaire est de faire rire ", Ciné-club, $n^{\circ} 3$ (nouvelle série), mars-avril 1950, p. 4 (c'est nous qui soulignons). 
$1895 /$

cité à faire corpus, c'est-à-dire à se détacher naturellement d'un ensemble plus large qui les excède tant temporellement que géographiquement. En se référant à un mode d'appréhension d'un comique qui serait proprement cinématographique, le critique de Ciné-Club érige surtout la « spécificité » en critère essentiel de définition, une démarche que nous chercherons ici à mettre à l'épreuve.

Si ces questions conservent partiellement leur portée heuristique, il ne peut nous échapper que leur formulation par Thévenot s'inscrit en un temps et en un lieu tout sauf indifférents : ce « retour à l'enfance » du cinéma comique est énoncé à une époque où il se trouve explicitement mis en scène ${ }^{2}$, et est lié à une tradition historiographique qui, depuis quelques décennies, a peu à peu perçu ces films par un prisme nostalgique les désignant comme une sorte d'âge d'or. Mais, plus encore, le fait que Ciné-club publie en 1950 un numéro intégralement dédié au cinéma comique français, et notamment à sa période des premiers temps, nous rappelle que ces films connaissent alors une nouvelle existence, grâce aux projections des cinémathèques, des festivals et des ciné-clubs. L'après-Seconde Guerre mondiale, avec son élan historiographique inédit dans les proportions qu'il atteint, ses ambitions critiques et théoriques, son retour à des films invisibles (pour la plupart) depuis des décennies, constitue incontestablement un moment singulier dans l'histoire des discours sur le cinéma comique français des premiers temps, voire, plus simplement, l'époque où s'instaure précisément et se généralise cette notion d' « école comique française ». Et c'est donc bien celle-ci qu'il s'agit de mettre en crise, notamment en montrant qu'elle n'est qu'une construction rhétorique, une formation discursive (au sens que Foucault donne à ce syntagme) qui prend place dans des discours sur le cinéma historiquement datés. Ce volume, et en particulier cette introduction, se fixent donc l'objectif d'interroger les modalités de constitution de cette formation discursive, sans pour autant adopter une structure chronologique et linéaire. On tentera plutôt de s'arrêter sur les différentes caractéristiques qui lui ont été attribuées, afin de montrer leurs variations au fil de l'historiographie et de parvenir, in fine, à une sorte d'état des lieux présent des façons de concevoir cet objet. Ainsi, cette introduction dessinera le passage progressif d'une croyance en ce que ces films représentent un " comique spécifiquement cinématographique " à la conviction qu'ils incarnent au contraire, au sein de la production française des vingt premières années, un lieu particulier d'hybridation entre des médias et des séries culturelles très variés.

2 Voir ces films français qui représentent la période « primitive » et ses bandes comiques : le Couple idéal (Bernard Roland, 1946) et le Silence est d'or (René Clair, 1947). 


\section{Relire l'historiographie du cinéma comique français}

\section{Premières classifications et modes de périodisation}

Qu'on le veuille ou non, notre connaissance s'est forgée à partir de ce syntagme d'« école comique française » et il convient donc de partir de cette notion cardinale et des significations qu'elle recouvre. Comme le remarque François Albera dans son texte, " on fait très tôt du "comique" "le" cinéma des origines", en se basant essentiellement sur une analyse quantitative (F. Laurent, cité par Albera, affirme, en 1912, que «le film comique entre bien, à lui seul, de moitié dans la composition des programmes ") : le comique est alors la "série " (puisque les films des grands éditeurs comme Pathé et Gaumont sont classés en séries - les scènes comiques constituent la deuxième série chez Pathé et la première chez Gaumont) qui compte le plus de titres. Mais, sur ce plan, il n'existe pas de réelle césure entre les toutes premières années et celles qui suivent : entre 1908 et 1914, cette série réunit à elle seule environ $40 \%$ de la production de Pathé et Gaumont, très loin, par conséquent, des onze autres séries (à l'exception des « scènes dramatiques ") ${ }^{3}$. Dès lors, au niveau de la périodisation, la production comique française des vingt premières années paraît constituer indéniablement une entité homogène, du moins dans sa dimension quantitative.

Pourtant, dès cette époque, certains commentateurs, envisageant le phénomène d'un point de vue plus qualitatif, attestent au contraire d'une hétérogénéité fondamentale qui diviserait cette production en deux tendances successives, prenant elles-mêmes la suite d'un premier âge marqué surtout par la figure de la poursuite. Ainsi Victorien Jasset, en 1911, décrit-il d'abord un comique " d'une originalité toute parisienne » qui « n'était ni la poursuite ni la comédie ${ }^{4}$, puis l'introduction dans cette production d'une " note sentimentale ${ }^{5}$. Se trouve ainsi dessinée la perspective d'une évolution des "scènes comiques " vers les " comédies ", qui n'est encore qu'esquissée mais semble vouée à s'amplifier. Si cette intuition n'est pas dénuée de pertinence (les comédies dominent la production comique chez Gaumont dès 19136), il n'en reste pas moins que " cette dichotomie entre "scènes comiques" et "comédies" n'est qu'une classification arbitraire figurant dans les programmes $»$. En s'en tenant aux

3 Voir en annexe l'extrait du catalogue Gaumont de 1908, pp. 291-293.

4 Victorin Jasset, Ciné-Journal (du 21 octobre au 25 novembre 1911), reproduit dans Marcel Lapierre, Anthologie du cinéma, Paris, la Nouvelle édition, 1946, p. 91.

5 lbid., p. 95.

6 Le dépouillement de Ciné-Journal nous indique que la société a édité cette année-là 85 comédies sur un total de 161 films comiques (toutes séries confondues). Leur domination est encore plus forte sur le plan de la longueur : si les comédies représentent près de $53 \%$ des titres comiques édités, le pourcentage atteint $63 \%$ lorsqu'on se réfère au métrage édité.

7 Laurent Le Forestier, "Le comique Gaumont, une école ? ", dans les Cahiers de la cinémathèque, " la Maison Gaumont a cent ans... ", n63/64, décembre 1995, p. 62. Sur l'apparition des « comédies » comme

1895 / r 
$1895 /$

catalogues de l'époque, on s'aperçoit que ces deux types de films humoristiques entretiennent des rapports plus synchroniques que diachroniques, ce qui permet de mettre en évidence la structure binaire d'un corpus prétendument unifié. Par conséquent, il faut voir cette distinction moins comme une manière de compartimenter l'ensemble de la production comique en deux séries distinctes ${ }^{8}$ que comme l'affirmation d'une hétérogénéité qui traverse la grande majorité des films comiques de la seconde période de ces vingt premières années. D'ailleurs, le terme de " comique ", utilisé en tant que tel par les maisons d'édition des films (ainsi qu'on peut l'appréhender non seulement dans les catalogues, mais aussi dans le matériel promotionnel ou encore les comptes rendus de presse), traduit bien la réalité des usages historiques, mais ne donne aucune garantie au plan de sa cohérence interne, pouvant se révéler dénuée de toute systématicité ou logique propre. II ne faut donc pas prendre ces termes de " comique » et de « comédie » comme des moyens, à l'époque, de nommer des distinctions, mais plutôt comme l'indice de l'existence de tendances encore partiellement ineffables à l'intérieur de l'ensemble des scènes comiques. De fait, l'émergence de ce principe de « comédie » marque moins une césure esthétique entre deux groupes de films qu'une caractéristique discriminante séparant deux « âges ".

Il y aurait d'abord des scènes au sein desquelles la figure et la situation utilisées (par exemple la poursuite, la course ${ }^{9}$ ) constituent plutôt l'invariant, et les personnages le variant (les belles-mères, les nourrices, les sergents de ville, etc.). En effet, dès l'émergence de la pluriponctualité, la farce - qui s'est imposée, sous l'influence évidente de la presse illustrée10, comme l'un des grands thèmes de la production des tout premiers temps, notamment via des personnages enfantins - se déploie désormais au travers d'une succession de tableaux dont l'espace est chaque fois comme « contaminé " par un même agent polluant, nocif ou

nouvelle série, voir également Laurent Le Forestier, « Les comédies de Léonce Perret, fleurons de la production Gaumont ", dans Bernard Bastide et Jean A. Gili (dir.), Léonce Perret, Paris/Bologne, AFRHC/Cineteca di Bologna, 2003.

8 Emmanuel Dreux reprend cette idée lorsqu'il développe cette "distinction entre les "scènes comiques" et les "comédies", les premières s'inspirant du spectacle (cirque, music-hall, café-concert, pantomime) et de la caricature, les secondes se référant plus ou moins explicitement au théâtre (vaudeville - au sens français du théâtre de boulevard -, théâtre naturaliste) " (le Cinéma burlesque, ou la subversion par le geste, Paris, L'Harmattan, coll. Esthétiques, 2007, p. 35).

9 II n'est pas anodin que, lorsqu'il s'est agi de faire une rapide histoire du cinéma comique français, en 1923, c'est justement la figure de la course qui a été mise en évidence pour caractériser cette première période, " avant que les héros comiques [fassent] leur apparition » (Albert Bonneau, " Un genre presque disparu. Les films comiques ", Cinémagazine, n³4, 24 août 1923, p. 265. Merci à Pierre-Emmanuel Jaques).

10 Parmi les recherches en cours sur ce sujet, citons les travaux de Pascal Lefevre, ainsi que l'article de Pierre Chemartin et Nicolas Dulac, « La figure du garnement aux premiers temps du comic strip et de la cinématographie ", dans Alain Boillat (dir.), les Cases à l'écran. Bande dessinée et cinéma en dialogue, Genève, Georg, 2010. 
destructeur : le Poil à gratter (Pathé, 1907) ; [la Machine à accélérer le temps] ${ }^{11}$; I'Arrosoir de Polycarpe (Éclipse, 1910) ; Calino arroseur public (Gaumont, 1910) ; Arthème sorcier (Éclipse, 1913), Rigadin et la baguette magique (Pathé, 1912), Rigadin avale son ocarina (Pathé, 1912) ; quand n'y circule pas le même objet : les Mésaventures d'un veston (Pathé, 1907) qui change constamment de propriétaire, ou le Costume blanc (Lux, 1908), qui se salit progressivement. Cette structure emprunte son principe à l'une des premières formes de sérialité au cinéma, et par ailleurs figure éminemment comique : la poursuite, qui constitue donc l'un des invariants dominants des premières années.

De nombreuses études ont démontré le rôle crucial joué par la course-poursuite dans la standardisation des pratiques filmiques qui s'est opérée dans les années 1904-1906. Le passage de ses éléments constitutifs au travers de différents espaces disjoints a favorisé l'émergence et la systématisation du montage entre les plans, désormais enchaînés en fonction d'une logique narrative fondée sur la continuité spatio-temporelle et le déplacement de mêmes figures humaines ${ }^{12}$. Plutôt centrées, au début, sur des figures de fuyards marginaux (voleurs, malades mentaux en fuite, comme dans Daring Daylight Burglary, Charles Urban, 1903 ; The Escaped Lunatic, Biograph, 1903 ; ou The Maniac Chase, Edison, 1904), les poursuites tendent à développer le motif de foules lancées derrière un seul et même individu. Selon une logique très répandue dans le cinéma des premiers temps, les mêmes idées sont souvent reproduites d'une firme à l'autre, comme pour la situation où un homme ayant passé une petite annonce se retrouve à la merci de tout un groupe de femmes : Personal (Biograph, 1904), How a French Nobleman Got a Wife through the "New York Herald" Personal Columns (Edison, 1904), Meet Me at the Fountain (Lubin, 1904). En 1905, Pathé en propose une version avec Dix Femmes pour un mari. En France, la poursuite s'impose comme une formule-clé des années 1905-1908, chez Pathé (le Voleur de Bicyclette, 1905 ; la Course aux tonneaux, 1905 ; la Course à la perruque, 1906 ; la Course des belles-mères, 1907 ; la Course des sergents de ville, 1907 ), puis chez Gaumont (Course à la saucisse, 1907 ; la Course aux potirons, 1908) ${ }^{13}$.

Cette tendance a été clairement cernée, dans I'historiographie du comique français, comme un tournant fondamental. D'après Jean Mitry, ce n'est qu'une fois passée celui-ci (« les courses-poursuites qui firent les beaux jours des années 1906-08 ») qu'a pu s'édifier une

11 Les Archives du Film conservent une copie de cette bande, qui n'a pu être ni identifiée, ni datée. 12 Outre Noël Burch, la Lucarne de l'infini, Paris, Nathan, 1991 (chapitre 6 : « Passions, poursuites: d'une certaine linéarisation »), lire Jonathan Auerbach, Body Shots. Early Cinema's Incarnations, Berkeley and Los Angeles, University of California Press, 2007, pp. 85-103.

13 Richard Abel, The Ciné Goes to Town : French Cinema, 1896-1914, Berkeley et Los Angeles, University of California Press, 1994, pp. 109-112. 
$1895 /$

"véritable école comique en France» ${ }^{14}$. Quant à Francis Lacassin, il y perçoit le début de ce qu'il identifie comme la période "formative » (1906-1911) du comique français ${ }^{15}$. Mais c'est peut-être accorder une importance excessive à ce qui n'est qu'une figure au sein d'une structure (invariant/variant) qui s'inverse progressivement avec l'apparition des personnages récurrents, notamment pour des questions de fidélisation du public, liées à la sédentarisation des salles. D'où l'apparition progressive de films structurés autour du personnage comme invariant (l'émergence des séries nominales : Boireau, Max, Rigadin, etc.) et de la situation/figure comme variant (une pratique sportive, artistique, une activité sociale, un rituel, etc.). Dans ce volume, l'article de Frank Kessler montre par exemple comment le motif de la boxe varie en fonction du personnage qui s'y adonne et surtout comment son usage révèle la tendance dominante au sein de laquelle le film s'inscrit (pour l'énoncer rapidement, le comique se situe dans la caricature de boxe, alors que la comédie s'origine dans une représentation respectant certains codes du vraisemblable).

L'hypothèse de constructions narratives reposant sur un rapport entre variant et invariant se trouve corroborée par certains témoignages, comme celui de Z. Rollini, le frère de Ferdinand Zecca qui a beaucoup travaillé pour la Comica (filiale de Pathé spécialisée dans les films comiques à partir du début des années 1910) :

J'ai servi deux cents fois le même cliché en échangeant le milieu, ou les types, à peu près sur ce thème : dispute entre époux, vaisselle brisée, chute dans un baquet, tuyau crevé, douche, course sur les toits, passage dans la cheminée, saut par la fenêtre, course précipitée et arrosage final. ${ }^{16}$

Curieusement, cette structure du cinéma comique français en deux périodes distinctes, qui verrait le comique céder progressivement du terrain à la comédie, clairement pressentie par Jasset en 1911, ne trouve guère d'écho chez les commentateurs des années vingt. Ainsi, Iorsque Louis Delluc s'intéresse en 1920 au cinéma comique français de l'après-Première Guerre mondiale, c'est certes pour stigmatiser un problème qui l'excède - celui de l'absence de metteurs en scène - mais, ce faisant, surtout pour marquer clairement la rupture avec la période de l'avant-guerre, perçue implicitement comme un tout homogène :

Rigadin, déjà d'un autre âge, va se noyer sous lui-même avant longtemps. Max Linder, si actif, si intrépide, si allant, ne peut se voir et, partant, se corriger. Va-t-on le laisser à son ancien

14 Jean Mitry, Histoire du cinéma - Art et Industrie II. 1915-1925, Paris, Éditions Universitaires, 1969, p. 41. 15 Francis Lacassin, Pour une contre-histoire du cinéma, Paris, Union Générale d'Éditions, 1972, p. 77. 16 Z. Rollini, « Des scènes comiques », Cinémagazine, n4, 11-17 février 1921, p. 18. Voir reproduction de cet article, pp. 258-260 (merci à Pierre-Emmanuel Jaques). 
procédé ? Il y gaspille des trésors de bonne humeur. Faute d'un impeccable metteur en scène, il perd les trois quarts de sa généreuse verve naturelle. ${ }^{17}$

Bien sûr, ce qui renvoie Rigadin et Max à un autre âge, aux yeux de Delluc, c'est l'arrivée en France des films comiques américains, qui prend une forme massive durant la guerre, consécutivement au ralentissement de la production française : une autre pratique du comique, liée à une culture différente, paraît en quelque sorte démoder une manière spécifiquement française. Le comique américain est donc à la fois ce qui, pour certains, ringardise le comique français, mais aussi ce qui le singularise rétrospectivement. Surtout, le critère discriminant appliqué par Delluc (la présence marquée d'un metteur en scène), s'il peut permettre de distinguer le cinéma comique français de son homologue américain du moment ${ }^{18}$, reconstruit l'avant-guerre en période unifiée. On peut alors lire les passages que Coissac, au milieu des années vingt, consacre à ce cinéma comme une forme de réponse à Delluc. En effet, les films comiques y sont perçus essentiellement à partir de leurs metteurs en scène, quitte à reléguer à l'arrière-plan les comédiens et donc une part non négligeable de ce qui caractérise ces films (la gestualité, le charisme, l'individualité, etc.) : Capellani est présenté comme celui qui « céda la place à Lucien Nonguet " pour les « scènes interprétées par André Deed »19, Bosetti, chez Gaumont « y faisait d'excellente besogne »20, etc. Implicitement, chez Coissac, le metteur en scène est le gage de qualité des films comiques, même si cette qualité reste à définir. Les comédiens, eux, ne servent qu'à rappeler les innombrables séries comiques du cinéma français, dans une logique d'inventaire :

Parmi les comiques que le cinéma nous donna d'applaudir aux côtés de Deed et de Max Linder, il faut citer le joyeux, l'irrésistible Boucot, créateur de Gavroche ; Nick Winter, détective extraordinaire, le rival heureux de Sherlock Holmes qui, en maintes circonstances, mit dans sa poche tous les policiers de l'Ancien et du Nouveau Monde ; Prince, inoubliable Rigadin ; Servaës, incarnation du personnage d'Arthème Dupin ; Bertho, hilarant Calino, spécialiste des poursuites et des chutes; Vandenne, aux succès très personnels, interprète de Max se marie, Max et sa belle-mère, Nick Winter contre Nick Winter, etc. 21

17 Louis Delluc, « les Films comiques ", Photogénie [1920], reproduit dans Écrits cinématographiques I, Paris, Cinémathèque française, 1985, p. 63 (c'est nous qui soulignons).

18 Même si Delluc, lorsqu'il évoque Chaplin, met bien plus en avant le dynamisme, la structure, le mouvement, les gestes...

19 G. M. Coissac, Histoire du cinématographe, Paris, Éditions du Cinéopse, 1925, pp. 400-401.

20 Ibid., p. 404.

21 lbid., pp. 415-416. 
Assurément, cette énumération proliférante a non seulement pour effet de recouvrir la première période du comique français, qui n'offre visiblement aucune de ces grandes figures, metteurs en scène ou comédiens, dont Coissac est si friand, mais surtout d'éluder les filmsmêmes, qui n'existent qu'à travers le listage de protagonistes cité ci-dessus. De fait, la tentative de réhabilitation de cette production comique face à la visée dépréciative de Delluc achoppe sur ce refus de revenir aux films et à leurs caractéristiques : Coissac perpétue le mirage d'un corpus unitaire, mais en inverse la polarité évaluative. À la même époque, Ricciotto Canudo parvient à un constat comparable à celui de Delluc, qu'il amplifie par une tentative de définition de cette spécificité française passée, toutes périodes confondues:

$1895 /$

$n^{\circ} 61$

septembre

2010

La définition du « film comique " est de la sorte, je l'avoue, très difficile. Depuis l'Arroseur arrosé des origines du cinéma, on s'est évertué à nous donner la grosse farce, mouvementée, basée sur un canevas banal et à peu près insignifiant, et dont toute la vis comica est dans le grotesque des gestes, des attitudes brisées par des chutes qui provoquent le rire, dans les courses déréglées et sottes comme un concours de sacs, ou enfin dans la puérile malice des sous-titres.

(...) Il sortira de cette crise, et de cette demande, que l'on s'efforcera de créer, enfin, le véritable « comique » de l'écran, qui ne sera pas seulement un acrobate ou un habile farceur, mais un véritable « comédien ».22

Ce cinéma, homogénéisé sans discernement, devient alors le repoussoir pour un hypothétique renouvellement à venir de la production comique française. La réunification du corpus correspond par conséquent à une stratégie critique, dont le principe sera repris plus tard par les Jeunes Turcs des Cahiers du cinéma : discréditer le passé proche et le présent, globalement, dans un même mouvement, pour mieux affirmer la nécessité d'un renouveau esthétique, prétendument attendu par le public et la critique. Et, dans les deux cas, c'est bien sûr la seule dimension esthétique qui sert à discréditer ce pan de la production française. Néanmoins, le propos de Canudo a le mérite de tenter de cerner les contours de cette entité, définie assez justement dans son rapport à la farce et au grotesque (un aspect du comique que le critique a toujours cherché à mettre en évidence, et sur lequel il n'a pas toujours occupé une position aussi méprisante, comme nous pourrons nous en rendre compte, voir p. 44). La référence à ces formes " basses ", trop populaires pour être acceptables, introduit, sans le dire vraiment, l'idée d'une correspondance entre ce cinéma et un certain socio-type de spectateur.

22 Ricciotto Canudo, «Films comiques ? ", Paris-Midi, 23 mars 1923, reproduit dans I'Usine aux images, Paris, Séguier/Arte éditions, 1995, pp. 213-214. 


\section{Un cinéma aux accents " populistes » ?}

Au milieu des années vingt, l'écrivain André Beucler l'affirme, plus explicitement, dans une longue réflexion sur le comique livrée dans le contexte très élitaire de I'Art cinématographique. II postule sans détour une telle connivence immédiate entre le cinéma, cet « art populaire par excellence » et le public le plus large, en vertu de "lois obscures et naturelles ». À ses yeux, cette alliance expliquerait la vulgarité récurrente, les " gros effets ", les " farces sûres » qui ont abondé dans le comique des premiers temps, trop élémentairement attaché aux mouvements corporels : " des gens qui tombaient dans la rue, d'autres qui se battaient, d'autres qui se lançaient à la poursuite d'un type plus audacieux que la masse. " La période qui a suivi ces premiers balbutiements, marquée par la production en série, se réduisent pour Beucler à un ensemble de "grossièretés, bouffonneries ou cochonneries ", un humour bas de gamme qui " exploite quelque disgrâce physique " et refuse l'expression des " sentiments » afin de privilégier l'interprétation facile de « choses immédiatement risibles ${ }^{23}$.

À l'unité du corpus répond en quelque sorte logiquement celle du spectatorat, perçu comme peu enclin à apprécier la qualité à une époque où, en France, la critique n'existe pas encore réellement. Par conséquent, la vision de ces films comme s'agrégeant à un tout homogène n'est pas dénuée de fondements idéologiques. Cette position trouve un écho paradoxal, bien plus tard, dans la manière dont Noël Burch divise lui aussi les vingt premières années du cinéma français en deux périodes :

Bien des films de cette première époque - et pas seulement les films comiques [mais particulièrement, tout de même, serait-on tenté d'ajouter] - reflètent même confusément et contradictoirement, le vécu, voire les aspirations profondes du peuple laborieux. En somme, nous avons affaire ici à une démarche plus démagogique qu'édifiante. ${ }^{24}$

Et il ajoute plus loin :

Les artisans de la première génération - Zecca, puis Heuzé, Nonguet et d'autres chez Pathé ; Alice Guy chez Gaumont - quelles que fussent leurs origines sociales [...] - ont su trouver rapidement une veine comique particulièrement riche dans les inimitiés de classe. Ils savaient solliciter la complicité de leur public habituel en prenant pour cible les traits, réels ou supposés, que ce public attribuait aux autres couches sociales. ${ }^{25}$

23 André Beucler, "Le comique et I'humour ", I'Art cinématographique, I, Paris, Librairie Félix Alcan, 1926, pp. 28-29.

24 Noël Burch, op. cit., p. 65

25 Ibid., p. 67. 
$1895 /$

De son côté, Francis Lacassin estime également que le médium filmique se destine " aux couches les plus modestes: peu familières des théâtres de boulevards, elles fréquentent les champs de foires, le cirque, le café-concert. C'est comme un reflet de ceux-ci qu'on retrouve dans le film comique voué à la grosse farce ${ }^{26}$. Il y a donc là une sorte de consensus entre un grand nombre d'historiens sur lequel il convient de revenir, tant il paraît avoir joué un rôle décisif dans le sentiment que ces scènes comiques des toutes premières années (avant 1908, environ) ont pu constituer un corpus homogène.

Pour appuyer son propos, Burch décrit l'action de bandes essentiellement comiques et « à trucs ${ }^{27}$, où des bourgeois s'adonnent à des comportements outranciers ou font l'objet de moqueries ou de dégradations vestimentaires, et qui peuvent être marquées par l'expression d'un « extraordinaire culte du plaisir, terrestre, populaire au sens plein du mot, qui ne pouvait que heurter le refoulement bourgeois en cette fin de siècle ". En témoignent notamment des films à teneur scatologique centrés sur l'univers des W. C. (Erreur de porte, 1904 ; Effets de melon, 1906) ou les dérèglements nutritifs de la maternité (Madame a ses envies, Gaumont, 1907). Quant à la présence massive de personnages populaires, tels les petits artisans urbains, elle s'explique d'après Burch par un effet de métonymie entre le développement encore artisanal d'une industrie du film centrée sur la capitale et les milieux sociaux qu'elle toucherait le plus directement : " avec ces films-ci, tout au moins, on a à faire à un cinéma parisien qui prend sa source dans le vécu de son public le plus proche. " Largement partagée dans I'historiographie du comique des premiers temps, même au-delà de France ${ }^{28}$, cette vue est fondée presque exclusivement sur l'analyse des films, et non pas sur une étude des discours et des pratiques qui permettraient de mieux évaluer le sens et la portée de la production cinématographique fragmentaire que cette époque nous a laissée.

Des bandes comiques françaises tournées jusqu'à la Première Guerre mondiale, il est effectivement assez aisé de dégager plusieurs exemples d'une confrontation avec la hiérarchie et les institutions dominantes. Dans divers films, sur l'ensemble de la période considérée, les autorités policières et militaires sont souvent victimisées ou tournées en ridicule, à des

26 Francis Lacassin, op. cit., p. 76.

27 « Mais ce n'est pas seulement dans les films comiques que se manifeste ce populisme envahissant. Quelques films à trucs traduisent même explicitement les fantasmes du travailleur exploité... ", (Noël Burch, op. cit., p. 72).

28 Thomas Brandlmeier (Filmkomiker, Frankfurt, Fischer Verlag, 1983, p. 86) perçoit le comique des premiers temps comme marqué par une attitude de provocation par rapport au système de valeurs dominants de la bourgeoisie ; pour Gerald Mast, (The Comic Mind. Comedy and the Movies, Chicago \& London, The University of Chicago Press, 1979 [1973], pp. 34, 41-42), la plupart des premiers films comiques américains sont destinés à un public mâle et prolétaire : on se moque des campagnards, des femmes moralisatrices et des hommes efféminés, des snobs, promouvant pour l'essentiel la boisson, la fumée, le divertissement physique. 
degrés variables. Dans la Course des sergents de ville, un chien poursuit les agents de police jusque dans leur commissariat. Les pouvoirs magiques de farceurs contraignent des soldats à défiler plus rapidement ([/a Machine à accélérer le temps]), des policiers à danser (Rigadin avale son ocarina), des pandores à prendre l'apparence de ballerines (fig. 1) et un cavalier militaire à se transformer en vache (Arthème sorcier). Le personnage-titre de Boireau spadassin (Pathé, 1913) écrase la tête d'un gendarme avec son épée et le fait rapetisser, tandis que celui de Bigorno couvreur (Comica, 1914) se bat en riant contre plusieurs policiers. Si le héros de Max prend un bain (Pathé, 1910) fait faux bond aux forces de I'ordre qui l'ont arrêté pour atteinte aux bonnes mœurs, et les fait même tomber du toit, il parvient, dans Max victime du quinquina (Pathé, 1911), à

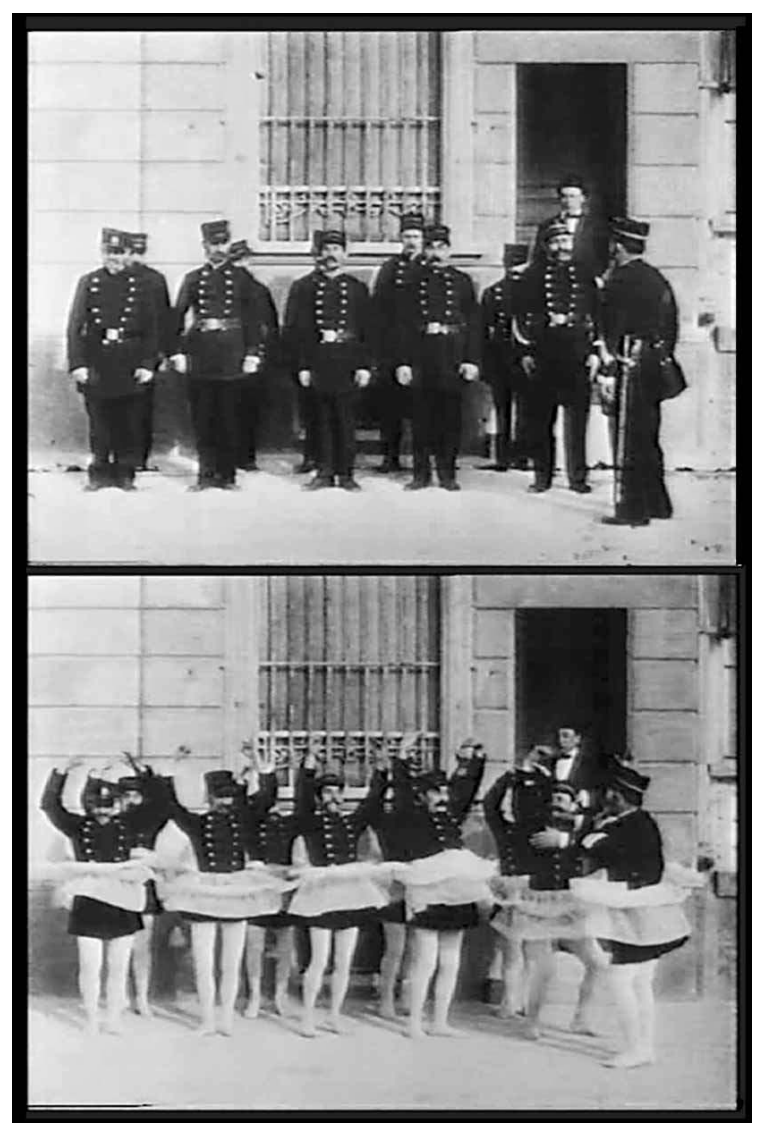

Fig. 1. Arthème sorcier, Éclair, 1913.
1895 / $n^{\circ} 61$ septembre 2010

19 contourner son arrestation pour ivresse, en passant inconsciemment pour un notable.

Plusieurs films témoignent également du « populisme » cerné par Burch pour la période des débuts, du moins si l'on assimile à cette tendance toutes les occurrences où l'on met à mal la distinction et le maintien de personnages aux allures distinguées. Conformément à la logique de rabaissement du noble vers le trivial et d'inversion propre au comique populaire - tel que I'a dégagé Bakthine pour le carnaval29 et que Burch voit témoigner, dans les

29 « Toute la logique des mouvements du corps vue par le comique populaire (et que l'on peut voir aujourd'hui dans les spectacles forains et le cirque) est une logique corporelle et topographique. Le système de mouvements de ce corps est organisé en fonction du haut et du bas (envolées et chutes). Son expression la plus élémentaire - pour ainsi dire le phénomène premier du comique populaire - est [...] une permutation permanente du haut et du bas du corps et vice versa. " Mikhaïl Bakhtine, l'CFuvre de François Rabelais et la culture populaire du Moyen Âge et sous la Renaissance, Paris, Gallimard, 1970 [1940], p. 350. 


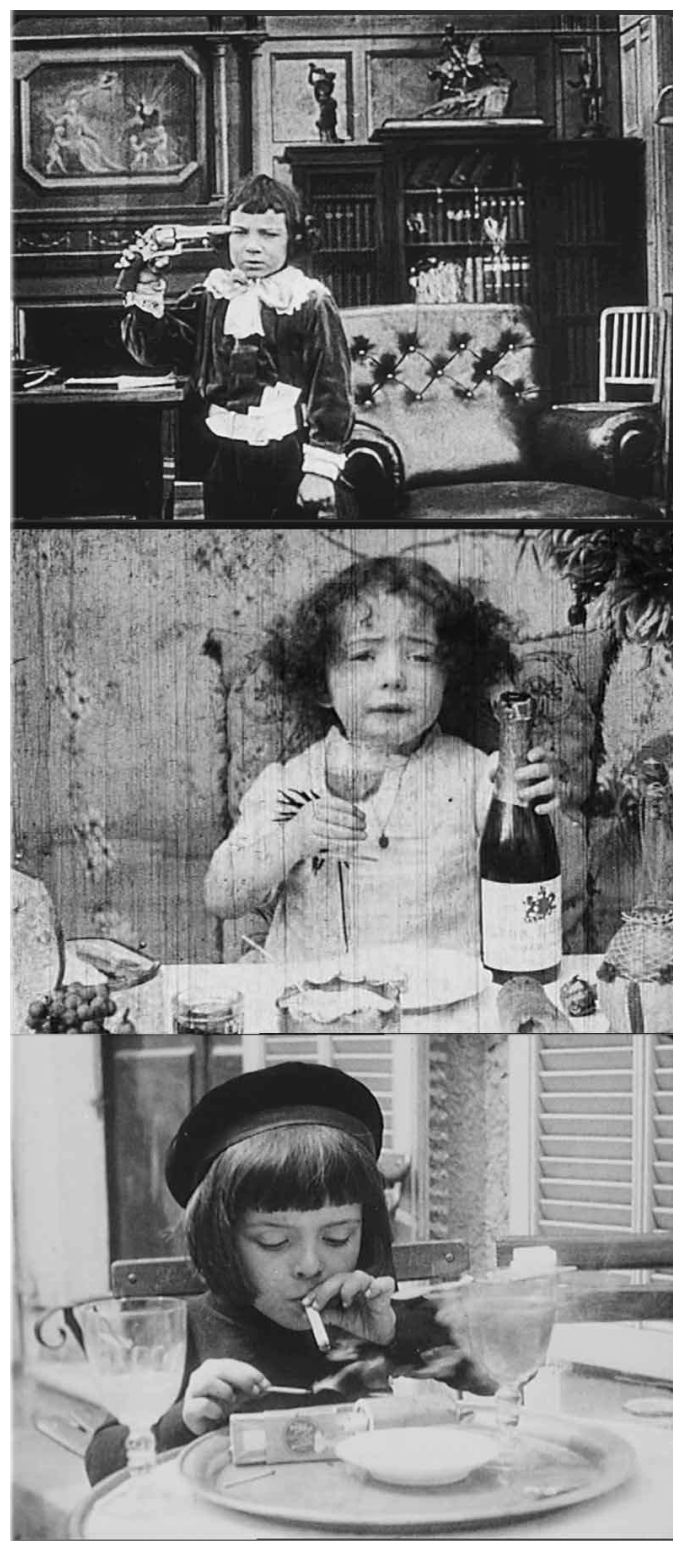

Fig. 2. Le Suicide de Bébé, Eclectic, 1913. La Journée de Lily Éclair, 1913. Toto ne boira plus d'apéritifs, Pathé, 1911.

30 Noël Burch, op. cit., p. 64. comiques des premiers temps, du caractère « vivace » de la " tradition rabelaisienne » des « couches populaires " 30 -, il s'agit alors de souiller les mises vestimentaires (/e Costume blanc; les Mésaventures d'un veston), d'étourdir autrui par sa mauvaise odeur corporelle (Parfum troublant, Nizza, 1911), de tourner en bourrique un médecin (l'une des victimes de l'irrésistible musique produite par Rigadin lorsqu'il avale son ocarina) ou de martyriser un homme distingué (à l'instar de celui qui reçoit une tuile au visage, avant de se faire littéralement enfoncer une cheminée sur la tête par l'ouvrier déchaîné de Bigorno couvreur). Cette dernière situation a presque valeur générique, tant revient constamment la mise à sac d'appartements bourgeois par des animaux en fuite, des propriétaires saisis de folie destructrice ou des employés de maison. Dans les Apprentissages de Boireau (Pathé, 1907), un enfant de prolétaire accumule les calamités partout où il se présente et se fait ainsi renvoyer de tous ses emplois successifs (qui dessinent d'ailleurs une trajectoire sociale descendante). Dans les Araignées de Rosalie (Comica, 1913), une femme de ménage explicitement paresseuse, en voulant se débarrasser d'horribles insectes, détruit et casse systématiquement bibelots, vases, assiettes, jetant ensuite sans ménagement les débris par la fenêtre. Du même esprit apparemment transgressif relèvent enfin les méfaits des enfants far- 
ceurs $^{31}$, surtout lorsqu'ils se livrent à des activités en principe réservées aux adultes (fig. 2), comme la prise d'alcool ou de tabac (La Journée de Lily, Éclair, 1913, La Ruse de Willy, Éclair, 1913 ; Toto ne boira plus d'apéritifs, Pathé, 1911) ou la manipulation des armes (Le Suicide de Bébé, Eclectic Films, 1913 ; Le Premier duel de Willy, 1913, Éclair).

Tous ces moments d'insubordination et de moquerie à l'encontre des conventions sociales ne peuvent pas, pour autant, permettre d'établir des constats à valeur générale, ni même de dégager des tendances claires, tant ils ne reflètent qu'une part infime de la vaste production comique des années 1905-1914. En outre, de nombreux contre-exemples viennent apporter une vision plus nuancée des séries comiques. L'analyse des représentations reste un exercice complexe où les interprétations demeurent le plus souvent insolubles. Que retenir, par exemple, d'un film comme Boireau Magistrat (Pathé, 1912) : la posture éminemment révolutionnaire adoptée par le héros, - poursuivi par les gardiens de l'ordre, celui-ci usurpe l'identité d'un homme de loi et fait acquitter des hommes du peuple, action qui le fait porter en triomphe - ou le retour à l'ordre final, où Boireau, l'air penaud, n'oppose aucune résistance à son encadrement par une troupe ?32 Ce type de sanction n'est en rien exceptionnel : dans les films centrés sur des farces, les mauvais esprits sont généralement pris à leur propre piège, stoppés dans leur action, ou convaincus de retourner dans le droit chemin : le héros de Bigorno fume l'opium (Comica, 1914) jure de ne plus recommencer ; le voleur pris au piège de la propriété mécanique dans Cottage hanté (Pathé, 1913) est embarqué par la police, tout comme Max, lorsque celui-ci est victime du quinquina.

C'est également le sort qui attend le clochard Fouinard dans ses pérégrinations. Tout au long de Parfum troublant, il ne cesse d'importuner une série de bourgeois par l'odeur incommodante qui émane de ses chaussures, profitant même de leur évanouissement pour les dépouiller. Mais, dans l'ultime tableau, il subit le même outrage de la part d'un policier qui l'emmène sous le regard triomphal de toutes ses victimes réunies. Le même vagabond, démasqué en tant que voleur à la fin de Comment Fouinard devint champion (Nizza, 1911), se fait rouer de coups par toutes les personnes présentes. Quant à la folie de Zigoto se prenant soudainement pour un taureau en plein milieu d'un café (Zigoto policier trouve une corde,

31 Sur cette topique enfantine, qui émaille d'emblée les productions Lumière, Edison, Biograph, etc., voir Tom Gunning, "Crazy Machines in the Garden of Forking Paths: Mischief Gags and the Origins of American Film Comedy », dans Kristine Brunovska Karnick and Henry Jenkins (dir.), Classical Hollywood Comedy, New York, Routledge, 1995, pp. 87-105. En France, d'une sérialité de sujets comme les Farces de Toto gâte-sauce (Pathé, 1905), Petits voleurs de pommes (Pathé, 1905) ou Petis voleurs de tomates (Pathé, 1906), on passe par la suite à de véritables héros récurrents comme Bébé, Bout-de-Zan ou Willy. Voir aussi François de la Bretèque, "Collection Alan Roberts (1) : Les mauvais garnements du cinéma des premiers temps », 1895, n¹9, décembre 1995, pp. 54-56.

32 À l'inverse, dans Calino avocat (1910), le héros, atteint d'une frénésie incontrôlable, enfonce une pioche dans un dos, tire, frappe un bébé et finit par laisser fuir son client !

1895 / 


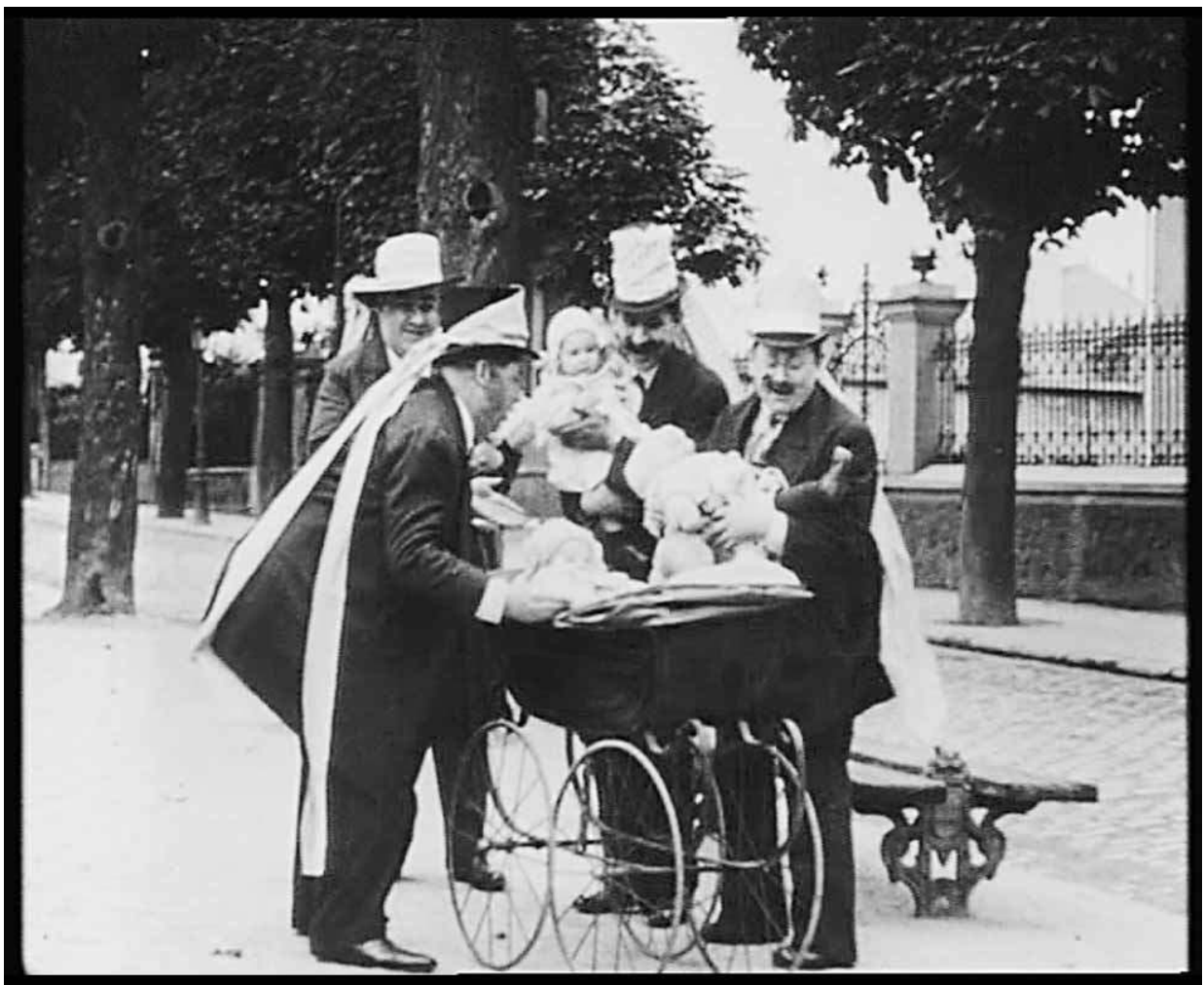

Fig. 3. Les Femmes députés, Lux, 1912.

Gaumont, 1911) ou la trajectoire dévastatrice de Roméo lancé à la poursuite d'un lépidoptère (Roméo collectionne les papillons, Comica, 1911), elles se voient finalement maîtrisées par de bons citoyens, qui débarrassent le cadre de ces éléments disruptifs. Une fois la parenthèse d'inversion " carnavalesque " terminée, les conventions reprennent le pouvoir. Il en va ainsi de l'expérience des Femmes députés (Lux, 1912), au terme de laquelle l'une des féministes du titre, convaincue de son erreur, retourne à la maison pour s'occuper à nouveau des bébés. Ce film fait la part belle aux images jouant de l'inversion temporaire des comportements genrés, tels ces trois hommes vêtus de chapeaux et de tabliers féminins pour aller promener leur progéniture (fig. 3)33.

Dans le même ordre d'idées, la porosité entre catégories sociales est montrée à la fois comme I'occasion d'une confrontation susceptible de provoquer l'hilarité et comme une source de

33 Motif que l'on retrouve dans le Truc d'Anatole (Gaumont, 1911), où le héros doit prendre en charge le ménage et se révèle incapable de faire la cuisine. 


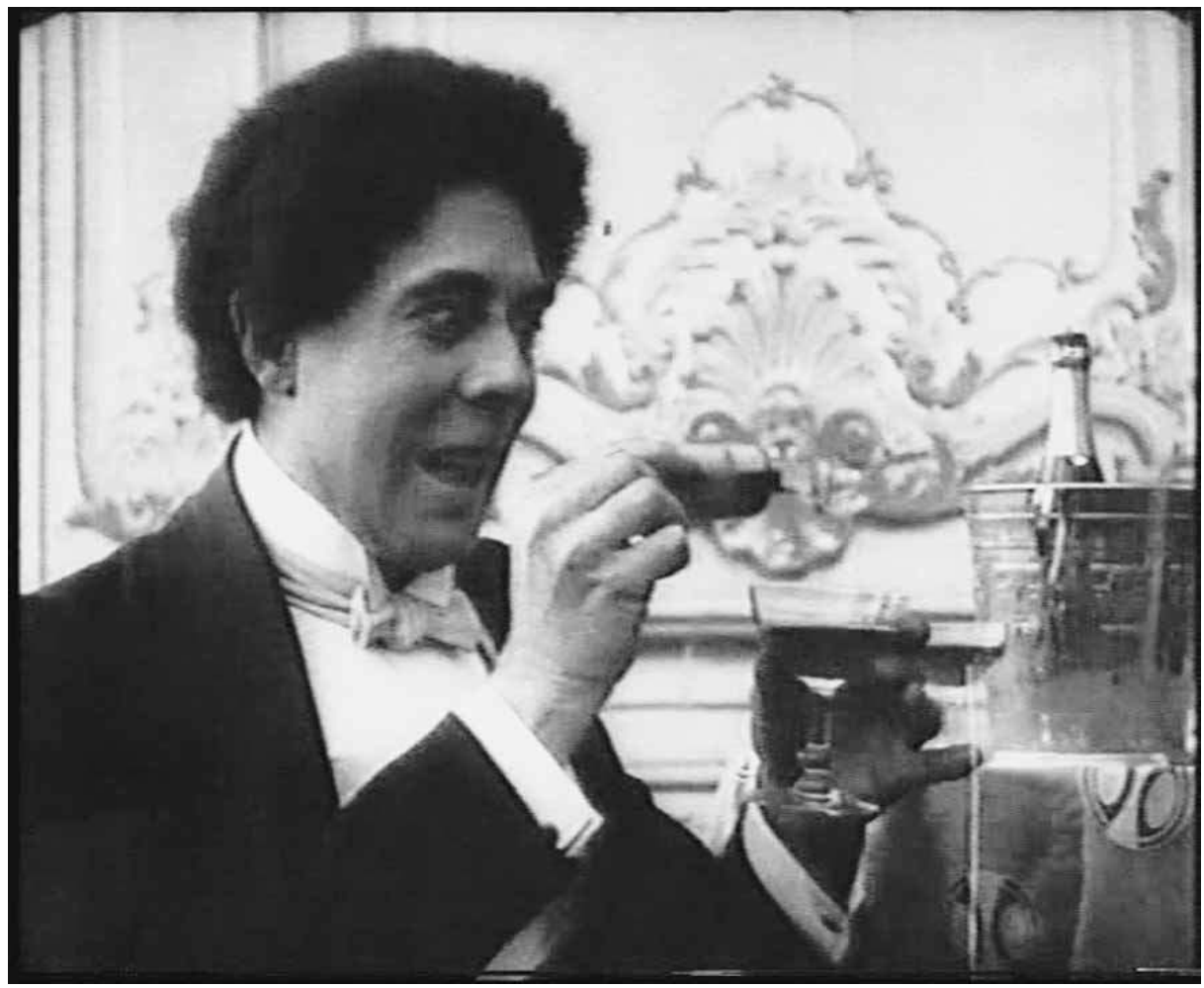

Fig. 4. Le Nègre blanc, Pathé, 1910.

danger : Calino, se faisant passer pour un prince lors d'une croisière, s'avère incapable de masquer ses basses origines - il multiplie les familiarités avec le capitaine et les passagères, veut montrer aux marins comment briquer le pont -, ce qui entraîne une arrestation acceptée dans I'hilarité (Calino, passager de marque, Gaumont, 1910) ; un Boireau bourgeois empruntant l'identité de son domestique pour se mêler à la populace se fait copieusement passer à tabac par des apaches (Boireau et la gigolette, Pathé, 1912) ; Gavroche, obligé par un brigand d'échanger ses vêtements avec lui, suscite dès lors la terreur dans un immeuble (Gavroche cambrioleur malgré lui, Éclair, 1913 - voir le résumé d'époque, sur la page promotionnelle reproduite en annexe, p. 304). Quant aux représentations " ethniques», elles participent bien d'une même logique d'inversion, mais celle-ci met d'autant mieux en évidence les schémas racistes assignant par exemple aux Noirs une position inférieure, perçue comme régressive vis-à-vis de l'Occidental (voir le résumé publicitaire de Gontran engendre une sombre postérité, Éclair, 1913, p. 308). Le cinéma reprend là des situations explorées en 
amont dans d'autres domaines du spectacle et des divertissements, à l'instar de la pantomime considérée dans ce volume par Patrick Désile. Ainsi le héros du Rêve de Dranem (Pathé, 1905) accueille-t-il avec l'effroi la transformation cauchemardesque de son épouse en Africaine et, dans le Nègre blanc (Pathé, 1910, fig. 4), Rigadin devenu Noir se voit-il rejeté par sa femme blanche. Lorsqu'il trouve une potion miracle qui lui fait retrouver sa " couleur » originelle, il se venge de son épouse en la noircissant à son tour. De cet ensemble d'exemples ressort la constance, dans les séries comiques conservées jusqu'à aujourd'hui, d'un travail ludique sur les conventions et les valeurs sociales et culturelles. Malgré cela, il paraît difficile de faire la part de la subversion et de l'idéologie au sein de ces infinis mécanismes de renversement à valeur polysémique.

Devant l'étonnante complexité que ces films offrent à toute tentative d'analyse des représentations, il convient de s'interroger sur les raisons, les présupposés et la signification d'un tel consensus sur ce point entre les historiens. Pour revenir aux discours de Canudo et de Burch, ces deux auteurs partagent visiblement, à leur manière, la croyance en un cinéma français des premiers temps (et plus particulièrement la production comique) conçu uniquement pour le peuple tandis qu'ils divergent dans leurs façons de le juger, mais à la marge : s'il est mauvais parce que populaire, chez Canudo, il est « démagogique " parce que fait par la bourgeoisie, chez Burch. Dans les deux cas, s'affirme une homogénéité, soit sur les vingt premières années du cinéma (Canudo), soit sur une période plus courte, courant à peu près jusqu'en 1908 (Burch), puisque les années suivantes verraient selon ce dernier l'avènement d'autres formes cinématographiques (notamment la comédie) - lié à un changement dans la sociologie des spectateurs - s'inspirant de la culture bourgeoise (vaudeville, théâtre de boulevard, naturalisme, etc.). Si la position de Burch peut nous paraître aujourd'hui plus acceptable parce que plus conforme à la « réalité » historique (deux périodes, après une transition autour de 1907-1909, qui correspond à cet événement majeur de la production comique : la sérialisation des personnages), sa façon de les remplir demeure contestable. Est-il si évident d'affirmer finalement, en creux, que la première période n'est pas construite sur des références culturelles " nobles" (le théâtre et la littérature par exemple, qui sont des sources d'inspiration d'un Feuillade dès 1906, par exemple avec son Thé chez la concierge, librement adapté en 1907 du Roman chez la portière de Monnier, mais on pourrait citer également le Billet de logement et bien d'autres scènes) et plus encore que tel film comique " reflète " le spectateur auquel il s'adresse ? Si le texte de Patrick Désile montre déjà combien on peut se leurrer en associant mécaniquement certains spectacles, comme le cirque et le music-hall, à un spectatorat « naturel » socialement typé, un film de 1907, le Cochon danseur (Pathé), souligne la complexité de ces liens possibles entre origine sociale des spectateurs et inscription 
d'un film dans un réseau de séries culturelles. En effet, cette scène comique Pathé (fig. 5) s'inspire assez ouvertement - comme en témoigne l'article de Fantasio reproduit ci-après (fig. 6) - d'un numéro de music-hall intitulé le Cochon mondain. Le changement de titre ne semble pas s'expliquer par la volonté de masquer la forme antérieure du sujet (ce qui n'aurait guère de sens puisque le costume est rigoureusement le même) mais bien plutôt par le souci de ne pas exclure une catégorie de public. Car, comme l'indique l'article, le spectacle n'est pas dénué d'une dimension contestataire : " II nous présente un porc de bonne compagnie, non pas même du demimonde, comme il s'en trouve, mais du monde. Il est vrai qu'il s'en trouve aussi ", ce que confirment aussi les attitudes reproduites, autant que son costume (haut-deforme, costume, nœud papillon,

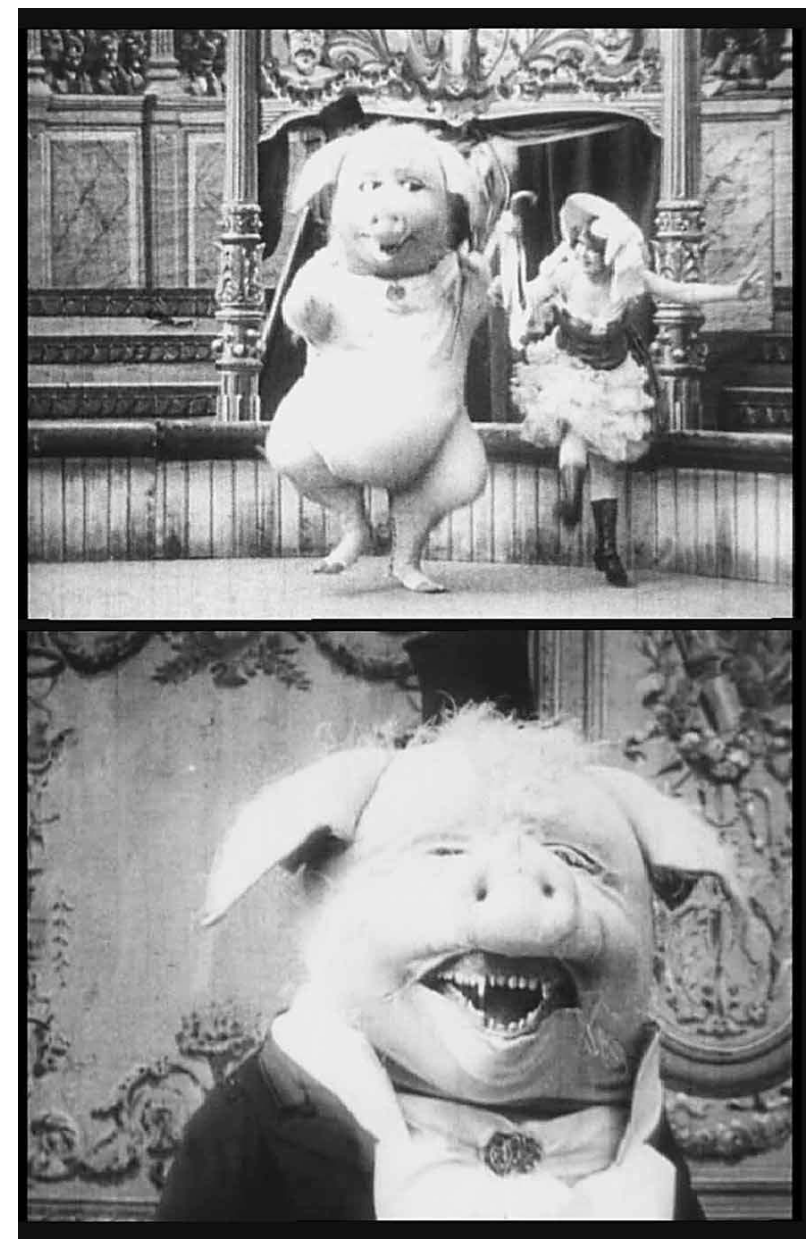

Fig. 5. Le Cochon danseur, Pathé, 1907.
1895 / $\mathrm{n}^{\circ} 61$ septembre 2010

25 lorgnons, etc.). En devenant sim-

plement " danseur ", le cochon perd ses attributs sociaux et paraît sous une apparence plus acceptable pour le public, peut-être pas mondain, mais en tout cas bourgeois, qui aurait pu se sentir visé par cette caricature. Ici, donc, une forme plutôt populaire de spectacle se trouve en quelque sorte émoussée pour satisfaire un public de cinéma plutôt aisé.

De fait, il nous semble au contraire que l'hétérogénéité de ce corpus témoigne de la pluralité de ses spectateurs, ce dont convenait d'ailleurs déjà, en son temps, Georges Méliès, au moins implicitement, lorsqu'il pensait possible cette association qui semble aujourd'hui incongrue à certains, entre « art », public cultivé et « burlesque » : 


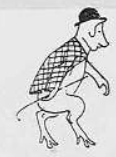

Nous avons vu souvent de braves porcs enrubannés s'efforcer, sous la baguette de dompteur: forains, d'imiter l'homme en quelques-uns de ses gestes fa miliers.

- Il y a, affirment les psychologues, tant de point communs entre eux!

Mais voici, cette fois, sur la scène d'un de nos plus fastueux music-halls un homme qui cherche, à son tour, à imiter le porc en quelques-uns de ses gestes familiers.

- Il y a tant de points communs ! continuent d'affirmer les psychologues.

Ceci n'est pas banal et l'artiste qui s'est donné cette fantaisiste spécialité est extraordinairement amusant.

\section{Le Cochon Miondain}

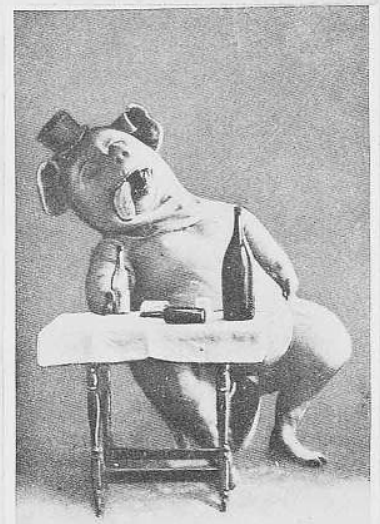

Il nous présente un porc de bonne compagnie, non pas même du demi-monde, comme il s'en trouve, mais du monde. Il est vrai qu'il s'en trouve aussi. Le porc se trémousse, gambade pirouette, danse et sourit comme un porc joyeux et bien élevé. Il a un petit air bon enfant qui plaît aux foules.

Celles-ci, devant tant de verve et de bonhomie, ne savent plus exactement si elles sont en présence d'un homme ou d'un animal.

Et les femmes, déroutées, les femmes qui dans leur langage usent si facilement du mot s cochon s) applaudissent de toute la force de leurs petites mains le clown merveilleux, grotesque et. symbolique.

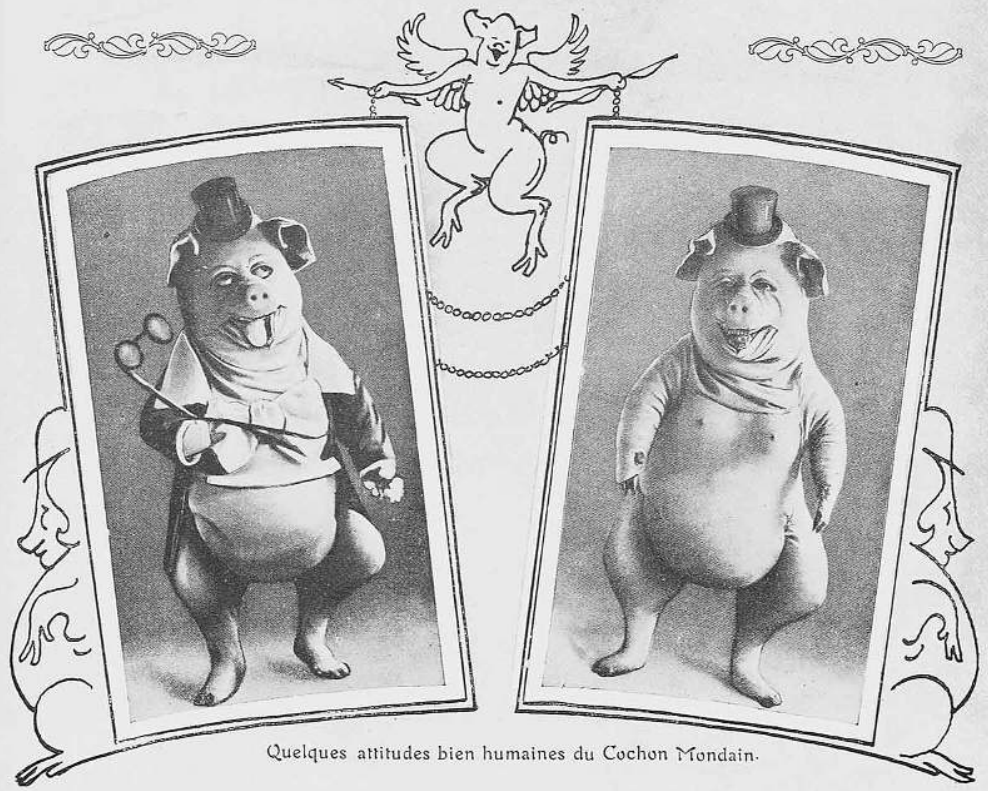

Fig. 6. Fantasio, n 16, 15 mars 1907, p. 119. 
Il est évident que l'expression d'une pensée éminemment artistique ou littéraire demande un jeu mesuré, une pantomime parfaite, en un mot capable d'intéresser les gens dont l'esprit est cultivé et qui savent reconnaître l'art partout où il est (même dans le burlesque et la caricature). ${ }^{34}$

Visant sans doute un public socialement mixte, ces films cultivent - sciemment serait-on tenté de penser - l'ambiguïté idéologique, et ce d'au moins deux manières. Tout d'abord au sein de chaque opus, comme on l'a pu déjà s'en rendre compte, en ménageant la possibilité d'une lecture plurielle. Le cas de Bébé est socialiste est particulièrement édifiant. Voici comment la notice Gaumont présente le début du film : «Le père de Bébé, député socialiste, prépare dans le silence du cabinet un grrrand discours. C'est une enfilade de logomachies sonores et creuses que le tribun lit à voix haute avec toute sa fougue et ses plus beaux effets oratoires. " L'engagement militant du père est donc clairement caricaturé, mais lorsque Bébé tente de mettre en application les principes de son père en invitant des chiffonniers à venir manger chez lui, le père effectue un revirement en mettant tout le monde à la porte, avant de corriger son fils. « Et Bébé, effrayé de l'abîme qui sépare, en socialisme, les vérités théoriques des réalités pratiques, lève les bras au ciel dans un geste de suprême découragement ». Si la fin de ce résumé peut paraître sans équivoque (mais l'évidence monosémique de ce discours écrit est sans commune mesure avec l'incontournable polysémie des films, surtout à cette époque), la perception de la bande par le public peut grandement varier selon qu'il adopte le point de vue du père (qui revient en quelque sorte à la raison et châtie son fils pour lui faire prendre le bon chemin) ou celui du fils (qui n'a pu mener à bien son expérience de socialisme à cause du reniement de son père). L'autre forme d'ambiguïté idéologique se situe à une échelle différente : non celle du film mais celle de la série. Cette indistinction caractéristique, que Gian Piero Brunetta a également perçue au sein des séries comiques italiennes 35 , se retrouve en effet dans l'absence d'homogénéité dans l'identité de certains héros, comme Boireau, dont le personnage oscille entre la bourgeoisie et le petit peuple, l'ancrage urbain ou campagnard, l'âge adulte ou enfantin. En effet, le personnage constitue certes un invariant, mais aux données sociales (et psychologiques) assez souples, au point que Bébé peut appartenir aussi bien à une famille bourgeoise qu'à un milieu prolétaire (le Noël de Bébé et

34 Georges Méliès, « le Merveilleux au cinéma ", I'Écho du cinéma, 24 mai 1912, reproduit dans Jean Giraud, le Lexique français du cinéma des origines à 1930, Paris, CNRS, 1958, p. 54.

35 D'après Gian Piero Brunetta (" II clown cinematografico tra salotto liberty e frontiera del West ", dans Paolo Cherchi Usai et Livio Jacob (ed.), I comici del muto italiano, numéro spécial de Griffithiana, vol. VIII, n²4-25, octobre 1985, pp. 15, 17, 19), Cretinetti (André Deed, l'interprète de Boireau) lui semble se borner à parodier, par ses attitudes corporelles, le système gestuel et les rituels d'une société en proie à la modernisation des transports et des communications et l'émergence de nouvelles classes sociales intermédiaires, mais sans réellement en mettre en cause les fondements.

$1895 /$

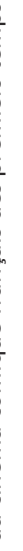


Bébé trouve un portefeuille, respectivement de 1911 et 1912) et l'on pourrait presque affirmer que l'univers dans lequel il s'inscrit est précisément celui qu'il tente (certes pas systématiquement) de subvertir : si dans les deux derniers films cités, il apprend les vertus bourgeoises au contact de la bonne société (I'honnêteté, la compassion, etc.), il découvre au contraire des principes apparemment opposés à son univers social dans Bébé est socialiste, principes qu'il n'abandonne que par la force, là où son père les renie par intérêt et individualisme. On en vient ainsi à considérer que ce corpus est fondamentalement diversifié, tant sur le plan de ses références culturelles que sur celui du discours qu'il promeut, au point que l'on peut se demander si cette notion d'« école comique française " n'a pas été élaborée afin de réunir, par un cadre seulement spatio-temporel, des films étonnamment disparates.

\section{Cinéma comique contre " Film d'Art "}

Cela étant, pour que cette notion puisse apparaître, il faut préalablement que cette production comique soit en quelque sorte réhabilitée (puisque la notion d'école, empruntée à I'histoire de l'art, induit une qualité commune à un groupe d'œuvres), et donc qu'on la relise en des termes plus convaincants que ceux de Coissac. Il semble que ce mouvement soit initié à partir d'une entreprise historiographique à laquelle participe Coissac, mais uniquement pour rendre compte de la période de l'invention : il s'agit du Cinéma des origines à nos jours, ouvrage collectif de 1932 dans lequel il revient à René Jeanne d'écrire l'histoire des films. À une époque où le cinéma peut paraître menacé, aux yeux de certains critiques, par le théâtre filmé, consécutivement au " passage au parlant ", René Jeanne développe ce qui va devenir un véritable topos de l'historiographie : I'histoire d'un cinéma français souffrant de la généralisation, à partir de 1908, des films d'art ${ }^{36}$ " aussi éloignés que possible de la vérité cinématographique » et en quelque sorte sauvé par des personnalités qui surent montrer la voie vers laquelle il convenait de se diriger. Au premier rang de celles-ci figure Max Linder :

Le premier il avait compris que le comique qui peut se dégager de l'écran doit être différent du comique théâtral. Il avait donc renoncé à ces artifices de costume et de maquillage auxquels à cette époque avait recours la plupart des comiques de théâtre et de café-concert, et il se présentait sous des apparences d'impeccable correction : chapeau haut de forme éblouissant comme un miroir à alouettes, jaquette soigneusement ajustée, souliers vernis, gants blancs et canne dés-

36 Pourtant, les fameuses séances du Film d'Art à la Salle Charras comportaient bien des " scènes comiques " (ainsi le programme pour la semaine du 25 décembre 1908 avec le Retour d'Ulysse, ou celle du 18 janvier 1909, où est remontré l'Assassinat du Duc de Guise). 


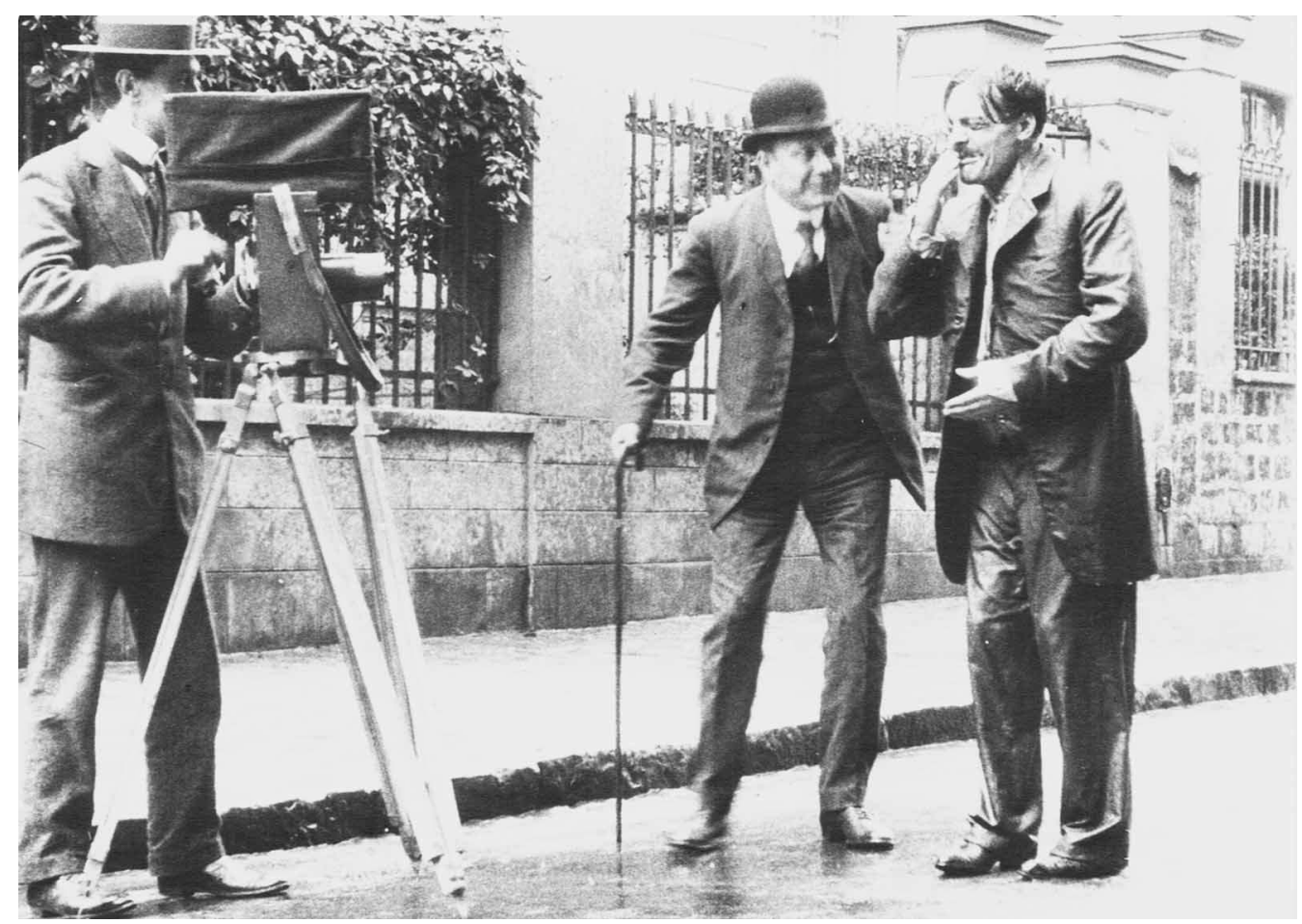

Fig. 7. Les Débuts de Max au cinématographe, Pathé, 1910.

involte, mais cette élégance - par un miracle de composition qui n'était peut-être qu'un effet du hasard - se trouvait précisément être celle que la foule, venant s'asseoir devant les écrans, pouvait admettre : ce n'était pas celle de l'homme du monde véritable, mais simplement celle du petit jeune homme - ou mieux encore du « calicot » supérieur - qui a bien regardé les catalogues des tailleurs et des grands magasins et du même coup elle se trouvait justement être celle qu'au delà de nos frontières les foules - qui alors regardaient encore Paris comme «la Ville Lumière " - s'imaginaient de très bonne foi être le chic parisien. Tout l'univers bientôt eut donc pour Max Linder les yeux d'une midinette de la rue de la Paix.

(...) Max Linder comprit à quel point cette habitude [la poursuite] était ridicule et il rompit délibérément avec elle - il n'y a pour ainsi dire pas de poursuite dans ses films - comme il comprit que ce n'était pas dans le répertoire théâtral - c'est-à-dire vaudevillesque : Dame de chez Maxim's et Billet de logement - qu'il fallait aller chercher des sujets de films. Ses films sont donc de petites comédies, à base d'observation et presque toujours d'une réelle simplicité qu'enrichit seulement un assez grand luxe de détails; les idées et les effets y sont heureusement schématisés et leurs 
différentes scènes s'enchaînent avec une logique rigoureuse - celle-là même que l'on retrouvera plus tard dans les meilleurs bandes de Charlie Chaplin et dans certains films de René Clair. ${ }^{37}$

Max Linder est donc à la fois, selon René Jeanne, celui qui sait mettre fin à un archaïsme (la poursuite, qu'il représente d'ailleurs comme tel dans les Débuts de Max au cinématographe en 1910, fig. 7) et celui qui parvient à tourner le dos à une pratique dominante mais injustifiée au regard de la "vérité cinématographique " (le vaudeville). Cette lecture s'avère fort discutable, Max Linder réfutant si peu le théâtre qu'il l'incorpore à ses récits, en croise le dispositif avec des projections en une expérience de ciné-théâtre et ne dédaigne pas plus les effets comiques jouant sur la corporalité et le trivial, typiques de l'époque de la poursuite.

$1895 /$ Nous reviendrons plus loin sur ces différents aspects. Retenons pour l'instant que ce point de vue téléologique, en ce sens que la situation présente (l'abomination du théâtre filmé) détermine le regard rétrospectif, s'impose durablement : la plupart des entreprises historiographiques des années trente et du début de la décennie suivante en reprennent le principe (Carl Vincent, Lo Duca ), voire la formulation (Valéry Jahier, André Boll39). Au-delà de la portée de son texte, René Jeanne a sans doute contribué à l'acceptation et à la circulation de cette idée, par l'organisation d'une rétrospective Linder au festival de Venise en 1938, durant laquelle est diffusé notamment Max victime du quinquina ${ }^{40}$, analysé par Carl Vincent dès 1939 dans son Histoire de l'art cinématographique. Nul doute que la forte présence de Linder dans le cinéma français de la première moitié des années vingt, son destin tragique et le visionnement possible de ses films en des occasions ponctuelles ont contribué à asseoir le mythe du génie sauvant, par le comique, le cinéma français de son influence théâtrale.

Si cette réhabilitation passe donc, dans un premier temps, par l'avènement historiographique de la figure de Linder, elle s'applique très vite à un ensemble plus vaste qu'il s'agit alors de circonscrire et de dénommer. C'est ainsi que Bardèche et Brasillach, partant de présupposés identiques à ceux de René Jeanne (les « incommensurables ravages » ${ }^{41}$ du Film d'Art), inventent «l'école comique française », soit une période précise de cette production. Cette " école »

37 René Jeanne, "l'évolution artistique du cinématographe », le Cinéma des origines à nos jours, Paris, Éditions du Cygne, 1932, p. 186.

38 Carl Vincent, Histoire de l'art cinématographique, Bruxelles, Éditions du Trident, s.d. [1939], (pp. 1416, « Max Linder, créateur d'un nouveau comique ») ; Lo Duca, Histoire du cinéma, Paris, PUF, coll. " Que sais-je ? ", 1942 (notamment p. 28 et p. 34).

39 Valério [Valéry] Jahier, « 42 ans de cinéma », le Rôle intellectuel du cinéma, Paris, Institut International de Coopération (Société des Nations), 1937 (pp. 24-26 : Jahier y cite explicitement René Jeanne) ; André Boll, le Cinéma et son histoire, Paris, Sequana, 1941 (p. 54).

40 Voir René Jeanne, Cinéma 1900, Paris, Flammarion, coll. 1900 vécu, 1965, p. 153.

41 Maurice Bardèche et Robert Brasillach, Histoire du cinéma, Paris, Éditions Robert Denoël, 1943 (première édition : 1935), p. 68. 
prend en effet place dans le deuxième chapitre de la première partie, intitulé "le cinéma d'avant-guerre (1908-1914) »), dont la stricte délimitation chronologique permet de situer en France l'origine de l'ensemble du cinéma comique : «Malgré certains efforts isolés, ce n'est pas en Amérique, mais en France, que devait se former le plus précieux de ce que nous a légué I'avant-guerre au cinéma : I'art du comique "42. Logiquement, cette notion nait donc au sein d'un discours nationaliste et xénophobe, construit sur la détestation de ce que peut représenter le cinéma américain (son cosmopolitisme, notamment). Mais comme il ne saurait être question de dénigrer totalement l'apport esthétique de celui-ci (en particulier pour le cinéma burlesque), le débat se déplace sur le plan d'une origine pensée, qui plus est, sur un mode nostalgique :

On éprouve à revoir certains films comiques de l'avant-guerre un étrange sentiment de déception : non pas déception devant les œuvres dont la plupart sont naïves et d'un comique rudimentaire, - mais enfin il fallait nous y attendre, - mais déception pour notre temps, devant ce qu'est devenu le rire au cinéma, alors qu'en ses débuts, il était si évidemment, mises à part quelques pantalonnades, rire de cinéma. ${ }^{43}$

Ce « rire de cinéma » se trouve là encore fort peu caractérisé, la seule ligne de partage entre le bon et le mauvais se situant bien évidemment du côté du rapport au théâtre :

(...) à côté du comique forain et ingénu, il [le Film d'Art] essaya de constituer un comique " distingué ", qui nous a valu par la suite tant de comédies filmées. (...) On pourrait s'étendre longuement sur ces transcriptions théâtrales, qui n'ont eu d'autre intérêt que d'apprendre aux acteurs à jouer, mais qui éloignaient le cinéma comique de son véritable destin.

Là encore, dans cette perspective, ce sont ses individualités comiques, mais plus largement représentées (Bardèche et Brasillach citent Onésime, Léonce, Polycarpe, Zigoteau - sic -, Calino, Gavroche, Nick Winter, André Deed, Prince-Rigadin, Bout-de-Zan, Marcel Levesque, etc.), qui sauvent le cinéma français. Ce discours, très proche de celui de René Jeanne, passe évidemment par l'exhortation des mêmes héros: Max Linder est ainsi le seul à bénéficier, dans ce chapitre, d'une partie autonome qui fait suite à celle consacrée à « l'école comique française ".

42 Ibid., p. 67.

$43 \mathrm{lbid}$. 
$1895 /$

On sait que le travail historiographique de Georges Sadoul s'est construit en grande partie en réaction à l'ouvrage de Bardèche et Brasillach, si bien qu'il peut sembler étonnant que celui-ci, dans sa grande entreprise de retournement du discours de ses prédécesseurs, ait conservé cette notion d'école comique française. Cependant, une lecture attentive des passages de ses livres et des articles où il évoque cette notion révèle un usage fort différent de celui de Bardèche et Brasillach. Cette " école comique française " n'apparaît pas comme telle dans le chapitre sur " l'évolution des genres chez Pathé (1903-1908) " du tome 2 de son Histoire générale du cinéma, ce qui peut sembler logique compte tenu de la périodisation, antérieure à celle choisie par Bardèche et Brasillach. En revanche, elle donne son nom à un chapitre (le sixième) du tome $3^{44}$. Sadoul se distingue cependant des inventeurs du syntagme en fixant son origine en 1909. Est-ce à dire que la reprise de cette notion, à ce correctif près, va de soi, pour Sadoul ? Ce n'est pas certain, puisqu'elle ne figure pas plus dans son Histoire d'un art - le Cinéma des origines à nos jours, publiée en 1949 chez Flammarion. Que s'est-il donc passé entre 1949 et 1951 pour que Sadoul se résigne, certes à sa manière, à intégrer "l'école comique française " dans son discours ? D'abord, celle-ci devient un enjeu historiographique. Jean Mitry, qui travaille en quelque sorte à la fois à côté et dans l'ombre de Sadoul, y consacre plusieurs textes, dont certains constituent partiellement des esquisses de sa future Histoire du cinéma. À la différence de ses prédécesseurs, Mitry s'intéresse surtout à Jean Durand, qu'il oppose explicitement à Max Linder :

\begin{abstract}
Certes, les films de Max Linder, qui furent les premières manifestations d'un comique psychologique qui devait aboutir à Chaplin, ouvraient une voie beaucoup plus féconde avec des perspectives infiniment plus vastes. Mais ils sont aujourd'hui considérablement dépassés et les meilleurs d'entre eux ont passablement vieilli. Au contraire, les films de Jean Durand, totalement dépourvus de caractères " humains " - ayant par cela même l'appréciable avantage de n'être pas encombrés de fausse psychologie - gardent encore pour la plupart toute leur fraicheur, toute leur spontanéité et tout leur charme. Leurs personnages ne sont que des fantoches, mais ce sont des fantoches pleins d'ironie, et leur verve caricaturale leur donne une vérité vivante autrement plus vraie et plus humaine que la fausse humanité du combien médiocre Rigadin. ${ }^{45}$
\end{abstract}

44 Le tome 2 de son Histoire générale du cinéma, « les Pionniers du cinéma, 1897-1909 », paraît en 1947 chez Denoël, tandis que le premier volume (" l'Avant-guerre ») du tome 3 (" le Cinéma devient un art, 1909-1920) est édité en 1951.

45 Jean Mitry, "le Comique au cinéma. II. Prélude à Mack Sennett : Jean Durand ", Travelling, ${ }^{\circ} 5$, septembre 1945, p. 150. 
S'il y a incontestablement une pose d'historien dans cette défense de Jean Durand - Mitry va même jusqu'à avancer exagérément que " pas une "histoire du cinéma" n'en a fait mention jusqu'ici »46) - elle s'opère malgré tout en prolongeant les discours antérieurs des historiens, à travers une reformulation de la notion de " vérité cinématographique ", transformée, d'une manière tout à fait propre à cet après-guerre, en essence cinématographique. Et c'est la conformité des films de Durand à celle-ci qui atteste de leur valeur. En effet, évoquant l'incontournable Onésime horloger (Gaumont, 1912), Mitry avance que « son thème (...) est des plus cinématographiques, puisqu'il intègre les procédés d'accéléré et de ralenti qui n'appartiennent qu'au cinéma ». Cependant, l'auteurisme (si l'on peut dire) de Mitry, en la matière, I'éloigne pour l'heure de toute visée globalisante d'un corpus comique propre aux vingt premières années du cinéma français. Mais rendant compte un peu plus tard (Bulletin de I'I.D.H.E.C., 1947) des "étapes du cinéma " et en particulier de la période comprise entre 1903 et 1910, Mitry délaisse ce point de vue initial (tout en conservant son intérêt pour Durand) pour une perspective plus large selon laquelle " malgré le "Film d'Art", il semble bien que le rôle capital du cinéma français entre 1903 et 1910 ait été la création du comique cinématographique ${ }^{47}$. Dépassant le cas de quelques personnalités qui en auraient influencé d'autres (Durand / Sennett), Mitry revient finalement à la position de Bardèche et Brasillach, mais en développant l'argumentation. S'il attribue en effet cette " création » aux Français, c'est essentiellement parce que leur mode de conception et de production des scènes comiques anticipe de quelques années ce qui va devenir le "comique cinématographique ", c'est-à-dire le burlesque américain (il n'est pas anodin, d'ailleurs, que Mitry ait recours plusieurs fois au terme de "burlesque " pour définir rétrospectivement le comique de Durand dans son article de Travelling, comme il le fait également dans cet autre texte) :

Délaissant peu à peu le burlesque collectif, le comique de faits dont aucun personnage particulier ne se détachait, on fit en sorte que ces événements soient suscités par un individu qui devint le héros de la parodie. ${ }^{48}$

Employé par Mitry dans sa valorisation du comique de mouvement hérité des scènes « populaires ", le terme de "burlesque » occupe une place centrale dans les écrits sur le cinéma comique des premiers temps. II nécessite à ce titre une mise au point.

46 Ibid., p. 153. Bardèche et Brasillach vantent déjà les qualités, certes sans citer Durand, d'Onésime horloger, film longuement analysé également par Mitry dans ce texte.

47 Jean Mitry, « les Étapes du cinéma. III. - De 1903 à 1910 », Bulletin de I'I.D.H.E.C., n9, juin 1947, p. 2. 48 lbid. 
$1895 /$ blement à I'univers de la scène, mais dans ses différentes actualisations, où se retrouvent aussi bien le show d'effeuillage - chez American Mutoscope \& Biograph : A Burlesque Queen (1899) ; Burlesque Queen and Country Photographer (1899) ; From Showgirl to Burlesque Queen, 1903 ; A Fire in a Burlesque Theater, 1904 ; Troubles of a Manager of a Burlesque Show, 1904, mais aussi $A$ Queen of the Burlesque (Edison, Ashley Miller, 1910); The Burlesque Queen (Powers Picture, Joseph A. Golden, 1910) - qu'une forme d'humour cocasse mettant en scène des acrobates et des animaux (Burlesque Cake Walk (1897) ; A Burlesque Bullfight (1911) ; Burlesque Cock Fight (1903) ; Burlesque Lions and Their Tamer, Hagenbeck Circus (1903) ; The Clown and His Burlesque Horse (1902), ou encore la parodie des œuvres célèbres (A Burlesque on Carmen, Essanay, Charles Chaplin, 1915).

En France, le terme "burlesque » est resté d'un usage marginal en ce qui concerne le cinéma ${ }^{51}$, jusqu'au début des années vingt, où a émergé un nouveau mode de définition lié

49 Francis Bar, le Genre burlesque en France au XVIle siècle : étude de style, Paris, D'Artrey, 1960 ; John Davies Jump, Burlesque, London, Methuen, 1972 ; Isabelle Landy-Houillon et Maurice Ménard (dir.), Burlesque et formes parodiques dans la littérature et les arts, Seattle / Tübingen, Papers on French Seventeenth Century Literature, 1987 ; Dominique Bertrand (dir.), Poétiques du burlesque, Paris, Honoré Champion, 1998.

50 Victor Clinton-Baddeley, The Burlesque Tradition in the English Theatre after 1660, London, Methuen, 1952. Robert C. Allen, Horrible Prettiness Burlesque and American Culture, Chapel Hill and London, The University of North Carolina Press, 1991.

51 Voir à ce sujet Emmanuel Dreux, op. cit., p. 39 et suivantes. L'auteur montre que si la notion de burlesque est utilisée dans le cinéma français, par exemple dans les catalogues de la Star Film (Phrénologie 
à l'engouement pour le slapstick hollywoodien de Mack Sennett, Hal Roach, Harold Lloyd, Fatty Arbuckle et, surtout, Charlie Chaplin. Se généralisant d'abord par le biais du matériel publicitaire et les bulletins des maisons d'édition, où l'étiquette « burlesque » qualifie avant tout les productions en provenance des États-Unis, la notion a fini par s'imposer au sein du lexique cinématographique français pour désigner une forme de comique qui repose non seulement sur l'exploration des potentialités expressives du mouvement corporel, mais aussi sur l'absurdité poétique ${ }^{52}$ de protagonistes en porte-à-faux avec l'univers social dans lequel ils évoluent. Dans sa définition du burlesque cinématographique, Emmanuel Dreux retrouve ces deux grands axes définitoires. D'un côté, le burlesque correspond à la part du comique détaché des enjeux narratifs et dramatiques, c'est-à-dire le plus éloigné de la comédie : " comique dans lequel, de prime abord, l'effet immédiat l'emporte sur la portée psychologique ou morale de l'œuvre, pour lequel le gag - le développement d'une idée comique prévaut sur l'anecdote et sur la progression dramatique du film. " De l'autre, la notion recouvre cette forme d'expression comique « dont les personnages sont moins le support d'une peinture de caractère, de ses ridicules et de ses travers, que le lieu d'expression d'êtres irréductibles et totalement singuliers ${ }^{53}$. Malgré I'abandon explicite des vertus édifiantes et représentationnelles sur lesquelles a pu s'appuyer la légitimation des formes humoristiques, ainsi que la reconnaissance de son émancipation nécessaire vis-à-vis de la morale et du réalisme au profit de nouveaux effets de déformation et de déréalisation, le burlesque apparaît donc toujours comme un moyen de valoriser le comique par sa possible accession à un statut élevé, qu'il s'agisse de complexité (le degré de " développement d'une idée comique ») ou de radicalité (la singularité extrême de ses héros). Nous allons aborder successivement ces deux aspects.

Un postulat largement partagé consiste à affirmer que les premiers films comiques, c'est-àdire ceux qui nous intéressent ici, en restent à des effets peu développés et que le " gag » véritable ne prend son essor que dans la seconde moitié des années 1910, au sein du cinéma américain ${ }^{54}$. En France, l'analyse du gag a effectivement été établie à partir d'une considé-

burlesque, 1901 - voir d'ailleurs l'emploi du terme dans un texte signé par Méliès en 1912, cité supra), elle demeure d'un usage marginal, sans commune mesure avec la catégorie dominante de « comique » (p. 35). 52 En juillet 1921, dans un article sur « les Genres», Henri Diamant-Berger associe ainsi le comique « burlesque " au " charme poétique » (texte reproduit dans ce volume, p. 265).

53 lbid., p. 17.

54 En voici une formulation très explicite : "Les "films comiques" $d$ 'avant-guerre et ceux de la première époque du "burlesque" utilisaient avant tout des matériaux élémentaires qui visaient des effets comiques immédiats et faisaient appel à la réaction instinctive du spectateur. Pour que l'effet comique se transforme en "gag", il faut faire intervenir un certain degré de préméditation et une organisation précise de la temporalité (ce fut le cas, grosso modo, après 1918-1920, c'est-à-dire pendant les années où furent 
$1895 /$

ration exclusive du comique américain muet. L'étude du corpus keatonien a notamment permis à Jean-Pierre Coursodon d'insister sur les notions de détournement, de changement de direction, et d'imprévu dans la conduite de l'action comique, et à Jean-Patrick Lebel de lancer l'idée d'un « double retournement "55. Mais ne peut-on pas, plus simplement, à l'instar de Noel Carroll56, se rabattre sur les principes les plus essentiels du gag visuel et estimer au fond que le rire procède, dans ce cas spécifique, du « jeu des interprétations variées projetées par une image ou une série d'images "? Carroll signale d'ailleurs - c'est important pour notre propos - que cette forme n'est pas spécifiquement cinématographique et qu'on peut la trouver aussi sur scène ${ }^{57}$ : juxtapositions incongrues, appariement de physiques aux antipodes l'un de l'autre... L'interpénétration soudaine d'éléments contrastés est en effet un principe unificateur qu'on retrouve dans la plupart des théorisations du gag. Celui-ci est toujours défini comme une suite de retournements, surprises, inversions, variations de points de vue, qui peut aller jusqu'à la re-fonctionnalisation d'objets ou de situations, voire la parodie ou l'anachronisme. Dans tous les cas, il naît de la tension provoquée par le croisement de deux univers opposés. En quelque sorte, Carroll revisite ici un principe fondamental du " comique de situation » que Henri Bergson a identifié dans le Rire, à partir d'une prise en considération du vaudeville, à savoir l'interférence des séries ${ }^{58}$. Nombre d'aspects du comique populaire, pour certains abordés dans cette introduction, sont d'ailleurs cernés avec acuité par Bergson dans ce même ouvrage, comme la répétition, la chosification de l'humain, le ridicule du cérémonial social, l'imitation et le travestissement, ou encore la référence au rêve.

De cette " interférence des séries » propre au gag visuel, dont l'inversion n'est finalement qu'une variante, témoignent plusieurs occurrences dans les premières bandes comiques. Sur la base de films de Boireau (notamment), François de la Bretèque montre l'existence de quelques effets de " déplacement systématique de la fonction des objets de son environnement ", d' " association de deux chaînes de causalité " ou encore d' « inversion complète de tous les signes ${ }^{59}$. Les images $d^{\prime}$ Incohérences de Boireau sont bien connues : le héros dort

produits les premiers courts métrages importants de Chaplin, de Keaton, de Lloyd, etc. » Guido Gola, « Le comique cinématographique : aspects d'une problématique ", dans Guido Gola, Aldo Lombezzi, Yves Froment et Wilbur Leguebe, Flashes sur le comique d'images dans le film et dans la B. D., Louvain-LaNeuve, Cabay, 1983, p. 41.

55 Jean-Pierre Coursodon, Buster Keaton, Paris, Atlas / P. Lherminier, 1986 [Seghers, 1973] ; Jean-Patrick Lebel, Buster Keaton, Paris, Éditions Universitaires, 1964.

56 Noel Carroll, « Notes on the Sight Gag », dans Andrew S. Horton (ed.), Comedy/Cinema/Theory, Berkeley/Los Angeles/Oxford, University of California Press, 1991, pp. 25-42.

57 Ibid., p. 26.

58 Henri Bergson, le Rire essai sur la signification du comique, Paris, PUF, 1940 [1899], rééd. Quadrige, pp. 68-77. Dans ces pages, le philosophe associe l'interférence à deux autres principes essentiels : la répétition et l'inversion.

59 François Amy de la Bretèque, « Les burlesques français avant 1914 dans leur rapport au langage ver- 
dans un lit dont le matelas est suspendu entre deux arbres, à la façon d'un hamac ; tire au fusil un poisson qui tombe du ciel ; pêche un lapin ; se fait propulser en l'air par un jet d'eau et retombe chez lui via la cheminée. Depuis l'Arroseur arrosé, les renversements finaux, où les farces se retournent contre leurs auteurs, ou les identités révélées au terme de certaines courses-poursuites, participent à l'évidence de cette même logique. On rencontre parfois des structures plus élaborées, telles que réclamées par les exégètes de Keaton : songeons au double renversement qui clôt le Nègre blanc, déjà évoqué ; ou encore à Comment Fouinard devint champion (Nizza, 1911), dans lequel le héros vole un veston sans se rendre compte de l'énorme « 19 » qui figure dans le dos du vêtement. Poursuivi, il se mêle à une course sportive où le chiffre est alors interprété comme celui de son dossard de compétition (refonctionnalisation d'un objet).

Outre le recours au gag visuel, l'autre argument de légitimation classique du cinéma « burlesque " repose dans l'identification d'une personnalité singulière, dotée d'un style propre. À quelques exceptions près, les historiens s'accordent à reconnaître à Max Linder cette qualité, tout en regrettant que ses moyens d'expression cinématographique soient demeurés rudimentaires au plan cinématographique (sans jamais préciser, d'ailleurs, la nature qu'aurait pu prendre ce travail spécifique) ${ }^{60}$. En effet, la valorisation traditionnelle du personnage burlesque au cinéma s'appuie le plus souvent sur la mise en avant d'un type particulier de figure : celle qui parvient à offrir, ainsi que le formule Gérald Mast, une traduction spécifiquement cinématographique des éléments comiques ${ }^{61}$. Lorsque Francis Lacassin retient, comme personnalités essentielles de la période, Roméo Bosetti et Jean Durand, Louis Feuillade et Max Linder, sans mentionner des vedettes de tout premier plan comme André Deed et Rigadin, c'est évidemment pour mettre l'accent sur les figures auctoriales par excellence que représentent les principaux cinéastes ayant œuvré dans le genre et, en ce qui concerne Max (dont il signale aussitôt le statut particulier), l'élément transitionnel fort avec la production hollywoodienne qui dominera le genre par la suite 62.

Linder est perçu comme celui qui développe le mieux un « comique d'observation »63 moins

bal ", dans Christian Rolot et Francis Ramirez (dir.), le Genre comique, Montpellier, Centre d'Étude du XXe siècle, 1997, pp. 43, 46, 50-51.

60 André Beucler, op. cit., p. 39 ; Gerald Mast, op. cit., p. 36 ; malgré le fait qu'il ne s'agisse que de « premiers croquis d'un cinéma futur ", les films de Max Linder «témoignent d'une indigence dans la mise en scène qui les montre en retard de plusieurs années sur les meilleurs films du moment. Entre 1909 et 1914 on ne constate aucun progrès sensible : les principes, les méthodes restent les mêmes. " (Jean Mitry, Histoire du cinéma - Art et Industrie II. 1915-1925, op. cit., p. 49)

61 " the one who translated comedy into cinematic terms » (Gerald Mast, op. cit., p. IX).

62 Francis Lacassin, Pour une contre-histoire du cinéma, op. cit., p. 76.

63 Charles Ford, Max Linder, Paris, Seghers, coll. Cinéma d'aujourd'hui, 1966, p. 38 ; Francis Lacassin, Pour une contre-histoire du cinéma, op. cit., p. 76 
Si l'agitation est leur seule façon d'exister à l'écran, elle n'est que très rarement le signe d'une instabilité profonde, qu'elle soit malaise existentiel ou obsession incurable. Max, lui, fait partie de notre monde : il offre une résistance physique et corporelle - de gestes - aux situations qu'il doit affronter, alors que les autres s'y jettent littéralement à corps perdu, avec fureur, hystérie ou simple bêtise (Rigadin). 66

Le film comique des débuts est devenu en quelque sorte insupportable par la manière décomplexée dont il met en scène le rapport de l'être humain à son propre corps : l'enveloppe charnelle y apparaît constamment relativisée, désindividualisée, malmenée, diluée dans les autres et le monde, sans que jamais le sujet humain ne paraisse s'en soucier ou souffrir. Le " burlesque ", au contraire, serait l'expression d'un individu marquant son autonomie vis-à-vis de I'univers dans lequel il évolue. Tandis que la plupart des comiques des premiers temps, développant un univers complètement " gratuit » et clos sur lui-même, ne parviendraient jamais, y compris dans leurs productions les plus sauvagement destructrices, à produire une telle mise en cause du monde. C'est justement cette constance du « prétexte " ${ }^{67}$ que Dreux identifie chez Jean Durand :

64 Jean Mitry, Histoire du cinéma - Art et Industrie II. 1915-1925, op. cit., p. 44.

65 Petr Kral, le Burlesque ou Morale de la tarte à la crème, Paris, Stock, 1984, pp. 130 et 156-157.

66 Emmanuel Dreux, op. cit., p. 137.

67 Ibid., pp. 140-141, 143. 
Ces trouvailles, souvent poétiques, n'ont d'autre but que leur démesure ou leur incongruité, données telles quelles sans autre justification que leur propre gratuité. [...] ... le burlesque de Jean Durand est basé sur une logique qui lui est propre, où la situation initiale n'est qu'un prétexte fort vague, très vite oublié, qui n'aura qu'un rapport lointain avec les images folles du film. 68

Cette position sur Durand s'oppose à celle qu'avait développée Jean Mitry, malgré le partage d'une définition humaniste du burlesque. Si I'historien souligne les limites d'une part substantielle du comique français des premiers temps, c'est en raison du caractère trop circonscrit de ses objets de moquerie, à savoir certains rituels sociaux, d'enjeux de bienséance ou de règles de comportement, d'un point de vue intermédiaire de la petite bourgeoisie : "Que cette caste disparaisse et, avec elle, toutes ces valeurs provisoires et le comique qui ne se fonde que sur elles disparaît également. "Seul subsiste pour Mitry, au-delà des époques, un comique basé sur des valeurs plus profondes et universelles. Ainsi Onésime lui paraît-il relever d'un « burlesque » qui « met en cause le monde et sa réalité concrète, en sa logique " chosale » ou événementielle... »69

\section{La consécration de "l'école comique française "}

Dans son article pour le Bulletin de I'I.D.H.E.C., en 1947, Jean Mitry dessine ainsi le portrait d'un cinéma comique français qui précède le burlesque américain sur la ligne de l'évolution du cinéma et son attention se porte donc prioritairement sur les liens de l'un à l'autre, et non sur ce qui singularise le premier. Développant dans ce texte une approche comparable à celle de son article sur Jean Durand, I'historien traite, au sein de cet ensemble, des qualités de chaque personnalité, en s'en tenant à une évaluation esthétique. Ainsi, expédie-t-il en quelques lignes le cas de Prince-Rigadin, " cabotin qui se croyait intelligent ", qu'il achève en ces termes: «Je n'ai jamais rien vu de plus sot »70.

Cette individualisation de l'ensemble "cinéma comique français ", ainsi que la façon de le concevoir comme anticipant sur le burlesque américain, sont peut-être liées aux déclarations de certains protagonistes devant la Commission de Recherche Historique de la Cinémathèque française à laquelle participe régulièrement Jean Mitry. La séance du 8 juillet 1944 fut entièrement dédiée à Jean Durand, ses interprètes et ses films, et celui-ci contribua à ancrer l'idée que cette période du cinéma comique français avait constitué un âge d'or : « si le cinéma

68 Ibid., p. 140.

69 Jean Mitry, Histoire du cinéma - Art et Industrie II. 1915-1925, op. cit., p. 51.

70 Jean Mitry, "les Étapes du cinéma. II. - De 1903 à 1910 », Bulletin de I'I.D.H.E.C., n¹0, janvier 1948, p. 3. Ce texte est la suite du précédent, paru dans le numéro suivant (et dernier) de la revue. Nous laissons délibérément I'erreur dans le titre (II.-, au lieu de III.-). 
français avait continué avec cet esprit de solidarité, il n'aurait pas été à la remorque, après, comme il l'a été " 71 . À la même époque, certains films de Durand commencent à circuler de nouveau, avec d'autres scènes comiques, notamment au sein d'un programme très vraisemblablement imaginé par la Cinémathèque française et destiné aux ciné-clubs, composé ainsi :

La conquête du pôle (Meliès)

La Vie de Jésus (Pathé)

L'Amant de la lune (Zecca)

Les Incendiaires (Pathé)

Dix femmes pour un mari (Pathé)

Le Tout petit Faust (Pappen)

L'assassinat du Duc de Guise (Calmette)

La victime de l'alcohole (Bourgeois)

Onésime horloger (Durant)

Boireau domestique

Little Moritz enlève Rosalie (Bozzetti)

Rigadin (Morica)

Max et le quinquina (Linder) ${ }^{72}$

De la $\mathrm{CRH}$ à ces projections, la Cinémathèque française a donc sans doute joué un rôle déterminant dans le regain d'intérêt suscité par la production comique française après la Seconde Guerre mondiale, en même temps qu'elle a défini un type de discours bien particulier à son sujet, que I'on retrouve chez Mitry et qui correspond à la vision de I'histoire du cinéma qu'avait Langlois : avant tout une histoire des films, basée sur leur évaluation et leur mise en relation par des systèmes de rapprochement plus ou moins inattendus (ce dernier point est moins vrai pour Mitry en cela que le lien Durand / Sennett peut paraître attendu, d'autant qu'il prend la suite de la doxa sur l'influence de Linder sur Chaplin, très présente dans les années vingt et trente). C'est ce principe qui est déjà à l'œuvre dans l'exposition Images du cinéma français, dont il existe un aperçu à travers le livre de Nicole Vedrès, publié en 1945.

71 Jean Durand lors de cette séance, cité par Francis Lacassin, À la recherche de Jean Durand, Paris, AFRHC, 2004, p. 79. Lacassin a beaucoup exploité, dans cet ouvrage, les témoignages devant la CRH mais, curieusement, il ne cite pas le texte de Mitry dans Travelling, dont il est pourtant très proche dans l'esprit.

72 Programme de la Guilde du film de la Chaux-de-fonds, édité 10 mars 1948, pour une séance le vendredi 12 mars. Conservé dans un classeur consacré à l'activité des ciné-clubs en Suisse, non indexé, à la bibliothèque de la Chaux-de-fonds. Nous avons gardé la présentation (ordre, attribution, orthographe, etc.) originale. Merci à Roland Cosandey. 
Celui-ci débute par le comique français des premiers temps, rattaché à des formes populaires (ou plutôt présumées comme telles) de spectacle :

À peine le cinéma était-il né, à peine eut-il saisi ce qu'il y avait de plus imprévu dans le geste de I'homme que s'inaugura la tradition du burlesque français. Éloignée du théâtre, assez proche du music-hall et du cirque, elle voulut un humour d'improvisation plus que d'intrigue, de manières plus que de mœurs. ${ }^{73}$

En regard de cette présentation se trouve une photographie de Max Linder qui, associée à l'expression de "tradition du burlesque français ", participe de la réaffirmation de l'existence passée d'une école comique française, au sein de laquelle les différences entre un comique inspiré du « music-hall et du cirque » et celui d'un Linder se trouvent effacées. Pour autant, cet ensemble homogène n'est pas perçu par Nicole Vedrès comme une entité a-historique. Au contraire, son évolution progressive vers une comédie plus proche du théâtre et plus respectueuse du réalisme est clairement énoncée, mais en donnant toujours l'impression de deux tendances qui se succèdent, plus qu'elles ne s'entremêlent :

(...) le public réclamait qu'on humanisât le personnage du héros comique ; il voulait de l'anecdote, du réalisme dans la parodie. On connaît ce qui suivit : le cinéma tentant de s'approprier les thèmes du théâtre léger, du vaudeville sentimental ou militaire. (...) Et si, peu après la disparition d'Onésyme (sic) et de Prince Rigadin, on put voir les comédies de Mack Sennett, si Chaplin concède volontiers ce qu'il doit à Max Linder, nous avons trouvé à notre tour chez les Marx et dans les burlesques américains le geste primitif de notre cinéma. ${ }^{74}$

Comme pour Mitry, ce propos s'inscrit dans un discours de renaissance, typique du cinéma français de l'après-guerre, en ce sens qu'il s'agit de franciser un point d'origine du cinéma pourvu d'une descendance prestigieuse, afin qu'un peu de ce prestige rejaillisse sur un cinéma français qui vit alors une situation difficile. Multiplier les tendances au sein d'un corpus unifié permet, dans cette perspective, de placer des films français en points initiaux de chacune des formes du comique américain (Sennett/Chaplin vs Marx). Les transformations du cinéma français sont donc en quelque sorte une nécessité historiographique, qui vaut moins pour les raisons qui y président, réduites au strict minimum (" le public », le « théâtre léger », etc.),

73 Nicole Vedrès, Images du cinéma français, Paris, Éditions du Chêne, 1945, p. 9. Voir reproductions pp. 99-111.

74 lbid., p. 10. 
que pour les possibilités qu'elles offrent de se raccrocher à des éléments postérieurs du cinéma.

Georges Sadoul, au même moment, n'a encore qu'une vision très partielle et partiale de ces films. Dans un texte pour Style en France, en 1946, il refuse de fétichiser une partie de cette production, sous prétexte qu'on pourrait y déceler les signes avant-coureurs du burlesque, et leur applique plutôt un regard condescendant peu éloigné de celui de Bardèche et Brasillach :

C'est un étrange destin que celui des comiques Pathé. La vulgarité de ces premières bandes dépasse celle des parades de Gaultier Garguille ou de Gros René. Pas mal de coups de pied au cul, et de la merde partout. À côté de ces gauloiseries de mauvais lieu, l'Almanach Vermot pétille d'esprit, les récits des commis-voyageurs sont distingués. Ces fabliaux eurent leur public, et le trouvèrent à la Foire d'où est issue, après tout, la Comédie-Française. ${ }^{75}$

Néanmoins, écrivant dans un volume qui fait suite à la première édition du Festival de Cannes, conçue comme une défense du cinéma français ${ }^{76}$, Sadoul passe outre son peu d'intérêt apparent pour les films (qu'il n'a peut-être pas encore revus en grand nombre) et les gratifie donc d'une valorisation finalement moins esthétique que quantitative : "Grâce aux pitres, aux clowns, aux figurants, aux cascadeurs, aux acrobates, une école comique naît. De 1908 à 1914, elle est la première du monde. Pas un pays qui nous surpasse, qui nous atteigne même ». Ce faisant, il renoue aussi avec les propos contemporains de ces films, qu'ils émanent des commentateurs (on l'a vu) ou des producteurs. N'était-ce pas, à peu de choses près, en termes purement quantitatifs que Léon Gaumont parlait de ces scènes comiques à Louis Feuillade, Iorsqu'il écrivait : " Hier soir j'ai assisté à des projections ciném. $\left(_{\imath}\right)$ toutes sont de P. (,) toutes sont comiques $(;)$ ce genre semble prépondérant chez ceux-ci en ce moment. Voyez donc à ne pas nous laisser enlever notre supériorité de ce côté " ${ }^{77}$ ? L'important résidait alors dans le caractère massif de cette production comique, susceptible d'offrir à un éditeur la domination d'une part importante (pour ne pas dire essentielle) du marché. Il y a par conséquent une cer-

75 Georges Sadoul, "Le cinéma, ce mot français ", Style en France, n4, "Cinéma ", juillet-aoûtseptembre 1946, pp. 9-10.

76 Le gouvernement français a repris ce projet de festival, qui date d'avant-guerre, après avoir renoncé à toute tentative, globale ou non, de nationalisation du cinéma français. II participe donc, avec d'autres éléments (comme la création du CNC), d'une stratégie d'intervention des pouvoirs publics destinée à donner des gages à la part importante des professionnels déçus par l'abandon de l'idée de nationalisation. 77 Lettre de février 1909 (mais s.d.), reproduite dans Alain Carou et Laurent Le Forestier (dir.), Louis Feuillade. Retour aux sources, Paris, AFRHC / Gaumont, 2007, p. 43. Gaumont y évoque bien sûr sa concurrence avec Pathé. 
taine logique à ce que Sadoul se saisisse initialement de cette notion d'« école comique française » sur ce même plan.

Entre ce texte et le suivant que consacre Sadoul à cette production prend donc place la réhabilitation esthétique de ces films par la Cinémathèque française. Symboliquement, c'est dans la revue Ciné-club, liée (comme son nom l'indique) à la Fédération Française des Ciné-Clubs (dont Sadoul est un des dirigeants) et à sa programmation, que I'historien revient sur cette période et achève de donner un sens précis à ce qu'il entend par « école comique française ». En premier lieu, il perçoit cette notion comme une manière d'agréger des films extrêmement divers, réalisés à des périodes différentes : il y aurait tout d'abord la période du comique Lumière, puis celle de "l'école Pathé ", ensuite une transformation progressive, à partir de 1905, d'un côté chez Gaumont et de l'autre chez Pathé, avant l'émergence de Linder. Énoncé en ces termes, ce schéma peut sembler convenu. Mais la nouveauté (qu'on pouvait déjà entr'apercevoir dans le texte de Style en France, mais de manière moins approfondie) tient à la tentative de singularisation de chacun de ces " sous-corpus ", notamment en les reliant aux « séries culturelles » (bien sûr, le terme n'apparaît pas chez Sadoul) d'où ils émergent. Le comique Lumière "puise (...) dans les traditionnelles "entrées" du cirque, les plaisanteries du music-hall et du café-concert... "78. L'école Pathé poursuit, "selon les enseignements de Lumière, le pillage du Pêle-Mêle, de I'almanach Vermot, du répertoire du Concert Pacra, des Folies-Bergère ou du Cirque Médrano... ", tout en s'inscrivant dans la lignée des "Gaultier, Garguille, Tabarin ou Gros-Guillaume [qui] ne reculaient pas devant ces grosses plaisanteries, et Molière lui-même, en pleine possession de son génie, [qui] ne dédaigna pas les clystères des apothicaires... ". Quant à l'évolution du comique chez Pathé, incarnée par exemple par André Deed, elle « se rattache aux spectacles populaires, comme aux plaisanteries traditionnelles dans les écoles, les casernes ou les ateliers ». Ce qui appert, c'est par conséquent la rigueur méthodologique de Sadoul, qui tente de définir précisément le comique du « cinéma français d'avant-guerre ", tant dans le temps (différentes périodes) que dans l'espace (diverses maisons de production) 79 , à la fois sur le plan de ce qui le caractérise intrinsèquement et sur celui de son ancrage culturel. Son « école comique française " se leste donc pour une bonne part de la dimension évaluative qu'elle pouvait avoir chez ses prédécesseurs, au profit d'une

78 Cette citation, ainsi que les suivantes, sont extraites de Georges Sadoul, « les Gags dans le cinéma français d'avant-guerre, sources et prolongements d'un jet d'eau ", Ciné-club, n³ (nouvelle série), marsavril 1950, p. 8. Voir la reproduction de cet article dans ce volume, pp. 266-268.

79 Remarquons que, dans le chapitre de son tome 3 consacré à cette " école comique française ", qui prolonge et développe cet article, Sadoul amplifie cette catégorisation en école, dans le temps et l'espace, par exemple en créant une " école niçoise " liée à la Comica, ainsi que son ancrage culturel (Feuillade se voit rangé du côté de la Commedia dell'arte ; Durand et Bosetti sont rapprochés de « la série en images des Pieds Nickelés »; etc.). 
approche plus « culturelle ». Incontestablement, c'est de ce Sadoul-là que notre numéro peut se rapprocher, tant il apparaît que cette singularisation d'un corpus éminemment diversifié à travers son ancrage culturel demeure un chantier peu exploité depuis les pistes dessinées dans son article.

\section{Vers une nouvelle histoire du cinéma comique français des premiers temps}

\section{Du " grotesque " des scènes " très comiques "}

Ouvrir ce cinéma à une nouvelle histoire, cela revient pour nous à concevoir ce corpus non comme un objet homogène, on l'a vu, mais encore moins comme un objet clos, d'où l'importance de le penser en relation avec la culture qui le précède et l'accompagne. Pour autant, il ne s'agit pas de faire comme si cette approche était résolument nouvelle, d'autant qu'on vient de remarquer que ses prémisses remontent au moins à Sadoul... voire plus loin encore. En 1908, Riciotto Canudo expose en effet les principes essentiels du « Théâtre Cinématographique » qu'il appelle de ses vœux et perçoit comme la résurgence, au cœur de la modernité technologique et scientifique, du grand spectacle collectif antique. Cette perspective explique l'attachement particulier du critique à l'idée d'un public jouissant, dans une immédiateté toute régressive et festive ( .... comme dans toute fête, l'humanité redevient enfant ») de deux types spectaculaires situés aux antipodes l'un de l'autre, mais complémentaires: « le très émouvant et le très comique ". Convoyée par le cinéma, moyen d'expression d'une nouveauté perçue comme absolue, à la fois mécanique et ultra-rapide, l'exacerbation de ces deux modalités expressives augurerait d'une « nouvelle Pantomime, une nouvelle danse de l'expression » à même de refléter les aspirations néo-communautaristes de son époque. Pour Canudo, le très comique - catégorie qu'on trouve effectivement dans les catalogues de la même année 1908, voir l'image reproduite p. 187 - vise à « repose[r] l'esprit, en dépouillant la vie de tout le poids de son manteau de solennité, sur lequel sont imprimées toutes les hiérarchies sociales, et en la montrant vêtue de facilité. »Cette mise en évidence salutaire opérée par les bandes comiques (on peut y rattacher les diverses occurrences «populistes » signalées plus haut) aurait l'avantage de révéler, avec une forme irrésistible d'ironie, les bases irrationnelles de l'existence. Outre la notion de " caricature », qui permet d'appréhender sous l'angle de l'épure et de la stylisation les performances outrées et extravagantes dévoilées par l'objectif cinématographique, c'est la catégorie visuelle du grotesque que Canudo choisir de développer prioritairement dans sa lecture des films comiques: 
La vie y est simplifiée par le grotesque, qui consiste exactement dans la déformation per excessum ou per defectum des formes établies. Le grotesque, compris du moins dans ce sens, détruit l'aspect terrible de l'existence, l'ouvre sur le rire. [...] Les Anciens connurent cette vérité et couronnèrent par le rire, avec la Farce, le spectacle tragique. Les Modernes qui ont perdu le sens de la nécessité découvert par les Anciens, le font aujourd'hui au contraire précéder par le "lever de rideau" mais le besoin reste le même. [...] Eh bien, je ne connais rien de plus superbement grotesque que les spectacles très comiques du Cinématographe. Car là on voit des apparitions extravagantes qu'aucun prestidigitateur ne pourrait jamais créer, et des transformations de mouvements et de figurations, qu'aucun homme ne pourrait réaliser devant les hommes, sans l'aide incroyablement habile de la mécanique et de la chimie. 80

Si Canudo voit le cinéma renouer avec la tradition grotesque la plus ancienne, c'est donc par le biais primordial des procédés techniques qui caractérisent sa production " très comique ". Le critique ne précisant pas la nature des pratiques filmiques auxquels il se réfère, il est difficile de cerner avec exactitude quels sont ces pouvoirs magiques qui s'avèrent susceptibles, à ses yeux, de supplanter les recettes des illusionnistes comme de suppléer aux limites physiques de l'être humain. S'il songe probablement aux divers « trucs » (arrêts de caméra, animation image par image, double exposition, accélérés, ralentis, retour en arrière...) qui abondent effectivement dans les bandes comiques françaises des premiers temps - nous y reviendrons -, Canudo exprime avant tout sa fascination devant la puissance phénoménale de nouveaux modes de représentation qui lui paraissent mieux adaptés que les modestes planches du théâtre aux conditions d'existence issues de la modernité scientifique.

Cette minoration de l'espace théâtral ne doit pourtant pas occulter toute l'importance de la scène dès que I'on se penche sur les rapports entre comique et "grotesque ". À partir du XIXe siècle, tout en conservant par ailleurs sa valeur très péjorative au sein du discours critique, ce terme est couramment employé dans la presse des spectacles pour se référer à un type de performance de cirque et de music-hall, entre clown et danseur bouffon, et dont les attitudes sont empreintes de bizarrerie et d'outrance (à l'instar de l'usage, dans les mêmes milieux, des termes « excentrique " ou « burlesque ») 81 . Ainsi les programmes des salles européennes de la saison 1896-1897 proposent-ils les numéros de Stepp et Frepp, « comique grotesque " (Variété National de Copenhague), Miss Mada, " artiste grotesque excentrique »

80 Ricciotto Canudo, "Trionfo del cinematografo ", Il nuovo giornale, 25 novembre 1908, repris sous le titre «Triomphe du Cinématographe » dans I'Usine aux images, op. cit., pp. 29-30.

81 Hugues Hotier, le Vocabulaire du cirque et du music-hall en France, Douai, 1973, p. 55. Réédition : Paris, Maloine, 1981. 
(Eden-Concert de Hambourg) ; C. Nobel, « original ventriloquiste grotesque et excentrique » (Circus Variété de Rotterdam) ; Heeley et Marba, « acrobates grotesques excentriques » (Théâtre-Variété de Prague) ; Hill and Hull, « grotesque excentrique » (Apollo Théâtre de Koenigsberg), etc. 82

C'est justement sur la base de prestations scéniques que Charles Baudelaire, dans ses célèbres commentaires sur le rire, avait lui aussi recouru à la notion de grotesque ${ }^{83}$. Une pantomime anglaise, vue dans les années 1840 au Théâtre des Variétés, avait effectivement laissé à l'écrivain le souvenir de fantaisies violentes et de farces monstrueuses. Celles-ci lui évoquaient un " vertige de l'hyperbole », une " ivresse de rire, quelque chose de terrible et d'irrésistible » où la monstration désinhibée (un Pierrot à bouche gigantesque, une scène de décapitation brutale) est traversée de moments fantastiques, à l'instar d'un corps étêté continuant malgré tout à se mouvoir84. Dans sa contribution au volume, Patrick Désile aborde précisément le cas emblématique de la pantomine de cirque, afin de mettre en évidence les nombreuses figures qui, à l'instar de cette tête tranchée, y circulent au XIXe siècle avant leur reprise, sous des formes plus ou moins adaptées, au sein du cinéma des premiers temps. Certaines idées énoncées par Baudelaire à propos du spectacle montré aux Variétés sont d'ailleurs proches de celles que défendra, un demi-siècle plus tard, Canudo à propos des comiques cinématographiques, surtout lorsqu'il avoue préférer au comique de mœurs " le rire causé par le grotesque ", d'ordre "primitif », produit « de la vie innocente et de la joie absolue ». Au nom de ce " grotesque comique absolu ", il rejette toute forme de " comique significatif " qui entretiendrait un rapport trop indirect et relatif avec ses spectateurs 85 .

Bien qu'exprimées dans des contextes différents, les opinions de Baudelaire et Canudo pointent une même culture moderne - bien qu'enracinée dans des formes archaïques ou primitives - du comique, fondée sur un rapport joyeux et immédiat à un spectacle où sont mises en causes les règles et les conventions (biologiques autant que sociales et culturelles) qui définissent l'intégrité du corps et l'espace normé dans lequel celui-ci évolue. Ce sont ces mêmes dimensions que Mikhaïl Bakhtine a cherché à mettre en avant dans sa revalorisation du grotesque dans la culture du Moyen Âge tardif, qu'il articule aussi aux productions de la fin du XIXe siècle et du début du XXe siècle. Dans sa réflexion théorique sur cette notion, Bakhtine veut en effet dépasser les approches qui, avant lui, comme chez Heinrich Schnee-

82 Programmes publiés dans l'Art lyrique et le music-hall. Journal hebdomadaire indépendant des artistes Iyriques, acrobates, attractions, variétés, cirques, ballets, 1896-1897.

83 Charles Baudelaire, "De l'essence du rire et généralement du comique dans les arts plastiques » [1855, 1868], in Critique d'art suivi de Critique musicale, Paris, Gallimard, 1976, pp. 185-203.

84 lbid., pp. 198-199.

85 Ibid., pp. 195-196. 
gans (Geschichte der grotesken Satire, 1894), ont certes judicieusement distingué le grotesque du comique bouffon (plus élémentaire, " rire direct, naïf et sans méchanceté ») et du burlesque (plus subtil, « rabaissement des choses élevées »), mais en l'enfermant dans une « exagération dénigrante réalisée dans des buts étroitement satiriques »86. Pour Bakhtine, le grotesque doit être plutôt articulé à une prise en compte de ses sources folkloriques où il possède une dimension $d^{\prime}$ " excès joyeux ", ouverte sur l'extérieur et en constante animation : « ... le corps grotesque est un corps en mouvement. II n'est jamais prêt ni achevé : il est toujours en état de construction, de création et lui-même construit un autre corps ; de plus, ce corps absorbe le monde et est absorbé par ce dernier... " ${ }^{87}$ Au-delà de la période historique qu'il étudie prioritairement, Bakhtine met en rapport le type de comique dont il parle avec la culture spectaculaire de son époque (il est né en 1895) :

Les formes du comique populaire de la place publique constituaient aussi une des sources importantes de l'image grotesque du corps. Nous ne pouvons que passer rapidement en revue un monde aussi vaste et varié que celui-ci. Tous ces bateleurs, trajectaires, theriacteurs, etc. étaient des athlètes, prestidigitateurs, bouffons, montreurs de singe (répliques grotesques de l'homme), vendeurs de panacées universelles. L'univers des formes comiques qu'ils cultivaient était I'univers du corps grotesque nettement affirmé. Aujourd'hui encore, c'est dans les spectacles forains, et à un degré moindre dans le cirque, que le corps grotesque s'est le mieux conservé. 88

Si cette dimension grotesque caractérise le spectacle vivant de la fin du XIXe siècle, elle ne peut dès lors que marquer les nombreuses bandes filmiques centrées sur la reprise d'attractions scéniques, sur le modèle des captations opérées pour le kinétoscope Edison, puis chez Biograph, Skladanowsky, Messter, Lumière ou Pathé89. Les premiers studios français enregistrent en effet nombre de performances d'artistes de la scène, parmi lesquels d'innombrables comiques de cirque et de music-hall.

86 Mikhaïl Bakhtine, op. cit., pp. 302-303.

87 lbid., p. 315. "Le visage grotesque se ramène en fait à une bouche bée, et tout le reste ne sert qu'à encadrer cette bouche, cet abîme corporel béant et engloutissant. " (Ibid.) On pense aussitôt à The Big Swallow (James Williamson, 1901), mais aussi à des occurrences mentionnées dans cette introduction, telles les dévorations finales des corps de Boireau et Onésime, ou des passages des ciné-poèmes d'AlbertBirot.

88 lbid., p. 350.

89 Voir les travaux de Robert C. Allen, Charles Musser, Frank Kessler... Pour un aperçu bibliographique et une étude plus spécifique du cas allemand, lire Laurent Guido, " "Auf die Bühne gezaubert, dass man erstaunt" : Cinéma, danse et music-hall au tournant du20e siècle ", in Seminar Journal of Germanic Studies, University of Toronto Press, volume XLVI, n 3, September 2010, pp. 207-224. 
À cet égard, la recherche en France ne fait que débuter (signalons toutefois les travaux fouillés, pour le sujet spécifique qui nous concerne, de Jacques Richard), nécessitant notamment un dépouillement de la presse des spectacles et la consultation de fonds d'archives spécialisés, afin de saisir la rencontre particulière qui s'est opérée entre le cinématographe et l'univers des scènes dites " populaires " d'où a émergé la plupart des personnalités créatrices du comique français des premiers temps ${ }^{90}$. La trajectoire de Roméo Bosetti91 est très révélatrice. Enfant d'artistes de cirque, I'Italien débute très jeune en France avec un numéro d'oies savantes. Également mime et acrobate, il mène une carrière au niveau international (en 1905, il tourne avec le cirque Barnum dans l'ensemble des États-Unis, en tant que trapéziste, jongleur, funambule). Son corps habitué aux exercices physiques les plus exigeants et les plus subtils, mais aussi à certains numéros types (comme le travesti), lui permet naturellement d'entrer chez Gaumont. De "régisseur général ", c'est-à-dire responsable de la figuration - une activité de liaison avec le monde des comédiens et des artistes de scène -, Bosetti devient metteur en scène en 1907. Cette promotion, qui se traduit par l'engagement spécifique d'un spécialiste du comique, témoigne de la place de choix accordée aux artistes de cirque et de music-hall, ainsi qu'à leurs méthodes et leurs usages. Dans le même ordre d'idées, le « transfert » de Bosetti chez Pathé, afin de prendre la tête d'une nouvelle unité de production, la Comica, signale l'investissement important de l'industrie cinématographique dans les séries comiques. Un article sur ce nouveau " roi des metteurs en scène comiques ", dans le corporatif I'Écho du cinéma (reproduit p. 294), met en valeur cette branche de premier plan pour la grande firme cinématographique :

C'est la série hilarante et célèbre des cascades exécutées avec un brio, une maîtrise que, seule, la troupe d'acrobates qu'a su réunir Roméo Bosetti est capable de réaliser. Cabrioles épiques, courses échevelées, poursuites abracadabrantes se succèdent sans interruption, réglées avec une science qui révèle un maître dans l'art de la mise en scène. Avec Comica, pas de meubles tombant sous la poussée d'un machiniste inhabile et toujours en retard ; pas de murs s'écroulant quelques minutes après le passage des personnages comiques qui, dans un défilé grotesque, se poursuivent sans répit [...] Au contraire, tous les effets comiques sont étudiés et réglés avec soin.

À l'instar de la grande vedette comique de Pathé, André Deed (Boireau), qui a été chanteur et acrobate de café-concert, notamment au Châtelet et aux Folies Bergère, tout en jouant au cinéma dans divers Méliès (la Dislocation extraordinaire, 1901), interviennent en effet chez

90 Sur ce point, lire Emmanuel Dreux, op. cit., pp. 115-116.

91 Sur Roméo Bosetti, lire Francis Lacassin, "Un maître oublié du burlesque : Roméo Bosetti ", Cinémathèque, $n^{\circ} 21$, printemps 2002 , pp. 55-71, et $n^{\circ} 22$, printemps 2003, pp. 26-49. 
Comica des artistes rompus aux excentricités scéniques comme le véhément jongleur et acrobate René Lantini (Bigorno) ou la vedette de music-hall Sarah Duhamel (Rosalie), spécialiste sur les planches du rôle de " commère » et qui partira ensuite chez Éclair pour incarner Pétronille. Dans trois cross-overs (Little Moritz aime Rosalie, Little Moritz demande Rosalie en mariage, Little Moritz enlève Rosalie), elle partage l'affiche avec Maurice Schwartz, qui possède lui-même une formation très polyvalente : jockey, acrobate, mime, danseur, chanteur de music-hall... Chez Gaumont, c'est également dans les troupes de cirque et les artistes itinérants que les cinéastes recrutent leurs interprètes (ainsi Jean Durand qui engage Clément Mégé pour poursuivre la série Calino, entamée par Bosetti ; Lucien Bataille pour Zigoto et Ernest Bourbon pour Onésime...) $)^{92}$. Dans les vingt premières années du cinéma, et plus particulièrement dans le genre comique, une série de "numéros gestuels ", déjà forgés (ou élaborés en parallèle) sur scène, le plus souvent dans les programmes de variétés, se voient donc repris, adaptés, voire amplifiés au cinéma : entrées et routines de clowns, d'acrobates, de funambules, de dompteurs, d'écuyers, de jonglerie, de prestidigitation, etc. En témoignent le numéro du Cochon danseur déjà évoqué ou la coexistence avec les animaux sauvages.

Cette présence animale renvoie autant à la reprise devant la caméra de numéros de bêtes savantes et de dressage, qu'à la prise en compte d'une certaine part de surprise, de risque et d'improvisation, comme en témoignent diverses bandes visiblement centrées autour des " meilleures prises » obtenues lors de péripéties liées à la circulation des animaux (Patouillard et l'ours policier, Lux, 1911 ; Zigoto policier trouve une corde, Gaumont, 1911). Certains films, comme Babylas vient d'hériter d'une panthère (Comica, 1911) et Madame Babylas aime les animaux (id., fig. 8) ou la seconde partie de Little Moritz chasse les grands fauves (Comica, 1912), renvoient à un sous-genre du film de poursuite, où l'on s'attache à la trajectoire d'un animal s'étant échappé et, dans la plupart des cas, retrouvant au final leur cage. Toute une série de bandes Pathé exploitent ce motif : Échappé de sa cage (1906); Pour un oiseau (1908) ; le Serpent boa (1909) ; Ménagerie en liberté (1910)93. Dans d'autres productions, comme Cunégonde membre de la SPA (Lux, 1912, fig. 9) ou Onésime aime les bêtes (Gaumont, 1913), c'est la transformation en zoo de l'espace intime de l'appartement qui est visée. A nouveau, le cinéma intègre là un type précis de numéro scénique, celui de la dompteuse (voir l'article de 1907 reproduit ci-après, fig. 10), dont Berthe Dagmar, actrice fétiche de Durand, était une spécialiste, aussi bien sur scène qu'à l'écran (ainsi dans Onésime gardien du foyer, Gaumont,

92 Jacques Richard a documenté nombre des personnalités ayant œuvré dans le cadre du comique français des premiers temps. J. Richard, " les Acrobates du rire », Archives, n89, septembre 2001.

93 Jacques Polet, « Un bestiaire illustré. Enjeux filmiques et symboliques du système animalier de l'écurie Pathé ", in Michel Marie et Laurent Le Forestier (dir.), La Firme Pathé Frères 1896-1914, AFRHC, Paris, 2004, pp. 43-150. 


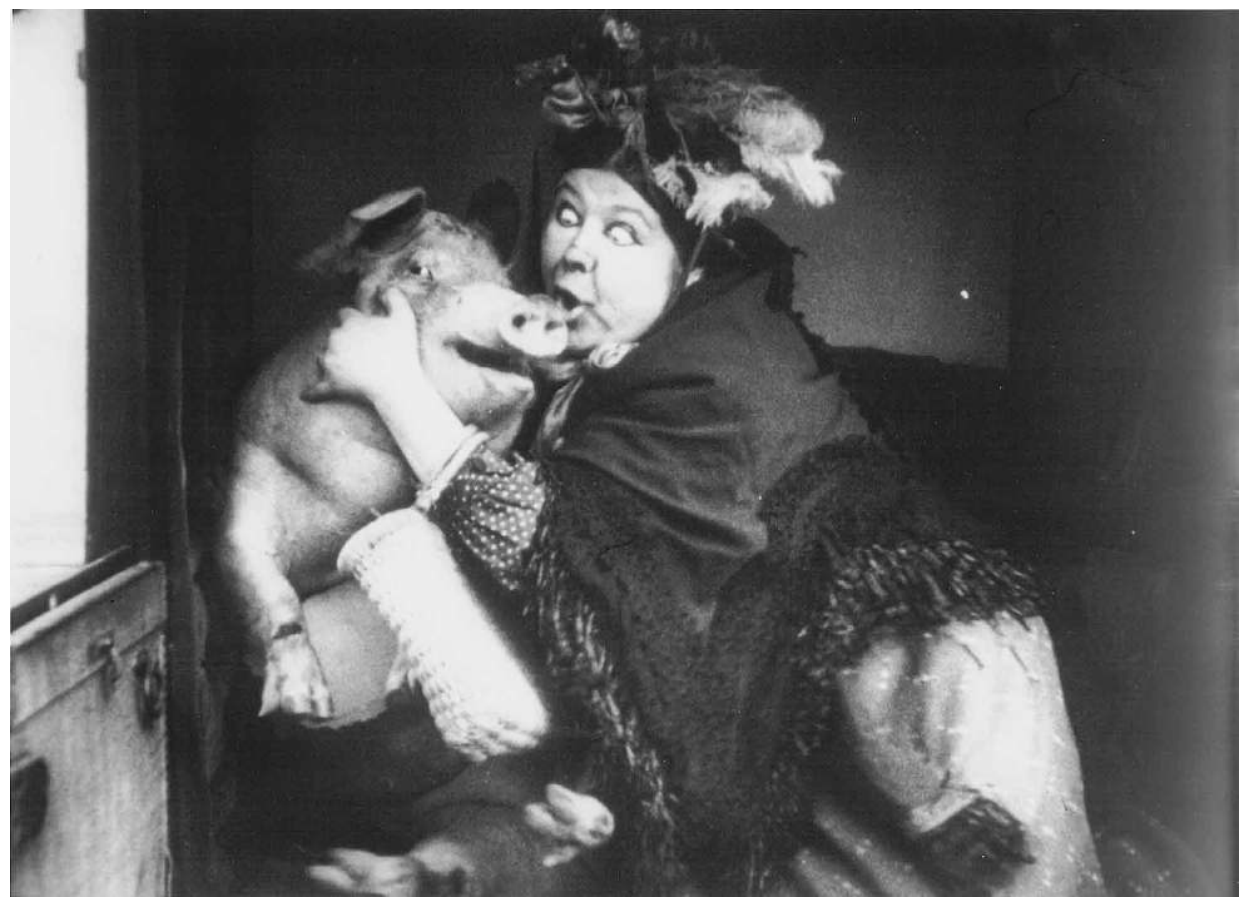

Fig. 8. Madame Babylas aime les animaux, Comica, 1911.

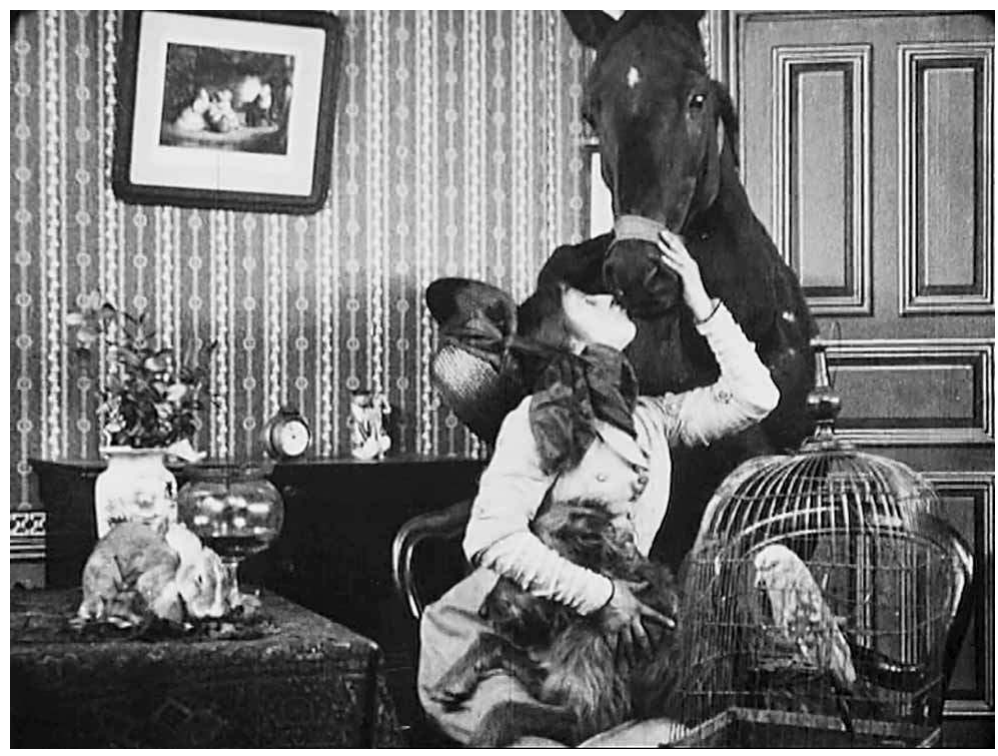

Fig. 9. Cunégonde membre de la SPA, Lux, 1912. 

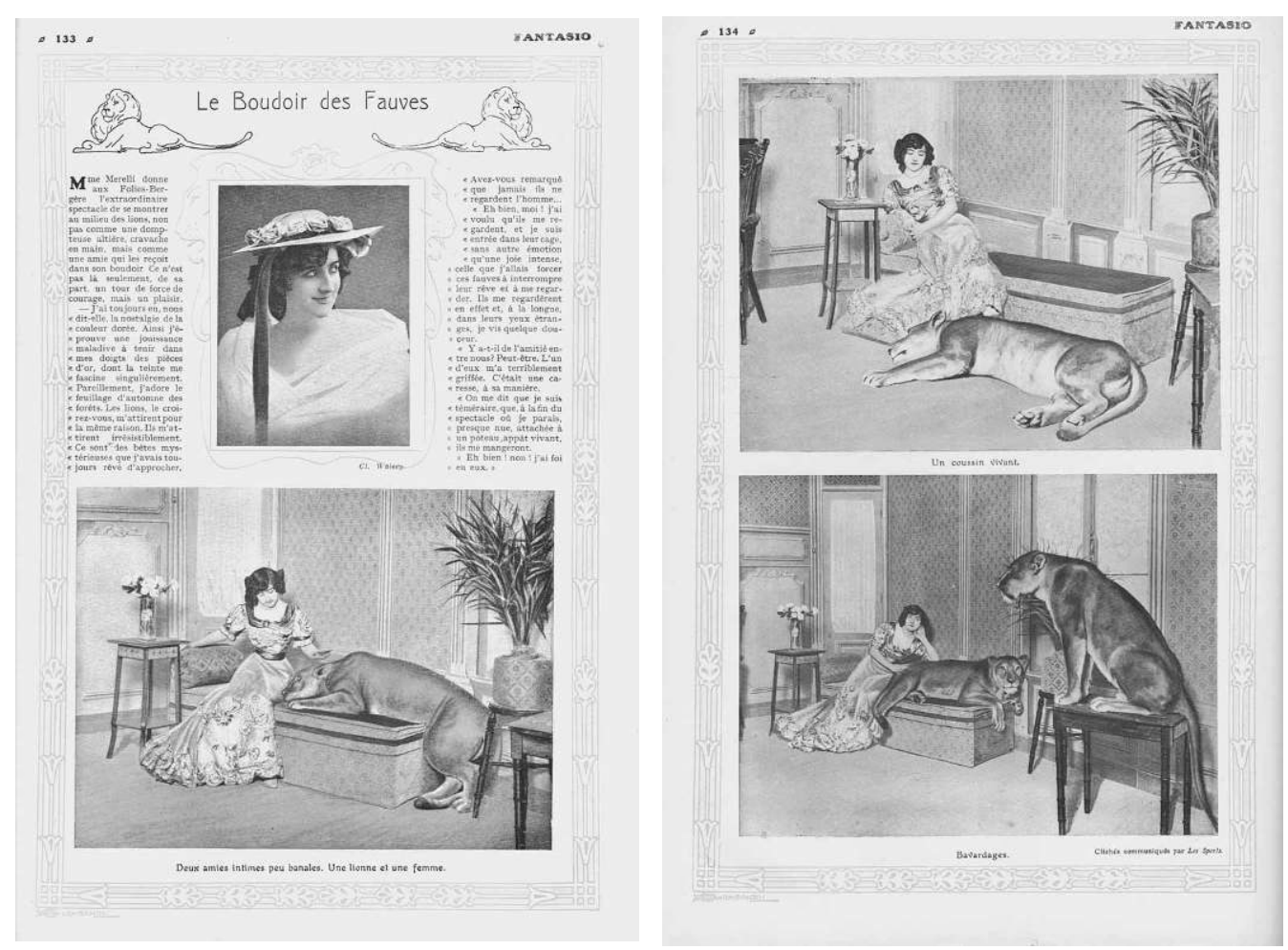

Fig. 10. Fantasio, n²2, 15 juin 1907, pp. 133-134.

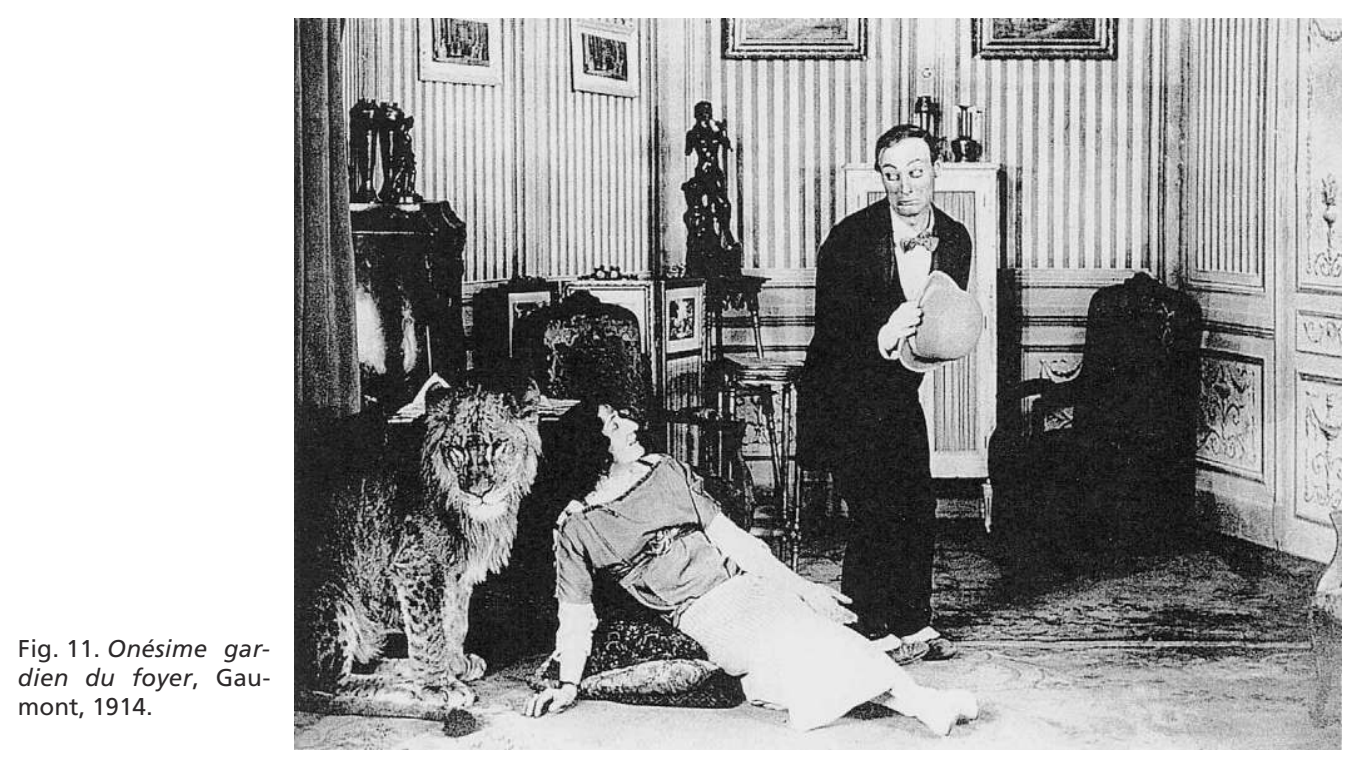

1895 /

$\mathrm{n}^{\circ} 61$

septembre

2010

51

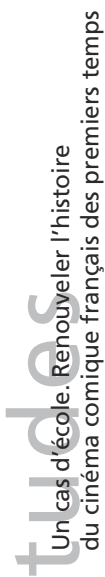

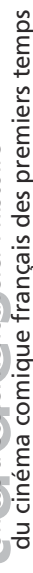


1914, fig. 11). Cette insistance sur la promiscuité avec les bêtes participe, elle aussi, d'une remise en question des frontières entre l'humain et l'animal. Ainsi le protagoniste de Zigoto policier trouve une corde, au terme de son aventure, se met-il soudainement à imiter luimême le taureau qu'il n'a cessé de poursuivre durant le film, se mettant à quatre pattes, se jetant la tête en avant, semant le trouble dans un café. De même, Monsieur papillon prend la mouche (Éclipse, 1913) met en scène un homme s'attachant finalement à un insecte lui ayant - indirectement - ouvert les yeux sur le fourvoiement qu'était l'institution du mariage. Cette relativisation des normes physiques, jusqu'à l'outrance et l'extravagance, est l'une des facettes du comique de type " grotesque ". En témoignent les appariements asymétriques (ainsi le rapport entre un homme fluet et une femme massive, dont le couple Little Moritz

$1895 /$

$n^{\circ} 61$ et Rosalie est l'incarnation emblématique), visages grimaçants, silhouettes nerveuses agitées de convulsions excessives, stéréotypes sociaux plus que caricaturaux, mais aussi corps mécanisés (exemples "stylisés ": les costumes du héros et de sa bonne dans Rigadin peintre cubiste, 1912 ; ou encore une affiche dédiée à André Deed, reproduite p. 244). De ce devenir-objet du corps humain, aspect central du comique au tournant du XXe siècle qu'Henri

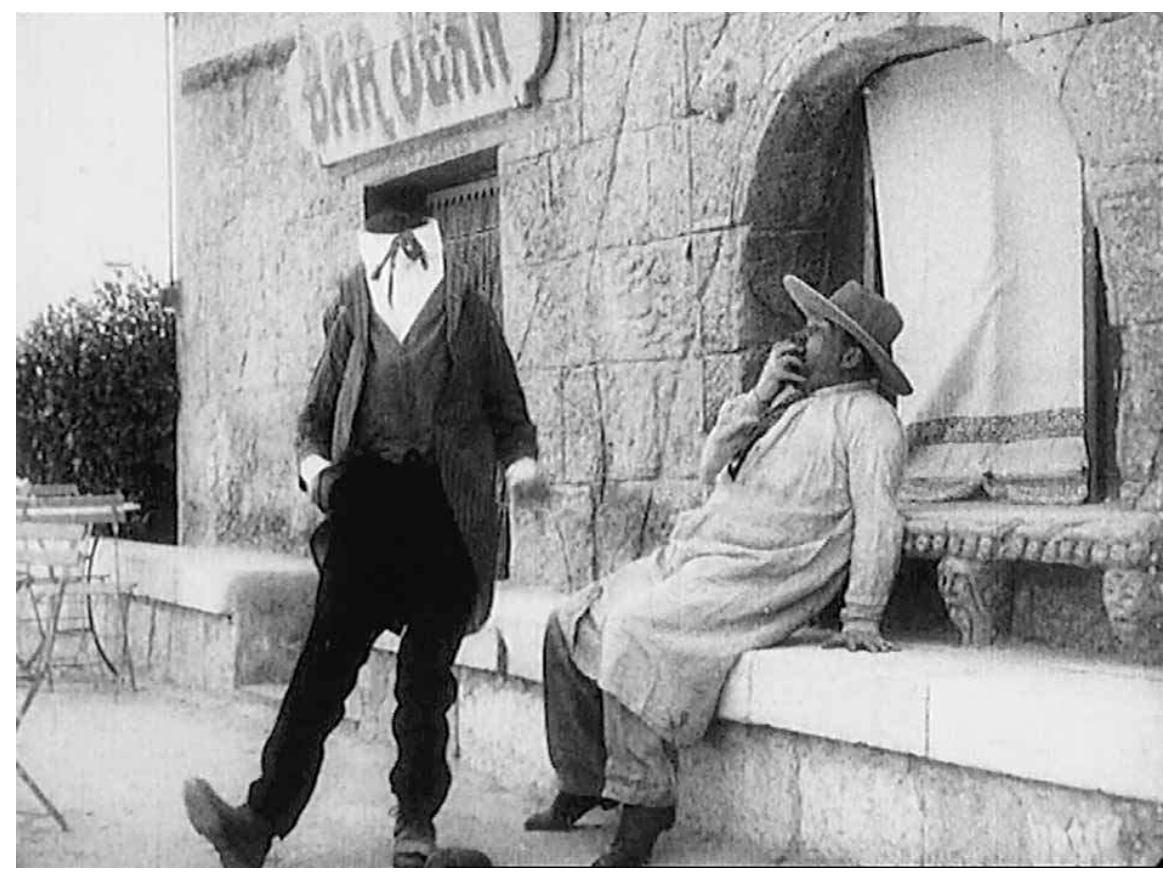

Fig. 12. La Chemise de Polycarpe, Éclipse, 1914. 


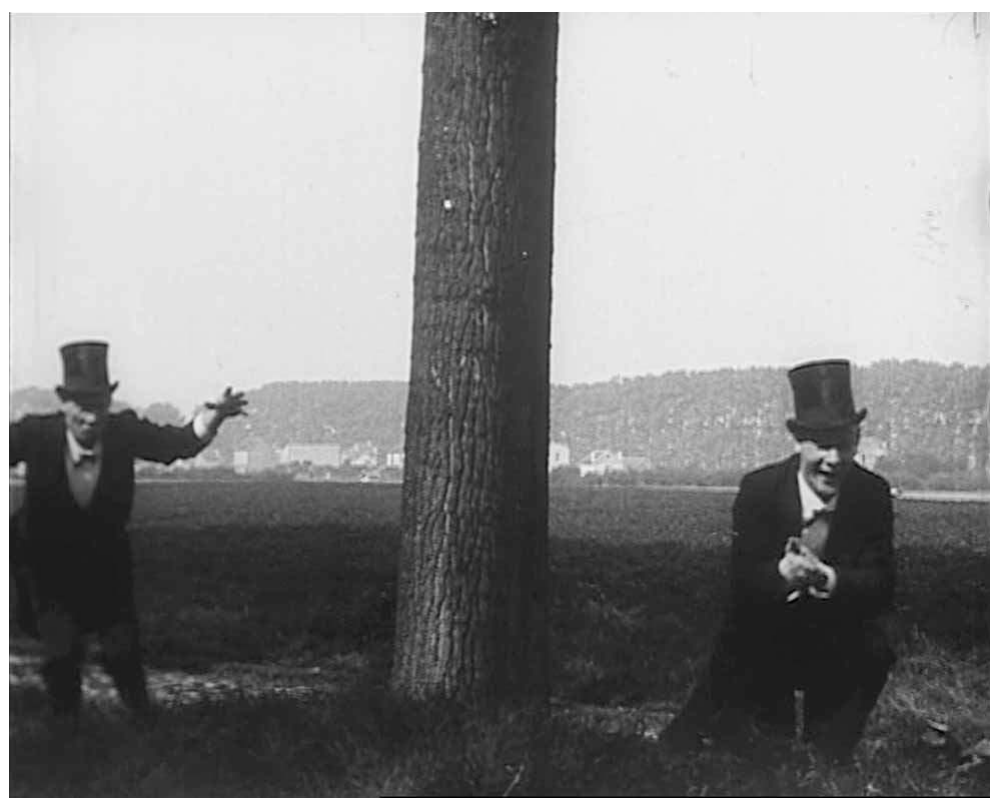

Fig. 13. Onésime contre Onésime, Gaumont, 1912.

Bergson aborde à maintes reprises dans son essai sur le Rire (1899)94, témoigne par exemple Calino arroseur public (Gaumont, 1910), où le héros, victime de cruels garnements, se voit adjoint une sorte de prothèse inamovible sous la forme d'une fontaine public. Transformé en calamité ambulante, cette machine à asperger est finalement retournée pour le bien collectif et installée au centre d'un parc. Ce principe de déshumanisation, dans la Chemise de Polycarpe (Éclipse, 1914, fig. 12), passe par un vêtement si amidonné qu'il donne au héros l'apparence d'une raideur toute mécanique. Lorsque le col remonte et masque le visage, il en devient une sorte d'homme invisible qui suscite l'effroi autour de lui. Dans une précédent scène de la même série, l'Arrosoir de Polycarpe (Éclipse, 1910), il avait déjà été victime de son propre appareil magique, rapetissant au point de se volatiliser complètement, à l'exception de ses vêtements. À la fin de Boireau bonhomme de pain d'épice (Pathé, 1913), le protagoniste central est transformé en biscuit géant que deux enfants achètent et dévorent ; et dans Onésime contre Onésime (Gaumont, 1912, - fig. 13), le Bon Onésime se débarrasse finalement de son encombrant alter ego en le démembrant et le mangeant !

94 Henri Bergson, op. cit., pp. 22, 27, 44, 59. 


\section{L' « inconscient corporel » de la modernité}

Au-delà de l'approche socio-esthétique impliquée par la référence au grotesque, la constance et la virulence de cet imaginaire débridé, où l'humain se voit sans cesse projeté au-delà de ses limites morales comme physiques, entraîne fatalement une lecture d'ordre psychanalytique. Noël Burch a notamment insisté sur la nécessité d'aborder systématiquement « l'extraordinaire symbolique qui affleure avec tant d'insolence dans les féeries et les films à trucs, et dans les étranges burlesques d'avant 1906, qui si souvent nous semblent plus angoissants que drôles ". Il préconise plus particulièrement de "répertorier les thèmes érotiques, scatologiques qui traversent presque tous les films, implicitement ou explicitement, analyser les structures régressives et hystéro-agressives qui les constituent, définir l'infantilisme au sens clinique qui les imprègne. Sans doute comprendrait-on alors à quel point le spectateur comme-il-faut pouvait se sentir incommodé devant cet étalage de tout ce que refoulait en ce début du siècle la bienséance bourgeoise. " ${ }^{95}$

Les films comiques des premiers temps semblent en effet mettre en jeu les différentes facettes du domaine de l'inconscient que Burch cite en vrac (perversions, régression, hystérie, infantilisme, refoulement...). C'est une recherche de cet ordre qu'a menée Rae Beth Gordon, dont la démarche historienne s'avère particulièrement précieuse pour le propos de ce volume. L'analyse des productions culturelles dites « populaires » (pas seulement le cinéma, mais aussi le théâtre et le music-hall) est, chez elle, constamment confrontée aux idées énoncées simultanément dans les champs de la médecine et de la psycho-physiologie. Nombre de procédés et de situations du comique se voient dès lors inscrits dans divers codes expressifs, le plus souvent gestuels - épileptique, mécanique mimétique, etc. - qui renvoient à la " dégérérescence " et aux " facultés inférieures », envisagées autour de 1900 comme "l'expression de I'inconscient corporel ».

Dans les scènes comiques, la visualisation de toute la " machinerie interne " se rapportant à cet inconscient corporel se traduit plus spécifiquement par la constitution d'un univers spatio-temporel qui semble accuser sans cesse son absence de matérialité. Ainsi la violence estelle omniprésente, mais les corps semblent évoluer dans un monde merveilleux où les blessures demeurent sans réel impact. Lorsqu'ils ne choisissent pas eux-mêmes les modes les plus dangereux d'auto-propulsion (caisson d'explosifs dans Boireau roi de la boxe, Pathé, 1912 ; jet d'eau dans Incohérences de Boireau, Pathé, 1913), les personnages projetés en I'air, balancés dans des soupirails ou des puits, défenestrés, roués de coups, transpercés, se relèvent, comme I'homme écrasé par une voiture dans The Motorist (R. W. Paul, 1906) et poursuivent normalement leur activité (Cottage hanté, Bigorno couvreur). André Deed semble 95 Noël Burch, op. cit., p. 64. 
s'être fait le spécialiste de ces tourments " pour rire ». Dans Boireau spadassin, le héros écrase la tête d'un policier avec son épée et le fait rapetisser ; transperce un homme corpulent, provoquant un jet d'eau perdue par I'homme qui maigrit spectaculairement (fig. 14). Boireau, roi de la boxe (voir couverture) frappe si fort qu'un homme voit son nez grossir et un autre sa tête devenir démesurée. Dans Une extraordinaire aventure de Boireau (Pathé, 1914), il se retrouve collé dos à dos avec un autre homme, relation siamoise qui finit par une opération chirurgicale de fortune... à l'aide d'une scie ! L'un des films les plus célèbres tournés en Italie par le même André Deed (Cretinetti e le donne, 1910, où le personnage, démembré par un groupe de femmes, se recompose tout seul, par le procédé de I'animation image par image), trouve l'un de ses héritiers

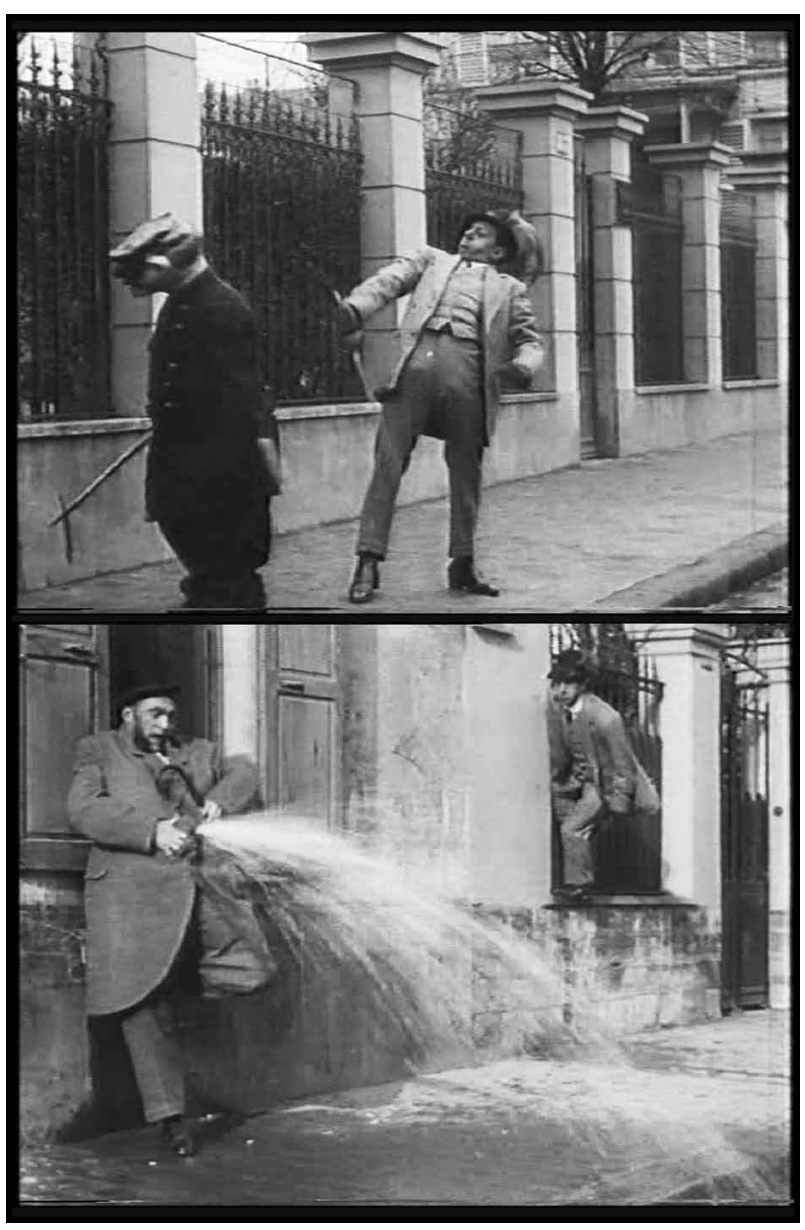

Fig. 14. Boireau spadassin, Pathé, 1913.
$1895 /$ $n^{\circ} 61$ septembre 2010

55

en France avec le Quadruple assassinat de John (Monofilms, 1914). Un homme y cherche à se débarrasser de sa femme, mais elle se relève lorsqu'il la lance par la fenêtre ; revient littéralement en arrière quand il la pousse dans l'eau ; et lorsqu'il se résout à la faire exploser, elle retombe en plusieurs fragments qui se recomposent en animation image par image.

Quelques scènes, situées dans le prolongement de Méliès (Hydrothérapie fantastique, 1909), pointent un référent décisif pour les conceptions relativistes et objectivantes du corps : I'expérimentation scientifique sur l'être humain. Outre la fameuse dissection exhibitionniste d'Onésime et l'étudiante (Gaumont, 1912), Rosalie n'a pas le choléra (Comica, 1911, fig. 15) dépeint les affres de son héroïne aux prises avec d'un service de désinfection des plus cocasses 

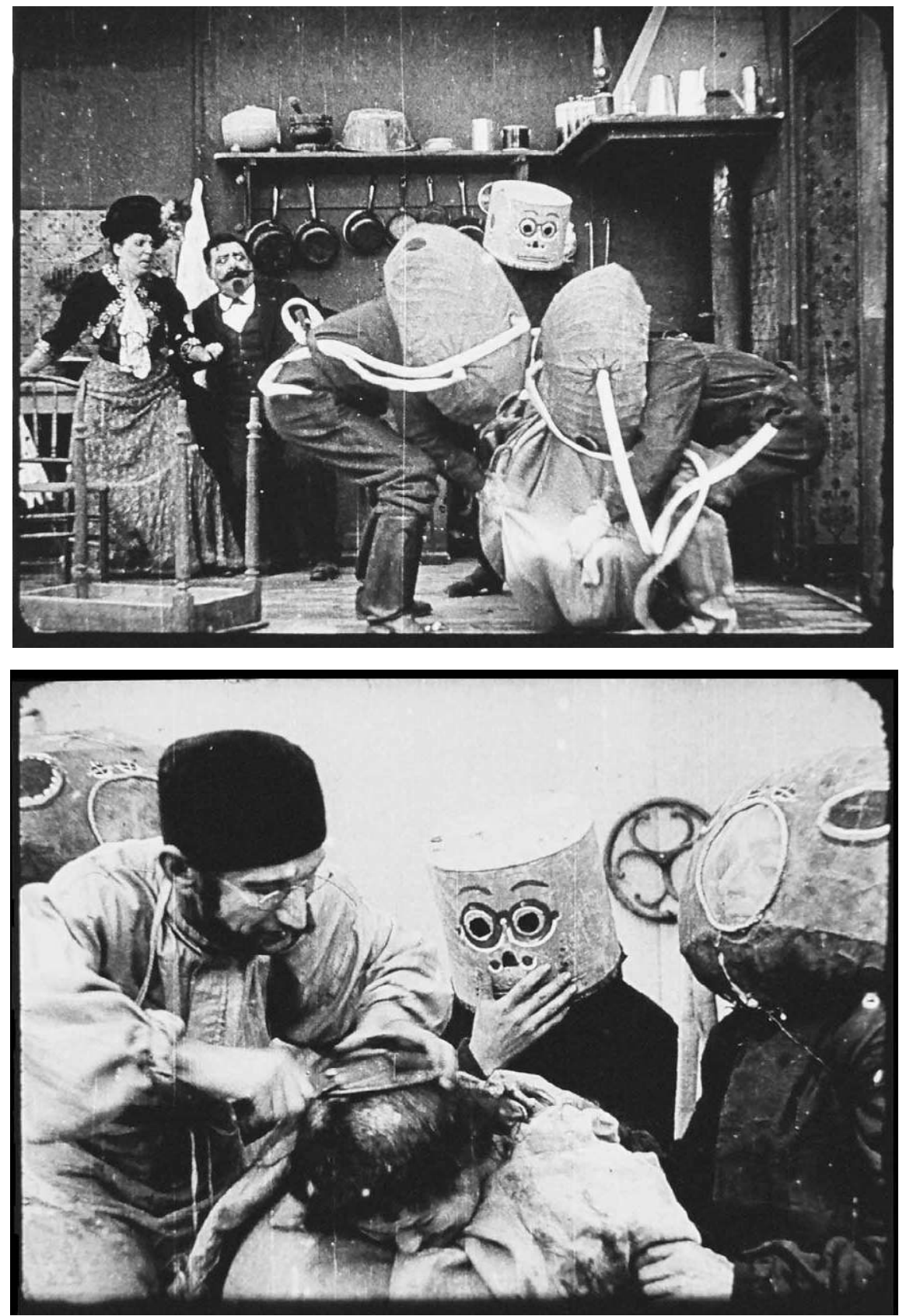

Fig. 15a et fig. 15b. Rosalie n'a pas le choléra, Comica, 1911. 
(masques et combinaisons ridicules, instruments gigantesques), mais dont les méthodes se résument à une série de tortures physiques, où on enferme la victime dans un sac, lui coupe les cheveux, la plonge dans une bassine, la recouvre de produit, puis I'asperge copieusement. Ce cauchemar d'un corps maîtrisé par un dispositif mécanique se retrouve dans des bandes comiques françaises qui exploitent au cinéma le motif de la maison mécanisée, qui sera aussi traité par Buster Keaton ou Charley Bowers. Si I'on assiste, dans Cottage hanté, au long martyr d'un cambrioleur pris au piège d'une demeure remplie de mécanismes de protection (fig. 16), voici le résumé qui nous est parvenu d'un Comica de 1912, la Maison électrique (le terme est largement répandu à l'époque, d'un ouvrage de vulgarisation sur les bienfaits de l'électricité, en 190096, au Catalogue de l'inventeur Gëorgia Knap, en 191497) :

Tartempion, ami du progrès, veut louer une maison électrique. Il visite un pavillon pourvu de tous les bienfaits de la science

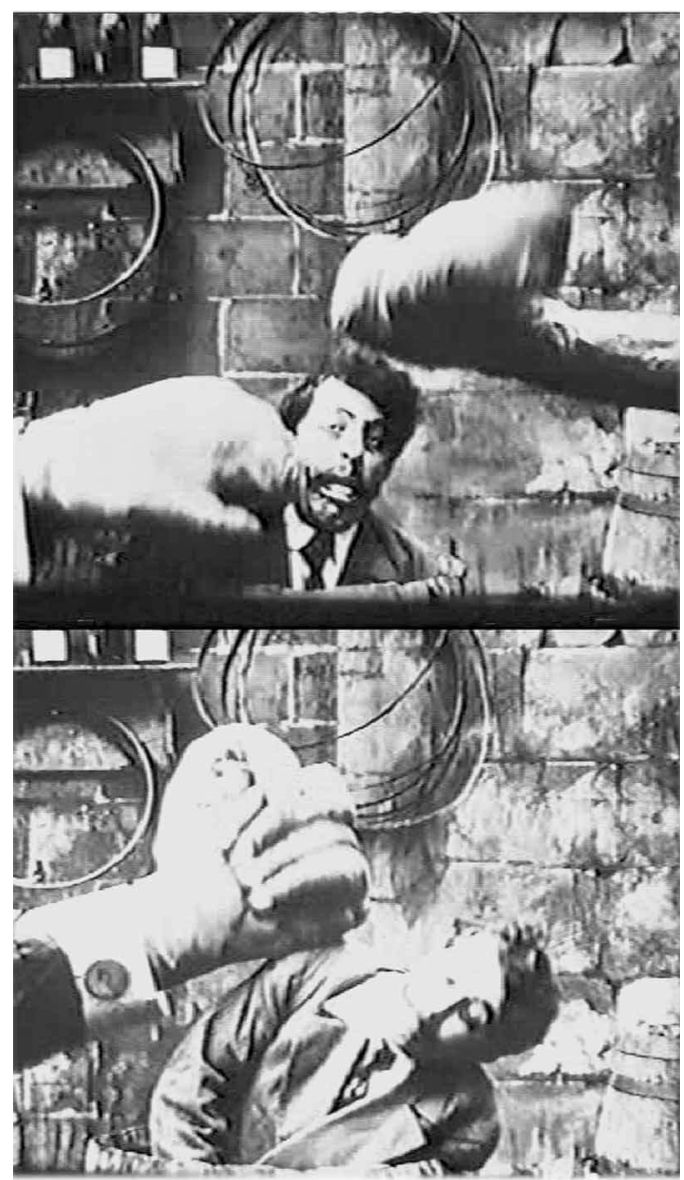

Fig. 16. Cottage hanté, Nizza, 1913.

moderne. Malheureusement, notre champion du progrès ignore comment il doit se servir des mille et un fils qui meuvent cette maison enchantée. Il reste devant un festin décevant, dont les mets se dérobent au fur et à mesure qu'il veut les saisir. Perdu dans un véritable labyrinthe, il est finalement, après maintes aventures, saisi, roulé comme un paquet et doucement déposé sur la chaussée, guéri à tout jamais de son goût pour le confort à outrance. »98

96 C. J. et L. Montillot, la Maison électrique, Grelot, 1900.

97 Gëorgia Knap, la Maison électrique. Applications entièrement nouvelles de l'électricité à l'Aménagement et au Service intérieur des habitations, Paris, 14, boulevard des Italiens et 2, rue le Peletier, Catalogue, 1914.

98 [Lucien] V[erhylle], « les Éditions Pathé frères. Comica. 9, avenue Notre-Dame, Nice », l'Écho du cinéma, $n^{\circ} 12,5$ juillet 1912, p. 2. Repris en annexe, p. 294. 
$1895 /$

$n^{\circ} 61$

septembre

2010

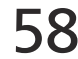

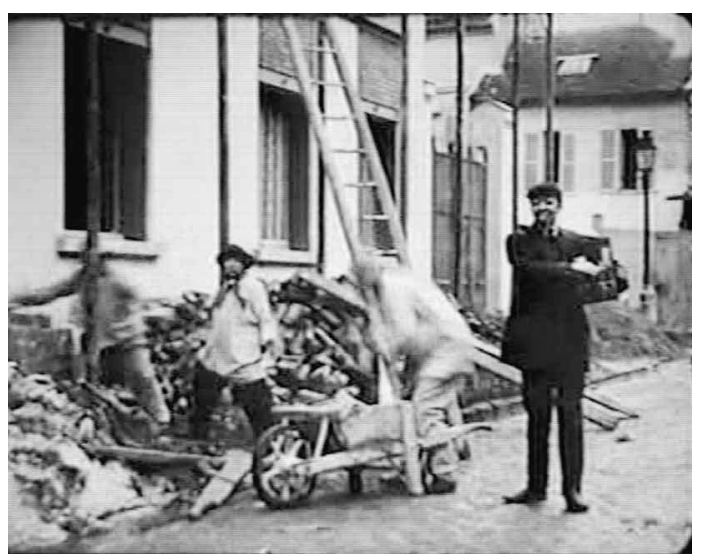

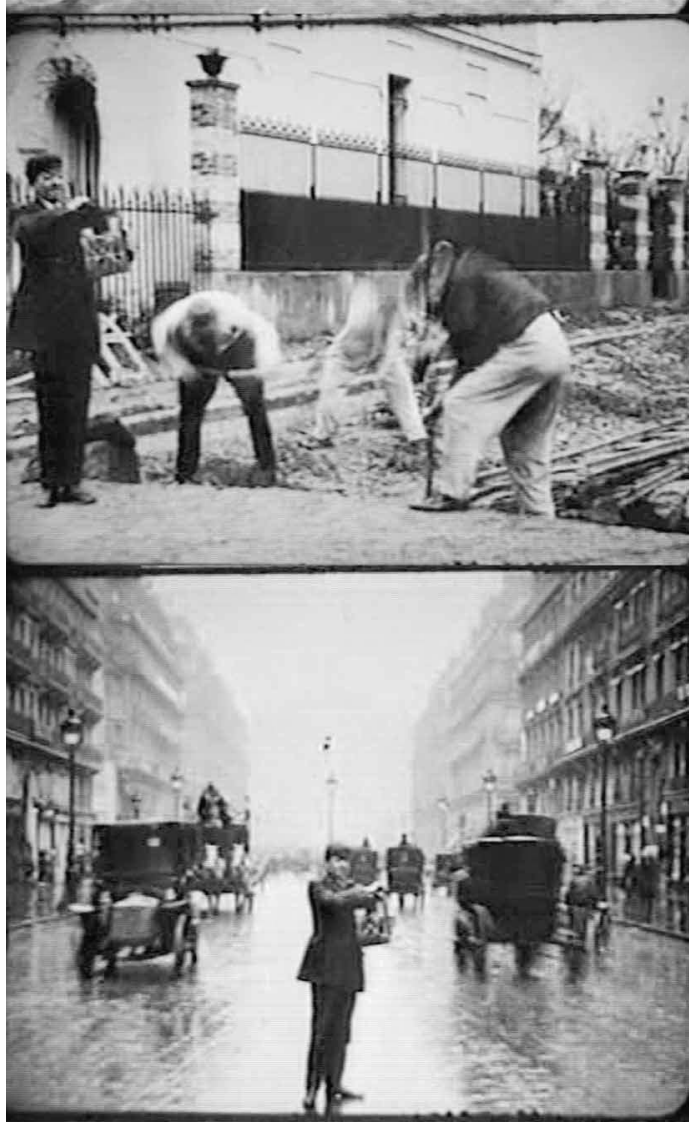

Fig. 17. [La Machine à accélérer le temps], film non identifié.
L'expérience de la modernité - plus précisément, l'emprise de plus en plus importante des techniques scientifiques sur la vie quotidienne - est donc souvent appréhendée, dans les bandes comiques, à partir de la nouvelle maîtrise rationalisée du corps sous l'action des mécanismes industriels. En effet, cette « machination du monde ", pour reprendre l'une des idéesforces de François Albera dans sa contribution au volume, possède avec le cinéma un instrument emblématique, qui renvoie directement à la manipulation rythmicomécanique des mouvements dans l'espace-temps. Situés au croisement de la culture de masse émergente et de certaines traditions populaires centrées sur la matérialité du corps, les films comiques des premières années du XXe siècle ne pouvaient donc que se faire, à des degrés divers, l'écho des tensions complexes suscitées par cette nouvelle perception machinique du monde. Ainsi le héros farceur de [La Machine à accélérer le temps], dans l'un de ses méfaits, se fait-il comme l'agent du taylorisme lorsqu'il s'en prend à un groupe d'ouvriers paresseux et se réjouit, à l'aide de sa boîte à manivelle ressemblant à un appareil cinématographique, de les faire désormais travailler à un tempo rapide, nettement plus productif (fig. 17). Toutefois, le fait que l'utilisateur de cet instrument magique soit in fine lui-même victime d'un enfant signale, une forme ironique de circularité, de 
retour du geste comique sur ses bases régressives et purement ludiques, une fois encore malaisément réductibles à toute lecture socio-politique ${ }^{99}$.

À cet égard, l'origine du rapport à la fois brutal et joyeusement irrespectueux vis-à-vis du corps qui se joue dans la plupart des bandes comiques, se trouve certainement en partie dans les attractions horrifiques qui ont marqué les scènes européennes depuis la période de la Terreur (sur le mode de la pantomime sanglante évoquée par Baudelaire, voir supra), ainsi que les tréteaux forains. Une bande comique, Zigoto à la fête (Gaumont, 1912) pointe justement cet univers, la visite d'une fête foraine par le héros se résumant à une suite de divertissements brutaux. Si ceux-ci suscitent dans un premier temps la jouissance transgressive du héros (un jeu de massacre, puis une galerie de figures de cires lui donne le prétexte de lancer un projectile au visage d'un policier et de tourner en ridicule un soldat), ils débouchent sur un combat inégal contre un Hercule, dont il sort débraillé et couvert de blessures. Cette représentation de la fête foraine nous rappelle aussi combien ce type de divertissement a pu compter pour l'ensemble de la population française. Les parcs d'attraction constituent indéniablement un "premier " lieu, avant les scènes comiques, où s'entrecroisent amusement et mise à l'épreuve du corps. Pour ne prendre qu'un exemple, au printemps 1911, est érigé vers le Pont de l'Alma, à Paris, un " park grandiose " " où se mêlent dans un désordre savant, les attractions les plus merveilleuses. Ici, c'est un " Scenic Railway ", un Tobbogan et un "Water-Chute " de proportions énormes et comme on n'en construisit jamais jusqu'ici »100. Parmi ces attractions, le motif de la chute, qui est au même moment une figure centrale des scènes comiques, prend donc une place majeure. Simple coïncidence ou au contraire représentation dans les films d'une forme de divertissement populaire, dont le cinéma permettrait peut-être de ressentir partiellement les effets, tout les insérant dans un récit (donc deux formes conjuguées de plaisir) ? Seules des études approfondies pourront y répondre. Ajoutons que la présentation de ce « park » par la presse insiste aussi sur le public auquel il s'adresse, moins populaire que l'on pourrait le croire : « Ce que l'on peut dire, c'est qu'elle formera une ville complète des plaisir et des divertissements, et que ce sera pour nos vraies Parisiennes une passion ". II n'y a bien sûr guère de raison pour que cette mixité sociale implicite ne s'applique pas également aux films qui mettent en scène ces attractions (chutes, etc.), et en particulier les scènes comiques.

99 De même, dans Onésime Horloger, l'accélération frénétique que le héros fait subir au monde n'a, pour seul objectif, que l'obtention finale d'un héritage ! Cette circularité se traduit également par la fréquence des allusions réflexives. De nombreuses bandes sont dédiées à la relation des héros de série avec le médium cinématographique : les Débuts de Max au cinématographe ; Cretinetti al cinematografo (1911) ; Bébé fait du cinéma (Gaumont, 1911) ; Rigadin veut faire du cinéma (Pathé, 1913) ; Léonce cinématographiste (Gaumont, 1913).

100 Ces citations, ainsi que celle qui suit, sont tirées de l'Excelsior, 19 mars 1911. 


\section{Le champ des attractions gestuelles : ouvertures intermédiales}

On comprend ainsi que l'un des enjeux centraux nous paraît être, aujourd'hui, d'interroger la place du cinéma comique au sein du régime des " attractions » qui a précédé, puis accompagné l'instauration graduelle des modes de représentations institutionnels centrés autour de la clôture narrative. Ce régime s'incarne également dans le jeu d'acteur, par l'interpellation fréquente du spectateur via le regard à la caméra. Cette théâtralité du geste a fait l'objet d'un rejet unanime au sein de l'histoire traditionnelle du cinéma, plus particulièrement vis-à-vis du cinéma comique français. Jean Mitry en a offert une stigmatisation emblématique à propos de Rigadin, qui lui semble « un acteur qui se sait comique ou qui, du moins, croit l'être au prix de moultes [sic] contorsions et clins d'œil à la cantonade. À chaque ins-

$1895 /$ tant, il semble dire "Voyez comme je suis drôle, n'est-il pas cocasse d'être dans ma situation ?" [...] Tout le contraire donc du "vrai comique" qui n'est drôle qu'à son insu "101. Cette condamnation est souvent reconduite, de nos jours, à l'instar d'Emmanuel Dreux qui estime, dans son ouvrage récent et très informé sur le " burlesque ", que Boireau " reste souvent démonstratif dans ses trouvailles [...] s'adressant à la caméra pour soutenir chacun des effets de sa bizarrerie, soulignant l'incongruité de ses gestes, ce qui ne profite guère à son personnage qui paraît toujours vouloir épater le spectateur, comme s'il le poussait du coude pour être plus sûr de son effet. „102 La présence de tels procédés est indéniable dans la plupart des films que nous avons pu visionner (gestes explicatifs, complicité des farceurs avec le public avant de commettre leurs forfaits, commentaires sur tel ou tel élément profilmique, marquage explicitement partagé du plaisir comme de la terreur). Une étude systématique des bandes conservées, qui demeurera d'ailleurs forcément très partielle, permettrait de déterminer d'éventuelles variations selon les interprètes, les studios, les époques. Dans les années qui précèdent la Première Guerre mondiale, cette dimension énonciative - souvent perçue comme archaïque, y compris dans certains discours esthétiques émanant de cette même période " transitionnelle " - paraît d'ailleurs toujours d'actualité. Ainsi, Max Linder lui-même, généralement perçu dans la postérité comme l'un des tenants d'un jeu résolument mesuré et épuré, y souscrit-il explicitement dans Max victime du quinquina, alors même qu'il parodie sans ménagement, dans Max joue le drame (1914), le jeu outrancier des tragédiens de théâtre, simulant une mort interminable avec emphase et force roulements d'yeux (fig. 18). En focalisant sur ce paramètre général, qui renvoie aux modalités expressives canoniques d'une époque, on oublie d'en analyser les fonctions singulières, propres à telle ou telle production (voir l'interprétation spécifique que Rae Beth Gordon donne dans

101 Jean Mitry, Histoire du cinéma - Art et Industrie II. 1915-1925, op. cit., pp. 47-48.

102 Emmanuel Dreux, op. cit., p. 139. 
ce numéro de la conclusion d'Onésime contre Onésime). Surtout, on détourne forcément son regard de principes gestuels plus subtils, que ceux-ci renvoient à des attitudes codifiées dans différents domaines ou à d'éventuelles singularités des comédiens comiques, y compris dans la gestion des apartés, qui peuvent être exécutés en fonction de modes d'appropriation très divers, des vitesses d'exécution à la précision des attitudes et des postures. II y aurait lieu aussi de se demander dans quelle mesure l'usage récurrent de la grimace, parfois en gros plan (qu'il soit final - emblématique -, ou non, comme le gros plan du visage de Onésime attaqué par les escargots dans Onésime dresseur d'hommes et de chevaux, Gaumont, 1913), n'est pas lié à la caricature, et notamment aux grosses têtes, qui exagèrent les traits et la taille du visage. Plus largement, les relations entre scènes

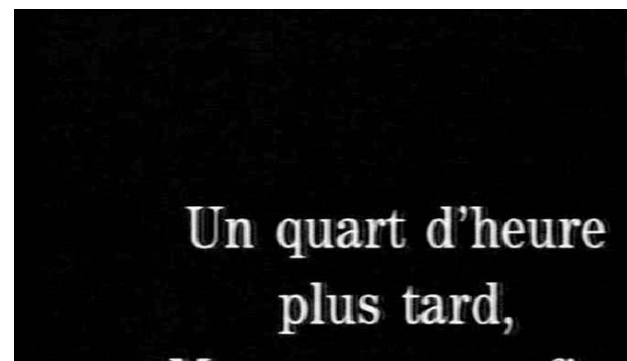
Max meurt... enfin.

comiques et dessins demeurent d'ail-

leurs un territoire grandement sous-exploité. Si les rapports de ces films avec les croquis d'humour ont parfois été soulignés (Lacassin, par exemple, a dressé le premier le lien entre la pratique de dessinateur de Durand et ses bandes, et Thierry Lefebvre l'a également étudié(103), l'influence de la publicité n'a pas encore été étudiée, alors qu'elle constitue un vecteur important du comique, charriant la plupart des thèmes exploités par les films de cette

103 Voir Thierry Lefebvre, " D'Ernest Bourbon à Onésime, naissance d'un personnage comique ", les Cahiers de la cinémathèque, "la Maison Gaumont a cent ans... ", op. cit., ainsi que son mémoire de maîtrise, dont est tiré cet article, Ernest Bourbon et les pouittes. Le personnage d'Onésime, 1912-1919, Université de Paris I, 1987 (sous la direction de Pierre Jenn). 


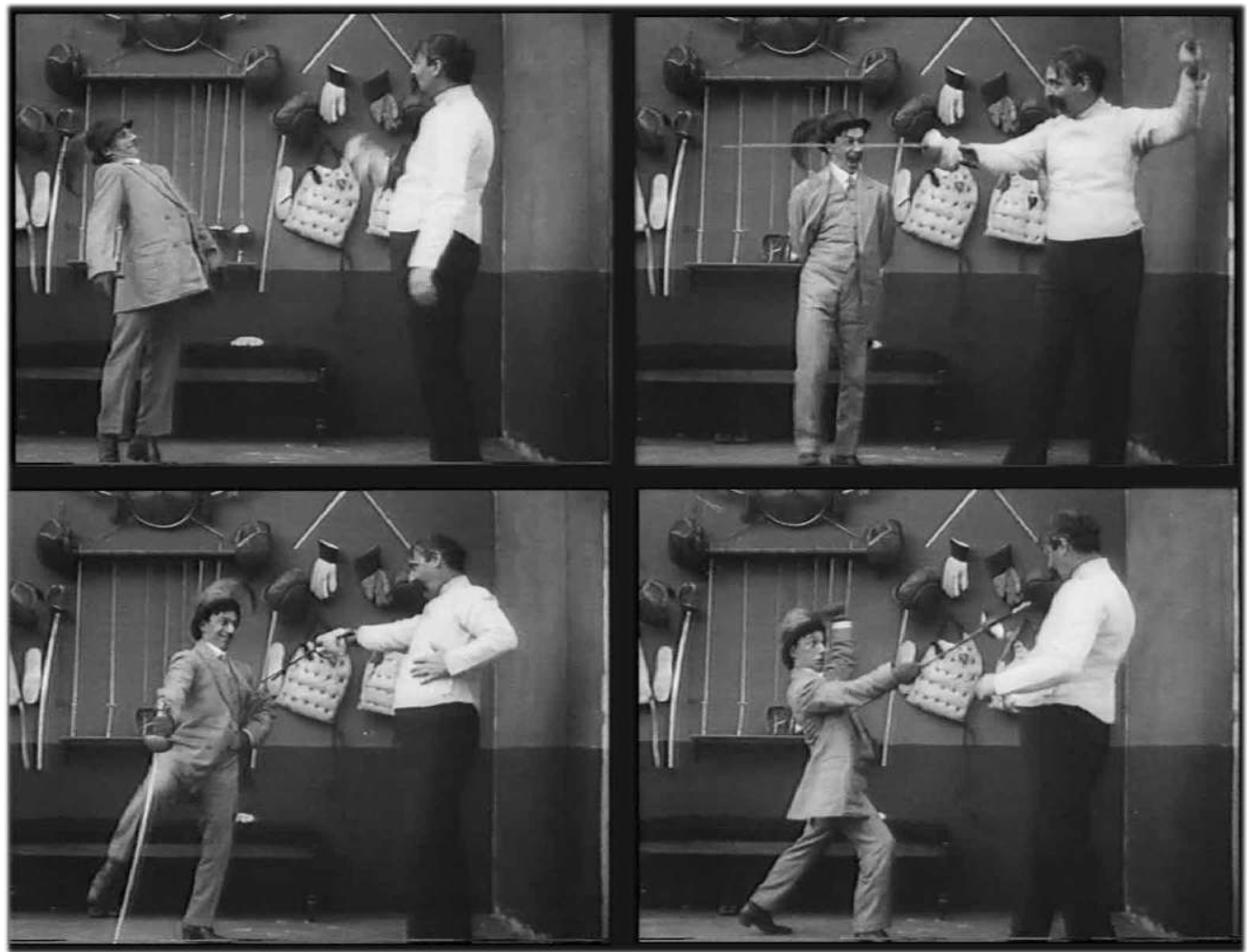

Fig. 19. Boireau spadassin, Pathé, 1913.

époque : par exemple l'alcoolisme (grand motif des scènes comiques), évoqué avec un certain humour noir en présentant un homme en deuil, avec sa couronne mortuaire, devant un comptoir, accompagné du slogan «l'usage du quinquina Dubonnet nous aide à supporter les plus grandes douleurs ", ou par la drôlerie plus involontaire (?) de cette campagne en faveur de la poudre Montavon (nom que l'on croirait inventé pour une fiction parodique) qui « guérit en quelques jours, avec une constance qui tient du prodige, l'ivrognerie » (la production comique regorge de ces élixirs aux vertus prétendument magiques).

La perspective de recherche autour de l'expressivité physique ouvre des voies très stimulantes, qui permettent de battre en brèche les jugements rapides, empreints d'évolutionnisme étroit, sur le jeu de certains protagonistes importants. Au-delà des dialogues fréquents qu'il engage avec le spectateur dans ses films des années 1912-1913, André Deed manifeste par exemple, au cours de cette même période, une inventivité faciale et gestuelle phénoménale (fig. 19). Basée sur la soudaineté des changement de rythme, son expressivité ultra-nerveuse est 
traversée de trajectoires rapides, de torsions et moulinets grotesques, d'étranges suspensions abruptes, le centre de gravité excessivement déplacé vers l'avant ou l'arrière, en interaction constante avec la composition du cadre et la profondeur de champ. En témoigne son entrée spectaculaire au début de Boireau en mission scientifique (Pathé, 1912), course d'une vélocité extrême, soudainement interrompue au profit d'une posture figée au centre de l'image. Cette attitude stricte et raide, torse bombé, seulement animée par un mécanique salut du chapeau, offre un écho inversé à la rangée de scientifiques situés derrière lui et qui s'assoient au même moment comme un seul homme.

Cette dimension chorégraphique du jeu comique prend place dans un univers de référence où, avant de célèbres films américains ( $A$ Night In the Show de Chaplin, 1915 ; Backstage de Fatty Arbuckle, 1919 ; The Playhouse de Buster Keaton, 1921), on convoque I'univers du spectacle, dans ses coulisses comme sur la scène : Calino au théâtre (Gaumont, 1909), Max joue le drame, Rigadin débute au music-hall (Pathé, 1911), Rosalie et Léontine vont au théâtre (Pathé, 1911), Bout-de-Zan vaudevilliste (Gaumont, 1914), sans parler d'innombrables références à la musique et à la danse, les motifs circulant d'un interprète à l'autre : la question de l'attraction irrésistible des sonorités musicales sur le rythme corporel ${ }^{104}$ dans la Flûte merveilleuse (Pathé, 1909), Rigadin avale son ocarina, Onésime et le cœur de tzigane (Gaumont, 1913) ; mais aussi, plus simplement, Max professeur de tango (Pathé, 1913) ; Casimir maître de danse (Éclair, 1914) ou Rigadin professeur de danse (Pathé, 1916)... De même, le sport, proche à la fois de la danse et de l'acrobatie, mais sur un mode plus explicitement moderne car indissociable de la rationalisation physique et de l'émergence des médias, apparaît comme un thème incontournable ${ }^{105}$. Occupant une place centrale, la boxe ${ }^{106}$ suscite différentes modalités d'intégration, dont Frank Kessler, dans son article pour cet ouvrage, montre toute

104 Cette idée de contagion rythmique, via la performance musicale, la danse ou le cinéma, traverse tout le volume. De certaines pantomimes étudiées par Patrick Désile aux chansons sur le cinéma qu'aborde Thomas Louis Jacques Schmitt reviennent les mêmes mécanismes de transe communicative que Rae Beth Gordon associe, pour sa part, aux effets d'un certain mimétisme psycho-physiologique. Voir à ce sujet Laurent Guido, l'Âge du rythme, Lausanne, Payot, 2007, pp. 261-265 (" Mimétisme et attraction du mouvement corporel »).

105 Calino fait du sport (Gaumont, 1909), Gontran fait du sport (Pathé, 1910), Max pratique tous les sports (Pathé, 1913), Willy et les gendarmes font du sport (Éclair, 1913), Little Moritz se fait les muscles (Pathé, 1911), Willy fait de la culture physique (Éclair, 1912), Polycarpe a des biceps (Éclipse, 1913), Zizi veut devenir fort (Lux, 1913).

106 Outre les divers titres cités dans ce volume, on trouve aussi Max champion de boxe (Pathé, 1910), Cunégonde veut boxer (Lux, 1911), Calino s'endurcit la figure (Gaumont, 1912), Match de boxe entre patineurs à roulettes (Pathé, 1912), Onésime champion de boxe (Gaumont, 1913), Willy contre le bombardier Wells (Éclair, 1913), Zizi s'entraine pour la boxe (Lux, 1913), Snob Boxeur (Cosmograph, 1914)... L'Italie n'est pas en reste, comme le montre l'étude de Gianni Haver, "Le Burlesque et la boxe, ou le noble art à l'épreuve du cinéma comique des années 1910 », in Michaël Attali (dir.), Sport et médias, XIXe-XXe siècles, Grenoble, Atlantica (à paraître). 
la diversité possible des usages, à partir d'une série de films comiques pourtant réalisés au cours de la même période.

L'intermédialité entre le cinéma comique et le monde du spectacle se fait plus concrète encore, si l'on prend en compte l'activité de nombreux interprètes, qui poursuivent en parallèle une relation plus ou moins soutenue avec la scène théâtrale. Plus modestement qu'un Rigadin, qui mène de front les deux carrières avec une égale popularité ${ }^{107}$, Max Linder se déplace pour quelques tournées européennes. Il y interprète sur les planches des scènes qui peuvent dans certains cas renvoyer à sa production filmique, comme Max Pédicure ${ }^{108}$. En 1911, il se rend par exemple en Espagne, en compagnie de Stacia Napierkowska (voir l'évocation de cette tournée par Rollini dans Cinémagazine, 8 décembre 1922). Au printemps suivant, il apparaît encore au Wintergarten de Berlin, prestigieux établissement et haut lieu de la rencontre entre music-hall et cinéma, puisqu'il s'agit de la salle où s'étaient déroulées, en 1895, les premières projections du Bioscop des Frères Skladanowsky. Durant certaines de ses prestations, Linder recourt à une forme de spectacle mixte : un film projeté dans la salle de spectacle le montre arriver en avion, image raccordée à l'apparition en chair et en os de l'acteur sur la scène. De ce même croisement effectif entre théâtre et cinéma témoigne également l'activité d'André Deed, à laquelle Jean A. Gili dédie sa contribution au volume. Entre 1909 à 1911, le protagoniste de Boireau et de Cretinetti (Gribouille) développe en effet une formule originale de "Ciné-Théâtre " qu'il emmène lui aussi à travers l'Europe. Quant à la troupe des Pouittes de Jean Durand, elle a notamment produit un spectacle de ce type sur la scène du Gaumont-Palace, lors du Noël 1913. Dans ce sketch, Onésime paraît live dans la salle après qu'un film a décrit une poursuite sur les toits de la grande salle parisienne ${ }^{109}$.

Ces quelques exemples ouvrent encore une voie de recherche qui s'avère particulièrement novatrice, dévoilant des pans de l'histoire du cinéma longtemps sous-estimés ou niés au nom de la spécificité du médium filmique. Elle ne concerne d'ailleurs pas seulement les spectacles exceptionnels mentionnés ci-dessus, mais des pratiques largement répandues au sein de l'exploitation des films, de l'incorporation des bandes cinématographiques dans les salles

107 Jacques Richard, "Prince Rigadin et son monde ", Archives, n92, novembre 2002, pp. 14-16. 108 Selon Charles Ford (op. cit., p. 28), Max Pédicure fut originellement un sketch théâtral créé par Max Linder. Mais si l'on en croit René Jeanne, l'ordre serait inverse : la saynète aurait été tirée du film (Cinéma 1900, op. cit., 1965, p. 150). Cela ne change pas rien au principe d'interférences entre séries culturelles, de "contamination réciproque "- pour reprendre les termes de Thomas Louis Jacques Schmitt dans ce numéro - qui prévaut chez la plupart des comiques français de l'époque, Linder comme les autres.

109 Sur ce spectacle et, plus largement, sur la figure d'Onésime, voir Francis Lacassin, « Cimiez Film ou

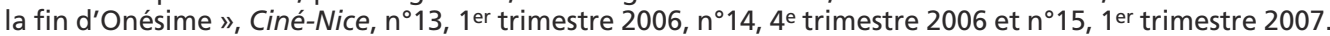


de music-hall jusqu'aux programmes de très nombreuses établissements de premier plan qui associent, à l'instar du Gaumont-Palace au cours des années dix et vingt, attractions scéniques live et films. Au sein de ces dispositifs particuliers, le genre comique prend à l'évidence une place particulière, comme le rappelle Jean-Jacques Meusy dans son texte pour ce volume. Il y montre notamment comment l'essor graduel des séries comiques, à partir de 1908, est étroitement lié à la nécessité de fournir aux exploitants des éléments de programme "doués d'une forte identité ", contrairement à d'autres formes cinématographiques brèves. De son côté, Thomas Louis Jacques Schmitt se penche sur les rapports divers qui se sont noués, à la même époque, entre les domaines de la chanson comique et du film, non seulement pour explorer la manière dont les artistes de la scène se sont approprié l'imaginaire du cinéma, mais surtout pour ouvrir une réflexion sur la circulation entre ces deux formes d'expression qui coexistaient alors dans les programmes des salles de cinéma (les " attractions » interprétées sur scène côtoyant les « phonoscènes " projetés sur l'écran). Tout comme Patrick Désile à propos de la pantomime, Schmitt insiste sur la nécessité de prendre en compte les particularités, par exemple typologiques, qui se manifestent dans ces spectacles que les chercheurs en cinéma ont trop souvent réduit, y compris pour les valoriser, à un même espace uniformément pensé comme " populaire ".

En concentrant le propos sur les relations intermédiales du cinéma comique avec les attractions scéniques, dans lesquelles il tire une part essentielle de ses ressources esthétiques et spectaculaires et avec lesquelles il noue continuellement des liens réciproques, nous n'avons pas encore abordé le problème de la structure même des films. C'est pourtant cette question qui a occupé une part prépondérante au sein de la réception et de l'historiographie du comique cinématographique des premiers temps. La plupart des commentateurs se sont concentrés sur une même exigence vis-à-vis de la production de films comiques, c'est-à-dire le dépassement de la simple juxtaposition d'effets comiques pour viser l'édification de formes cohérentes. Si ce mouvement vers une certaine homogénéité de $I^{\prime}$ " œ œuvre » comique a été le plus souvent avant tout pensé à l'aune de la narrativité, elle a pu également retrouver, dans la réalité des pratiques, des modes de structuration qui nous font, encore une fois, nous tourner vers l'univers de la scène. En dépit de son autonomie, l'attraction de music-hall, de variétés ou de cirque n'est en effet pas forcément pensée comme une production isolée, mais bien comme un numéro dans une chaîne dynamique qui a été envisagée comme une forme d'intégration obéissant à une logique d'agencement en fonction du tempo, des types de sujets, des ambiances qu'ils sont censés convoquer. C'est bien ce qui transparaît du propos de l'un des maîtres d'œuvre de la Comica, déjà cité. Quand Z. Rollini admet avoir "servi deux cents fois le même cliché ", il énonce tout de même une suite d'actions linéarisées en vertu de certains critères : insistance sur le prétexte

$1895 /$

$n^{\circ} 61$ 
initial et la conclusion, alternance entre des mouvements de trajectoires contrastés, eux-mêmes opposés à des moments plus statiques, etc. : « dispute entre époux, vaisselle brisée, chute dans un baquet, tuyau crevé, douche, course sur les toits, passage dans la cheminée, saut par la fenêtre, course précipitée et arrosage final $» 110$.

\section{"Comique "/« comédie ": une relation complexe et dynamique}

L'un des principaux modes d'appréciation du cinéma humoristique, dans l'historiographie française, a justement consisté à évaluer les films à l'aune de ce degré d'intégration d'effets comiques, perçus comme une série de moments autonomes, au sein d'une chaîne causale. C'est bien le point de vue qu'émet Charles Ford sur Max Linder : " Et lorsque, d'aventure,

$1895 /$ une poursuite est mise au point dans un de ses films, c'est toujours "en situation", selon l'expression employée de nos jours, c'est qu'elle est nécessaire à l'action, qu'elle s'y intègre logiquement. " 111 Cette affirmation n'est pas dénuée de fondements. Certes, au cours des années 1910, la poursuite demeure un élément constitutif du film comique. Mais, loin de constituer son ressort principal, elle n'en représente souvent plus qu'un segment spécifique permettant d'exacerber la dynamique centrale de l'action. Même si le moment de poursuite conserve sa force attractionnelle propre, servant par exemple à déplacer dans l'espace public la posture humiliante dans laquelle se retrouve le protagoniste central (Linder contraint de se mouvoir en baignoire, dans Max prend un bain), elle vise, dans les récits introduisant des canevas de conquête romantique, à représenter une confrontation décisive entre le héros et ses principaux opposants. C'est généralement le père qui occupe cette dernière fonction, comme dans les films réunissant Little Moritz et Rosalie (Comica, 1911, fig. 20 - par exemple dans Little Moritz demande la main de Rosalie, via une course débridée en voiture infernale) ou, chez Max, dans Coiffeur par amour (Pathé, 1915) où le héros, après avoir entraîné le géniteur de sa bien-aimée dans différents recoins d'une ville, finit par pousser celui-ci dans l'eau.

Cette emprise progressive des rouages narratifs basés sur la romance hétérosexuelle est clairement perceptible dans la production des studios français des années 1910, où le nombre des « scènes comiques » cède de plus en plus de terrain aux « comédies ». Cette opposition rejoint une problématique récurrente de la réflexion théorique sur le comique cinématographique, où l'on puise à différentes sources pour tenter de légitimer le bien-fondé de cette distinction. Ainsi, Gerald Mast évoque l'Antiquité grecque afin d'établir une ligne de partage, entre,

110 Z. Rollini, op. cit. On retrouve ici la relation dynamique entre mouvement narratif et stase attractionnelle qui a été formulée, à propos du film comique, par Donald Crafton, « Pie and Chase : Gag, Spectacle and Narrative and Slapstick ", dans Kristine Brunovska Karnick et Henry Jenkins, Classical Hollywood Comedy, New York, Routledge, 1995, pp. 106-119.

111 Charles Ford, op. cit., p. 25. 
d'une part, les formules caractéristiques de la comédie ancienne entrecoupée de parades et d'intermèdes plus ou moins autonomes (la parodie d'autres œuvres ; l'épuisement d'une même situation calamiteuse poussée à ses limites ; la comparaison symétrique entre différents milieux sociaux...) et, d'autre part, les schémas narratifs propres à la comédie nouvelle, centrée essentiellement sur les péripéties d'un amour contrarié et une répartition hiérarchique des rôles. Quant à Andrew Horton, il prend appui sur la psychanalyse freudienne pour inscrire la comédie romantique dans le cadre d'un comique œdipien, basé sur « I'adaptation, la compromission, l'intégration sociale ", s'opposant dès lors à un comique pré-œdipien fondé sur « la réalisation des désirs et des rêves ". Cette dimension triviale et régressive du rire serait reliée d'une

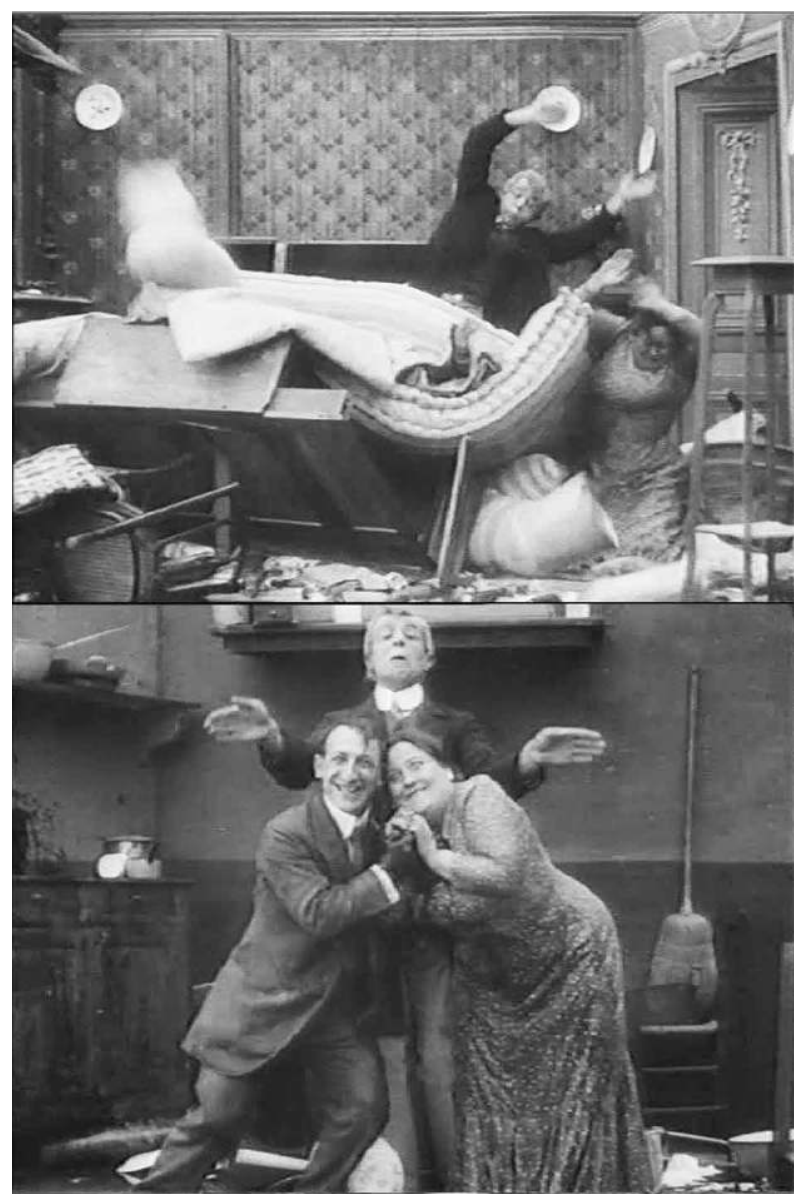

Fig. 20. Little Moritz demande la main de Rosalie, Comica, 1911. manière privilégiée à l'enfance, c'est-à-dire à une période qui précède celle des conflits œdipiens et l'idée de socialisation ${ }^{112}$. La Lune de miel de Zigoto (Gaumont, 1912, fig. 21), expose brutalement la tension qui se joue entre ces deux pôles, en confrontant un couple de jeunes mariés, parfaitement heureux, à trois amis qui s'adonnent sans limite à l'exercice de destruction systématique propre aux séries réalisées par Durand. Le duo romantique persiste dans son étreinte, malgré les débris de meubles qui les recouvrent, les étages qui s'effondrent les uns sur les autres, et les jets d'eaux pointés sur eux par des pompiers tentant d'arrêter un incendie.

112 Andrew S. Horton (dir.), Comedy/Cinema/Theory, Berkeley/Los Angeles/Oxford, University of California Press, 1991, p. 10. 


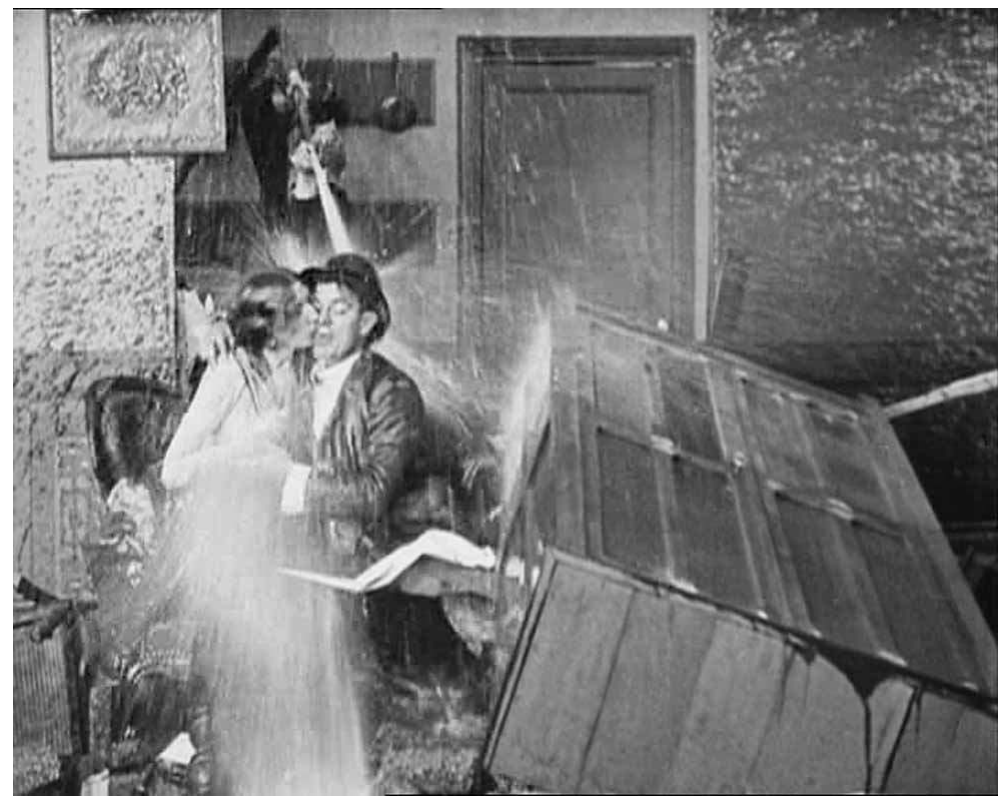

Fig. 21. La Lune de miel de Zigoto, Gaumont, 1912.

Victimes des héros farceurs dans nombre de premières bandes comiques, les amoureux acquièrent donc graduellement le statut de personnages principaux (voir par exemple l'affiche de Mariage au téléphone, 1912, p. 251). Mais l'entreprise de séduction engagée par le protagoniste masculin apparaît moins comme le moteur véritable du récit qu'une simple mise en train. Si le préambule-type chez Max Linder consiste en une séance de séduction dans un parc (qu'on retrouve aussi dans le Cauchemar de Rigadin, Pathé, 1913), les développements ultérieurs de l'action demeurent avant tout ancrés dans l'exploitation de situations comiques. Dans Max collectionneur de chaussures (Pathé, 1912), le repérage et la filature d'une touriste a pour principal aboutissement une farce à rebondissements fondée sur un échange de souliers. Si l'Anglais tel que Max le parle (Pathé, 1914) débute par un charmant flirt lors d'un voyage ferroviaire, les retrouvailles parisiennes du couple se résument en fin de compte à un rinçage en règle de Max, caché dans une douche (fig. 22). Dans Max et le sac (Pathé, 1917), la recherche de l'accessoire d'une jeune femme, pour plaire à celle-ci, sert essentiellement à motiver le surgissement inopiné du héros dans l'espace intime d'autrui (chambre d'hôtel, cabine de plage). Ce basculement dans le trivial, en dépit de prémices romantiques, se retrouve aussi dans la série de films où Max emprunte l'identité d'un corps de métier réclamé par le père de sa proie : le Hasard et I'amour (médecin, Pathé, 1913) ; Max pédicure ; Coiffeur par amour (près de dix scènes de Max 
déclinent ce même titre, en variant les professions). Dans la plupart des films tournés par Deed chez Pathé à la même époque (Boireau magistrat, 1912 ; Boireau et la gigolette, 1912 ; Boireau au harem, 1912 ; Boireau et la demi-mondaine, 1912 ; Boireau fille de ferme, 1912 ; Boireau et la fille du voisin, 1912), la présence de ces ressorts de comédie voisine également avec des paramètres comiques plus immédiatement matériels et physiques, qui le rattachent aux postures grotesques et aux destructions spectaculaires des productions Comica ou des bandes tournées chez Gaumont par Jean Durand ${ }^{113}$.

Dès lors que le personnage devient prééminent, sa récurrence rend possible la définition de caractéristiques psychologiques et sociales et donc le déploiement de moments de comédie. D'où le fait que certaines séries (Bébé, Rigadin, etc.), au-delà de la difficulté à fixer un usage du voca-

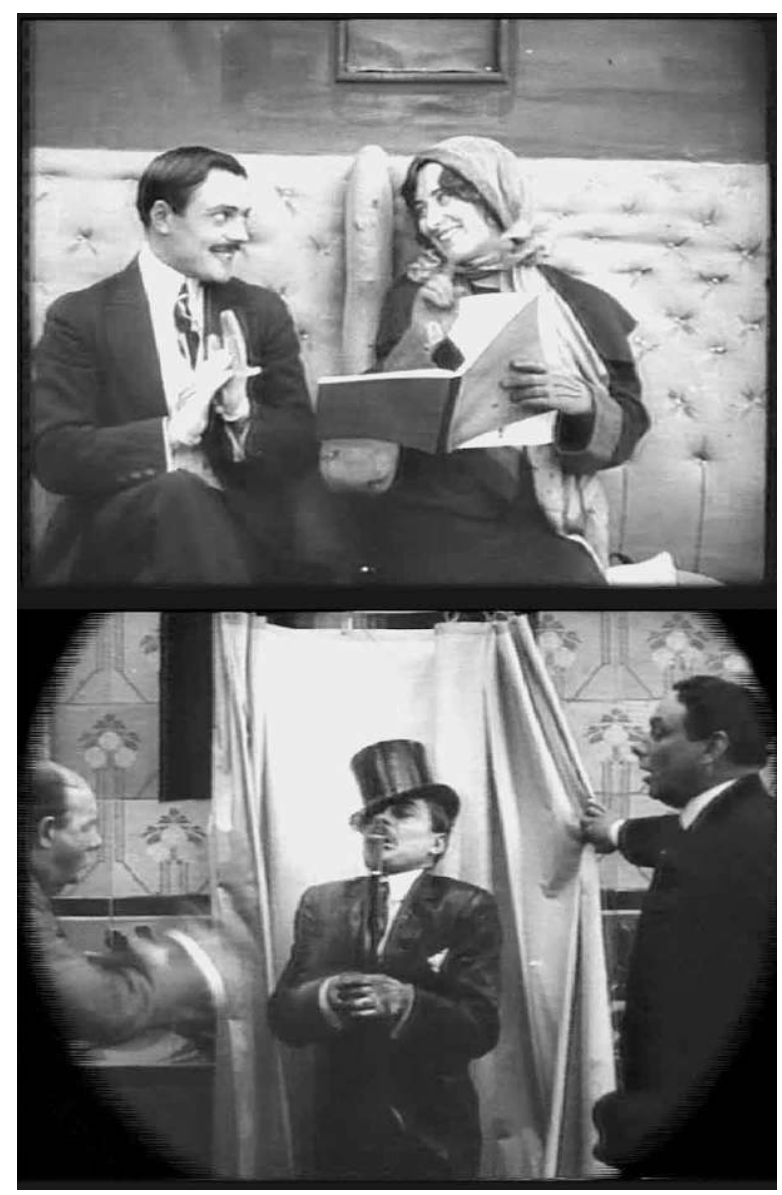

Fig. 22. L'Anglais tel que Max le parle, Pathé, 1914.

ble, puissent être alternativement classées parmi les " scènes comiques " et les " comédies ". Une série comme les Bébé, par exemple, se développe à partir d'une situation de base généralement proche de la comédie et de son jeu autour des savoirs (Bébé cachant quelque chose à ses parents, qu'ils finissent par découvrir, tandis que le spectateur est

113 Le même mouvement de croisement entre comique et comédies se joue, à la même période, dans les ciné-vaudevilles réalisés par Feuillade, c'est-à-dire la série la Vie Drôle, où revient fréquemment Marcel Lévesque. Lacassin y perçoit une articulation entre le comique d'observation sociale, une structuration narrative plus affirmée et une forme d'extravagance rythmique : une « vision caricaturale de la société fondée sur le mouvement, mais aussi l'exagération du détail et le quiproquo. ", ou encore, à propos de l'un de ces films de Feuillade (I'Illustre Mâchefer) : " l'expressionnisme du burlesque mis au service d'une intrigue dramatique élaborée "Francis Lacassin, Pour une contre-histoire du cinéma, op. cit., p. 79. 
$1895 /$

$n^{\circ} 61$

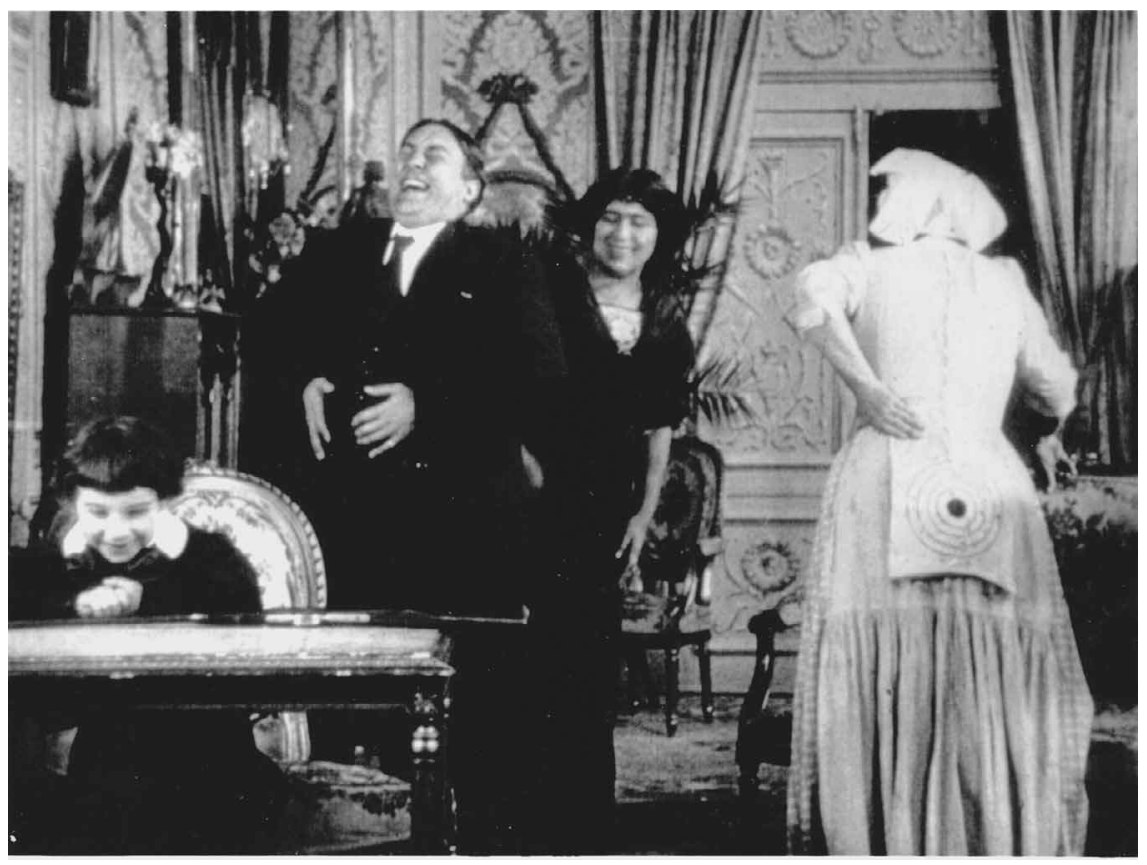

Fig. 23. Bébé tire à la cible, Gaumont, 1910.

volontiers omniscient), tout en s'articulant parfois autour de moments comiques très précis, jouant sur les ressorts classiques du genre (le trivial, par exemple, lorsque Bébé tire à la carabine sur les fesses de sa bonne dans Bébé tire à la cible, Gaumont, 1910, fig. 23). De même, une scène comique comme Little Moritz demande Rosalie en mariage (1911), dont Frank Kessler donne un résumé dans son texte, se déploie à partir d'un argument de comédie, en ce sens que sentiment et psychologie sont les conditions nécessaires au surgissement du comique : le timide Little Moritz veut épouser Rosalie mais le père de celle-ci refuse, à cause du caractère du prétendant. Le film pourrait donc parfaitement, à partir de cette prémisse, imaginer diverses stratégies permettant au héros d'atteindre son but en contrevenant à l'interdiction du père. Le comique provient ici du choix de développement : Little Moritz opte pour la solution la moins vraisemblable, qui serait inacceptable pour la comédie (essayer de changer son caractère, pour s'endurcir en prenant des cours de boxe). Un grand nombre de personnages comiques de cette époque pourrait correspondre à cette tendance à l'ambivalence, parmi lesquels Rigadin, défini à la fois par son ancrage du côté de la comédie théâtrale (en mettant par exemple en avant « les œuvres de Labiche et de Bisson adaptées à l'écran, toujours avec Prince ») et par sa gestuelle comique (" le nez en 
I'air, l'œil écarquillé, la mine ahurie, Prince entre en scène ; on rit. Le comique au geste si drôle, à la physionomie si gaiement expressive conquiert d'emblée le public par son talent si fin et si varié et ses trouvailles d'une fantaisie inénarrable »), soulignée par le dessin des affiches de ses films (voir pp. 242-243). De fait, scènes comiques ou comédies, ces films sont le lieu de croisement entre les genres, les tons, les univers culturels, et le fait qu'on puisse les verser d'un côté plutôt que l'autre (parfois contre la classification choisie à l'époque) tient essentiellement à une sorte de dosage entre vraisemblable et absurde. Des productions comme les Léonce (série réalisée et interprétée par Léonce Perret pour Gaumont) ou le Hasard et l'amour ("Comédie sentimentale de Max Linder jouée par l'auteur », 1916) s'inscrivent par contre nettement plus dans le genre de la comédie romantique que du comique. Dans ces films se fait jour une logique de montage schématique qui épouse la structure d'alternance propre au couple. Ainsi la seconde partie de le Hasard et l'amour est-elle organisée en fonction d'une symétrie entre les actions respectives des deux protagonistes principaux, qui se retrouvent à Monte Carlo pour soigner la même neurasthénie. Au-delà de l'espace spécifique de la comédie sentimentale, cette intégration du comique dans un cadre narratif plus vaste se manifeste également dans le film à épisodes. C'est cette question qu'aborde François Amy de la Bretèque dans son étude sur le rôle attribué aux acteurs comiques chez Louis Feuillade. Son analyse des Vampires, avec Marcel Levesque, ou de Tih-Minh, avec Biscot, démontre que le personnage comique, s'il conserve bien une part de ses particularités énonciatives empreintes de " théâtralité " - ainsi, Levesque ou Bout-de-Zan entretiennent-ils, par le regard caméra, une relation différente, plus immédiate, avec le spectateur - , participent néanmoins, et parfois de manière très productive, à l'économie narrative d'ensemble du serial où ils occupent la fonction de "préposé au rire $"$.

Entre popularité et appropriations d'avant-garde : quel(s) public(s) pour le comique ?

Dans I'historiographie du comique français, cette tendance à la narrativisation n'est pas toujours perçue comme un progrès indiscutable, même chez ceux qui ont fustigé l'ancrage du premier cinéma comique dans la farce grossière et les gesticulations de foire. Dès 1926, André Beucler signale ainsi que le « faux genre comique » n'est pas seulement « celui qui provient de certaines acrobaties ", mais aussi celui qui tire ses effets " de l'imprévu des situations, du caractère des personnages, de l'attente du dénouement ou des simples histoires trépidantes ". Si celles-ci ont effectivement permis au genre comique de se développer, estime Beucler, c'est malheureusement au prix d'une regrettable inféodation aux méthodes et aux pratiques du théâtre : "Par paresse, par faiblesse et peut-être aussi pour faire plaisir à la

1895 / $\mathrm{n}^{\circ} 61$ septembre 2010 
foule on a cru bon d'en rester à la transposition du vaudeville.»114 La référence à ce dernier type de spectacle, ancré dans les comédies à rebondissements grivois et quiproquos, est assez pertinente. Elle concerne une part importante des interprètes comiques dont le jeu relève moins immédiatement de l'acrobatie : Max Linder a passé par l'Ambigu et les Variétés ; avant d'interpréter Cri-Cri, Patouillard ou Gavroche, Paul Bertho a été un acteur de revue ayant joué Labiche, Offenbach ; René Gréhan (Gontran) a été ancien pensionnaire du Gymnase et du Châtelet ; Prince est un habitué de l'Odéon et des Variétés.

À cet égard, Rigadin est sans nul doute la personnalité la moins appréciée dans l'historiographie du cinéma comique ${ }^{115}$ : Francis Lacassin oppose " le médiocre Rigadin " au " merveilleux Max Linder "116 et Jean Mitry juge Prince digne d'être retenu avant tout pour son

$1895 /$ « succès commercial », là où Max Linder l'est pour son « talent » et Onésime pour sa « verve comique $" 117$. Mitry justifie explicitement cette condamnation par l'ancrage de Prince dans le vaudeville (contrairement à un Linder qui n'y serait pas resté longtemps) : " Avec Rigadin, ce n'est ni le cirque, ni le music-hall qui sont en cause, mais le théâtre, la comédie des boulevards. Les situations relèvent souvent des caleçonnades épiques du bon gros vaudeville et le personnage, sorte de jobard ou de cocu magnifique...."118 Contrairement au mépris élitaire d'André Beucler, la référence au cirque et au music-hall est chez Mitry positivée et ce renversement s'étend logiquement à la conception du public : "La bourgeoisie bien pensante les prisait fort [les Rigadin] quand elle n'avait que dédain pour les idioties farfelues de Calino et d'Onésime. "119 Dénuée de toute assise, cette affirmation a au moins l'avantage d'être cohérente avec son propre système de référence, puisque les films de Jean Durand, d'après I'historien, " firent la joie du populaire ", mais demeurèrent « mal compris à une époque où le vaudeville était roi »120. En témoigneraient les productions Gaumont, d'abord Bosetti, puis surtout Durand, pour des "centaines de films qui furent les plus extravagants de leur temps", sous l'inspiration des «traditions du burlesque anglo-saxon » :

Parodies caricaturales et bouffonneries satiriques faites d'une multitude de gags plus ahurissants les uns que les autres, cocktail de courses-poursuites et de farces funambulesques, tenant à la fois du cirque et de la « non sens story », singeant les conventions avec une joie corrosive dans un cli-

114 André Beucler, op. cit., p. 30.

115 Du moins jusqu'à la récente étude fouillée de Jacques Richard, dans Archives, qui a rendu justice au rôle central occupé par Prince dans le panorama du comique français des premiers temps.

116 Francis Lacassin, Pour une contre-histoire du cinéma, op. cit., p. 77.

117 Jean Mitry, Histoire du cinéma - Art et Industrie II. 1915-1925, op. cit., p. 41.

118 Ibid., pp. 47-48.

119 Ibid.

120 lbid., p. 48. 
mat délirant et surréel, ces petits films, mal compris à une époque où le vaudeville était roi, préludèrent aux fantaisies époustouflantes de Mack Sennett et apportèrent, avec un esprit frondeur, une poésie de l'absurde alors pratiquement inconnue au cinéma. Sans doute était-ce moins du comique proprement dit que du burlesque, les motivations mettant en cause la logique et la vraisemblance bien plutôt que les caractères, mais ce sont les seuls films comiques de cette époque qui aient encore aujourd'hui une réelle puissance explosive et qui témoignent d'une authentique poésie. Onésime horloger, Onésime douanier, le Noël d'Onésime, Onésime cœur de Tzigane, Onésime aux enfers, Onésime contre Onésime, Onésime et l'étudiante furent, parmi cent autres (1911-1912), de petits chefs-d'œuvre de drôlerie cocasse et anarchisante l'esprit de destruction, de dégradation s'en donnant à cœur joie à propos de tout et de rien. ${ }^{121}$

Singerie des conventions, exaltation du mouvement débridé, climat fantastique, rejet de l'intrigue schématique, poésie de l'absurde et de la destruction anarchique : cette citation convoque la plupart des traits définitoires du « burlesque ", tel que forgé, on l'a vu plus haut, dès le tournant des années vingt à partir du corpus américain. Celui-ci est d'ailleurs convoqué ici à la fois en amont, par la référence à la scène du music-hall, et en aval, par l'influence sur Sennett. Comme le signale l'allusion au climat " surréel », c'est aussi en liaison avec certaines expérimentations artistiques de l'entre-deux-guerres que s'est opérée, en France, cette redéfinition du « burlesque » qui, comme le spécifie sans détour Jean Mitry, se distingue même du " comique proprement dit » (!). À l'orée de la décennie, Louis Delluc met par exemple en rapport le slapstick avec la mouvance poétique d' « avant-garde », en l'occcurence dadaïste : s'il qualifie sobrement Fatty à la clinique (Good Night Nurse !, Roscoe Arbuckle, 1918) de " dada »122, il précise les motivations l'ayant poussé à attribuer le même qualificatif au Larron, c'est-à-dire sa " consommation d'autos, de motocyclettes, d'ascenseur, d'explosifs »123. Son compte rendu très descriptif de Vague à l'âme indique bien que cette mise en parallèle entre dadaïsme et burlesque cinématographique, ainsi que ce fétichisme des aspects éminemment spectaculaires de la modernité américaine (vitesse, mécanicité, etc.) recouvrent au fond une démarche très littéraire, où le critique s'essaie visiblement à l'écriture poétique :

Film dada. Les cabines de bains volent dans la mer. Les autos bondissent au faîte des sky-scrappers. De jolies baigneuses peu vêtues vont de bras en bras. Un parapluie emporte l'homme léger

121 lbid.

122 Louis Delluc, "Fatty à la clinique », Paris-Midi, 29 juin 1920, reproduit dans Écrits cinématographiques III2, Paris, Cinémathèque française, 1990, p. 186.

123 Louis Delluc, «le Larron ", Paris-Midi, 25 novembre 1920. Ibid., p. 217. 
par à travers le ciel. Des jets d'eau scandaleux giflent l'espace, les nuages et les passants. Police, police, téléphone, auto, canot, tramway. Libertinage aigu, naïveté aiguë, folie aiguë. Dans mon enfance, les jongleurs américains étaient beaucoup plus calmes. Il est vrai que la guerre est venue puis LITTÉRATURE, puis DADA $C^{\circ}$, et les films affolants sont devenus fous pour tout de bon. ${ }^{124}$

$1895 /$

De manière plus générale, les potentialités cinématographiques de recréation fantaisiste de I'univers, accentuée dans les films humoristiques, ont suscité l'intérêt de nombreux artistes de la première moitié du XXe siècle. Dans sa contribution au volume, François Albera rend compte des multiples rapports que les milieux d'« avant-garde » ont pu engager avec le premier cinéma comique, élargissant le propos pour inscrire ces diverses relations - conceptions esthétiques comme expérimentations créatrices - dans un contexte culturel plus vaste, relatif à l'impact social, dès les années 1890, de la modernité scientifique. Au cours de sa réflexion, Albera rappelle notamment toute la stimulation que certains poètes (Apollinaire, Soupault, Cendrars...) ont pu tirer de la fascination exercée par les techniques spécifiques du cinéma, très présentes dans les films comiques. Cette voie a été également empruntée, au sein du même champ poétique d'" avant-garde ", par Pierre Albert-Birot dans ses textes recueillis dans Cinéma. Drames Poèmes dans l'espace (1919) ${ }^{125}$. Dans 2+1=2, Essai de drame cinématographique, son "scénario " poético-filmique emprunte initialement aux conventions du théâtre de boulevard, c'est-à-dire un triangle amoureux entre un mari, sa femme et leur ami. Mais cette trame sert en réalité de prétexte pour le développement d'une suite enlevée de situations qui renvoient immédiatement à la façon dont les scènes comiques des premiers temps ont usé des « trucs » cinématographiques : des meubles et autres objets d'un salon se transforment ou se mettent à se mouvoir tout seuls (comme dans Bigorno fumeur d'Opium) ; les personnages disparaissent ou apparaissent soudainement ; s'envolent, se multiplient sous la forme de doubles; se transforment l'un dans l'autre ; rapetissent ou grandissent l'un par rapport à l'autre (comme sur l'affiche de Little Moritz est trop petit, Pathé, 1910, voir annexe p. 241). Dans ses six Poèmes dans l'espace, Albert-Birot pousse plus loin encore ses rêveries : les formes y sont souvent cycliques, comme dans les cas où le personnage central, c'est-à-dire « l'auteur ", reprend in fine sa position et sa forme initiales après toute une série de transformations tourbillonnantes, et où s'estompent, à l'instar d'innombrables films comiques cités dans cette introduction, les frontières entre l'humain et l'animal, l'objet et le vivant, etc.

On s'en rend compte, l'attrait général exercé par les ressources techniques du cinéma, telles

124 Louis Delluc, "Vague à l'âme ", Paris-Midi, 26 mai 1920. Ibid., p. 181.

125 Pierre Albert-Birot, Cinéma. Drames Poèmes dans I'espace composés en 1919, Paris, Sic, 1920. Textes repris dans Pierre Albert-Birot, Cinémas, Paris, Éditions Jean-Michel Place, 1995. 
qu'exploitées dans les films comiques, renvoie essentiellement à la représentation dématérialisée des corps qu'a rendu possible l'usage des retours en arrière, des doubles expositions, des arrêts de caméra pour transformation, des dédoublements oniriques, des accélérés, des escalades filmées en plongée, des accélérations vertigineuses, des animations image par image d'objets ou d'êtres humain... Grand pourfendeur des premiers comiques, André Beucler ne se doutait-il donc pas, en 1926, que son objet de mépris avait déjà partiellement exploré le recours aux " trucs » que l'écrivain percevait pourtant, au même moment, comme la base possible d'un nouveau « comique purement cinématographique " : " l'on pourrait obtenir un chef d'œuvre en utilisant les procédés les plus parfaits, le ralenti, la surimpression, l'accéléré, la déformation sous toutes ses formes, l'usage du contraste. Il y a dans ce système la source d'un comique à surprises qui demeure inépuisable. »126

Inépuisable, il l'est tout autant, ce comique français des premiers temps et, bien évidemment, il ne saurait donc être question de l'épuiser. Espérons, plus modestement, que ce numéro puisse contribuer à redynamiser un champ de recherches peu exploité ces dernières années dans la communauté francophone. Et ce alors que des points importants demeurent encore méconnus... et le resteront toujours à l'issue de ce volume. Tenons-nous en à deux pistes, essentielles pour l'objet qui nous intéresse, au point qu'elles ont parfois été rapidement évoquées dans ce texte d'ouverture : la consommation de ces films par le public; le rôle joué par les bandes comiques, et plus particulièrement les comédies, dans les tensions très fortes, avant-guerre, entre théâtre et cinéma.

Pour ce qui concerne le public, le texte de Frank Kessler s'achève en soulevant une question que nous aimerions reprendre à notre compte : A-t-il existé une géographie sociale des salles de cinéma, en France et plus spécifiquement à Paris, qui pourrait nous en dire beaucoup, à travers une analyse détaillée des programmes, sur les usages sociaux de ces films comiques ? Cette hypothèse mérite effectivement qu'on lui prête attention. En effet, à une époque (la première moitié des années 1910) où le prix d'entrée le plus modique au Gaumont-Palace se monte à $0 \mathrm{fr} 85$, certains cinémas, situés en périphérie, proposent des tarifs bien inférieurs, pour attirer une autre clientèle. C'est ce qu'affirme du moins un responsable de Pathé lorsqu'on l'interroge sur la concurrence entre théâtre et cinéma :

(...) les théâtres ont leur public et les cinémas le leur. Pour juger de celui qui fréquente les cinémas, il ne faut pas regarder sur les boulevards, où une clientèle élégante achalande les établis-

126 André Beucler, op. cit., pp. 40-41. 
sements cinématographiques, mais dans les quartiers de la périphérie. Là, les places varient entre $0 \mathrm{fr} 15$ et $0 \mathrm{fr}$ 75. Il n'est pas niable que les habitants de Belleville et de Ménilmontant qui se paient régulièrement une séance de cinéma ne descendent pas dans le centre de Paris pour assister à la représentation d'une pièce de théâtre. ${ }^{127}$

Partant de ce constat, un travail sur les programmes permettra donc peut-être d'évaluer dans quelle mesure les éditeurs et les loueurs adaptent la constitution des séances, le choix des films, à la fréquentation des salles. Surtout, on pourra éventuellement parvenir à des conclusions probantes sur les liens entre les personnages représentés à l'écran et le public, ainsi que sur la dimension idéologique de ces films.

$1895 /$

Si nous avons émis l'hypothèse de l'existence d'au moins deux périodes au sein de cette " école comique française " en nous basant sur des critères " objectifs » (la généralisation des séries comiques de personnages et une production traversée par des liens possibles avec le théâtre), sans doute mériterait-elle d'être replacée dans le contexte plus large des rapports très tendus entre théâtre et cinéma à cette époque, et dont les expériences de ciné-théâtre sont en quelque sorte les stigmates. Au point que ces tentatives, probablement très fréquentes, entrent dans ces débats. Ainsi, un écrivain de l'époque, interrogé sur l'opposition entre ces deux formes de spectacle (théâtre et cinéma) répond : "Quant à la conception de l'établissement mixte " cinéma-théâtre ", il convient, à mon avis, de la repousser énergiquement. Ne confondons pas les genres. Aucun d'eux ne gagnerait à cette formule bâtarde "128. Surtout, les défenseurs du théâtre contre le cinéma trouvent des raisons d'espérer en un avenir radieux pour le spectacle vivant dans des arguments, certes grandement anachroniques, du côté des films comiques: " Je pense que le public se lassera au cinéma parce qu'il sera très difficile de renouveler les films. Déjà, le genre « poursuite » semble épuisé. (...) II me semble qu'il [/e public] adore surtout les farces et les mélodrames muets. On aura peine à les varier ${ }^{129}$. Dès lors, doit-on voir les séries constituées autour de personnages récurrents (que ce commentateur ignore) et plus encore les comédies comme une manière de concurrencer plus encore ce théâtre qui souffre d'une crise inédite depuis l'apparition du cinéma ? Il y aurait lieu, pour y répondre, d'analyser précisément tous les emprunts (situations, comédiens, effets scéniques, etc.) au théâtre de cette production comique de la première moitié des années 1910. On le voit : les chantiers sont encore vastes...

127 « Le cinéma contre le théâtre - Les Grandes enquêtes d'Excelsior », Excelsior, 19 novembre 1913. 128 " Le cinéma contre le théâtre - Les Grandes enquêtes d'Excelsior » (réponse de Gaston Devore), Excelsior, 27 octobre 1913 (I'enquête court sur plusieurs numéros).

129 « Le cinéma contre le théâtre - Les Grandes enquêtes d'Excelsior » (réponse de M. Nozière, critique dramatique à Gil Blas, au Matin et à I'Intransigeant), Excelsior, 12 novembre 1913. 